\title{
4. Das rote Licht der Partisanenfotografie
}

Nachdem die Streitkräfte des Königreichs Jugoslawien eine Niederlage erlitten hatten und die Monarchie am 14. April 1941 kapituliert hatte, rief die Kommunistische Partei Jugoslawiens im Juli desselben Jahres zum Widerstand gegen die Achsenmächte und die neu gegründeten Satellitenstaaten auf. Den Aufständischen schlossen sich Fotografen an, die sehr bald den Grundstein für die Partisanenfotografie legten. Es handelte sich überwiegend um gewerbliche Fotografen oder Hobbyfotografen der Vorkriegszeit, aber auch Personen aus Bergsteigervereinen, die sich eine Zeitlang der Amateurfotografie gewidmet hatten. In den Partisaneneinheiten existierten in jenen Jahren weder die notwendigen Voraussetzungen für eine qualitativ hochwertige fotografische Produktion, noch für die Entwicklung von Negativen und die Erstellung von Positiven. Es fehlte an Fotolaboren mit zugehöriger Ausstattung, an Dunkelkammern, Chemikalien, Entwicklungs- und Fixierbädern, Vergrößerungsgeräten sowie rotem Laborlicht. In einer Zeit konstanter Truppenbewegungen, Standortänderungen und dauerhaftem Aufenthalt im Freien war es überaus schwierig, optimale Temperaturen der für die Entwicklung und Fixierung der Filme notwendigen Chemikalien sicherzustellen. Die Fotografen standen nicht nur vor immensen Herausforderungen, sondern verwendeten auch lediglich Schwarzweißfilme, sodass sie die Welt ausschließlich in Grautönen auf Papier festhalten konnten.

Ferner war es unmöglich, Konversionsfilter zu beschaffen, die auf ein bestimmtes Lichtspektrum Einfluss zu nehmen vermochten, mit der Folge, dass das wichtigste Symbol des Partisanenkampfes, der rote Stern, ein kaum sichtbarer Fleck auf der Partisanenmütze wurde. Sich mit der Zeit an komplexe Bedingungen gewöhnend, lernten die Partisanen aus diesen Gegebenheiten das Maximum herauszuholen und auch den roten Stern erkennbar zu machen. Obwohl sie monochromatisch aufgenommen wurden, schimmerten die Partisanenfotografien rötlich - in der symbolischen Farbe des Kampfes der Proletarier und der von ihnen angestrebten Veränderungen. In unserem Unterbewusstsein schuf die Fotografie paradoxerweise jenes latente Bild, das diesen schwarzweißen fünfzackigen Stern bis heute in der Pracht seiner Doppeldeutigkeit sieht: Leben im Tod und Frieden im Krieg. In diesem Kapitel wird ein Überblick über die fotografische Produktion gegeben, wodurch weitere Besonderheiten der Partisanenfotografie greifbar werden. 


\section{Die Anfänge der Partisanenfotografie}

Die ersten Partisanenfotografien entstanden 1941, als die Fotografentätigkeit noch ungenügend organisiert war. Im August desselben Jahres hielt Slavko Smolej, Mitglied des Fotoklubs Ljubljana, die Folgen einer Sabotageaktion an einem Aquädukt in der slowenischen Region Gorenjska fest. Ausgeführt wurde diese Aktion von einer aus dem Städtchen Jesenice stammenden Partisanenkompanie. ${ }^{1}$ Die Ereignisse in den Partisaneneinheiten fotografierten Kommandanten wie Mirko Bračić, Jule Sočan und Jože Kotnik. ${ }^{2}$ Illegale Aktivisten, die noch in slowenischen Städten lebten, zum Beispiel Jule Sočan in Ljubljana, ${ }^{3}$ verteilten illegale Literatur, Gedichtbände und Flugblätter, aber auch Fotografien von Objekten und Standorten, in deren Nähe sie sich selbst befanden. Sočan schloss sich schon bald den Partisanen an und nahm zwei Fotoapparate mit, mit denen er später wertvolles Bildmaterial über die Tomšič-Brigade sammelte. Fotografien wurden auch für die Fälschung von Ausweisen eingesetzt, was für Parteimitglieder und Untergrundkämpfer von erheblicher Bedeutung war, da sie auf diese Weise ungehindert zwischen einzelnen Städten und Ortschaften reisen konnten. Wichtig war dies für die Koordinierung und Verbindung aller Teile der Widerstandsbewegung sowie für die Übermittlung von Nachrichten.

Nicht allein Fotografen, die sich den Partisanen anschlossen, nahmen ihre Fotoapparate mit. Nach den ersten bewaffneten Auseinandersetzungen und als eine Art Kriegstrophäe gelangten auch deutsche Leica-Fotokameras in die Hände der Partisanen. Der große Stellenwert, der der Erbeutung der Fotoausrüstung zugemessen wurde, zeigt sich in vielen Berichterstattungen, in denen die Anzahl der abgenommenen Kameras und Filme genau dokumentiert wurde. Entsprechende Angaben finden sich schon in den frühesten Berichten, etwa in der Mitteilung des Stabs der in Serbien operierenden Ersten Šumadija-Einheit der Volksbefreiungsarmee vom 14. Oktober 1941, in der die sichergestellten Waffen, Munition, Lebensmittel und Fotogeräte einzeln aufgelistet sind. ${ }^{4}$

Nach dem erfolgreichen Aufstand in Serbien im Juli 1941 und der Ausrufung des ersten befreiten Gebietes im besetzten Europa, der »Republik von Užice«, am 24. September 1941 verfügten die Einheiten über bescheidene Mengen an Fotomaterial bzw. Fotografien. Das Fotostudio, welches mit den Vorbereitungen für die Ausstellung über die UdSSR im Kleinen Saal des Falkenhauses in Užice betraut war, verwendete für diese Ausstellung überwiegend Grafiken, Skizzen, Zeichnungen und Gemälde, ${ }^{5}$ während nur ein kleiner Teil auf Fotografien entfiel. ${ }^{6}$

Nach dem Zusammenbruch der »Republik von Užice« am 29. November 1941 nahm der Widerstand der Partisanen in Serbien ab. Die meisten Streitkräfte der Partisanen zogen sich in Richtung Sandžak und später nach Bosnien und Herzegowina zurück. Serbien befand

\footnotetext{
1 Fabec, Franc und Vončina, Dejan. Slovenska odporniška fotografija 1941.-1945. Ljubljana: Modrijan 2005, S. 44.

2 Kladnik, Tomaž, Jurjavčić, Katarina und Dežman, Jože. Vojne fotografije 1941.-1945. Partizanske jedinice. Ljubljana: Defensor

2010, S. 22.

3 Fabec, Franc und Vončina, Dejan. Slovenska odporniška fotografija 1941.-1945. Ljubljana: Modrijan 2005, S. 45.

4 Zbornik dokumenata i podataka o narodno-oslobodilačkom ratu jugoslovenskih naroda. Bd. I/20: Borbe u Srbiji 1941-1944. Belgrad 1965.

5 Glišić, Venceslav. 1986. Užička republika. Belgrad: Nolit 1986, S. 174-175.

6 Ebd.
} 
sich unter deutscher Besatzung und die Marionettenregierung des Generals Milan Nedić unterstand der deutschen Militärverwaltung, die alle Aspekte des zivilen Lebens regelte. Die Militärverwaltung stellte Genehmigungen für knapp ein Dutzend Fotostudios und Fotografen aus, die Aufträge von Angehörigen der deutschen Wehrmacht annehmen durften. ${ }^{7}$ Während des Krieges arbeiteten in Serbien die Fotografen Aleksandar Aca Simić und Milan Roglić, der eine ikonische Fotografie von Personen auf einem Motorrad mit Beiwagen bei den Belgrader Demonstrationen gegen den Beitritt des Königreichs Jugoslawien zum Dreimächtepakt schuf. ${ }^{8}$ Neben diesen beiden Fotografen waren auch die Fotostudios Miroč und Urošević, die Belgrader Fotoagentur sowie die Fotosektion der Abteilung für Staatspropaganda tätig. Als in Serbien wirkender Fotograf ist aber vor allem Rista Marjanović hervorzuheben, dessen Fotoserien über den Rückzug der serbischen Armee im Ersten Weltkrieg sowie später Aufnahmen der Befreiung Belgrads zu seiner Berühmtheit geführt haben. Besonders eindrucksvoll ist seine Fotoserie, die Soldaten in Bauernkleidung ohne Schuhe zeigt. ${ }^{9}$

Innerhalb der Partisanenbewegung in Serbien war überdies die Arbeit des Amateurfotografen Rade Jokić interessant, der als einer der ersten Partisanenfotografen überhaupt gelten dürfte. Aus einer kürzlich erschienenen Untersuchung über sein Leben und Werk geht hervor, dass Jokić für die Produktion seiner Fotografien das glänzende Bromidpapier Agfa Brovira in einem Format von $9 \times 12 \mathrm{~cm}$ verwendete. ${ }^{10}$ In dessen Besitz kamen die Partisanen höchstwahrscheinlich im Zuge ihrer Kämpfe gegen deutsche Einheiten oder hatten es auf andere Art und Weise von deutschen Soldaten erhalten. Vor dem Krieg hatte Jokić eine Fotokamera vom Typ Leica IIlb mit dem 5-cm-Objektiv Summar erstanden. ${ }^{11}$ Damit nahm er einige der ersten Partisanenkämpfer wie Filip Kljajić-Fićo, den Maler Boro Baruh und den Bildhauer Vlado Piperski auf. Häufige Motive seiner Fotografien waren Partisanenkolonnen, das Leben der Einheiten und der Bauern. Auf einem der Fotos, das im August 1941 in der Nähe von Valjevska Kamenica entstand, ist auch Stjepan Filipovićl ${ }^{12}$ zu sehen, wie er zusammen mit anderen Partisanen vier deutsche Spione vor das Erschießungskommando führt. ${ }^{13}$ Bei näherer Betrachtung von Jokićs Bildern stellt sich beim Betrachter der Eindruck ein, als hätte der Fotograf für seine Aufnahmen keine Zeit, als würde er der Kolonne hinterherlaufen oder immer weiter zurückbleiben:

"Die Bedingungen, unter denen die Fotos entstanden, waren sehr schwierig. Ich musste schnell einen günstigen Winkel für die Aufnahme finden, während die anderen sich rasch entfernten, sodass es danach galt, die Kolonnen bergauf wieder einzuholen. Es war alles andere als leicht, Aufnahmen zu machen, auch deshalb, weil es bei den Kameraden an Verständnis mangelte. Wäh-

\footnotetext{
7 Novo vreme, 22. Mai 1941.

8 Roglić schloss seine Ausbildung zum Fotografen in Marseille ab; während des Zweiten Weltkriegs war er offizieller Fotograf der Regierung unter Milan Nedić. Seine am 27. März 1941 aufgenommene Fotografie wurde nach dem Krieg in nahezu allen schulischen Geschichtsbüchern abgedruckt.

9 Radanović, Milan. Oslobođenje. Beograd, oktobar 1944. Belgrad: Rosa Luxemburg Stiftung Southeast Europe 2014, S. 81.

10 Matić, Branko. Valjevski partizani 1941-1942 na fotografijama Rada Jokića. Valjevo: Eigenausgabe des Autors 2015.

11 Ebd., S. 16-23.

12 Stjepan Filipović (27. Januar 1916-22. Mai 1942) war ein jugoslawischer Widerstandskämpfer, der Ende 1941 von Anhängern der königstreuen serbischen Tschetnik-Bewegung gefangen genommen, gefoltert und später durch die "Serbische Staatswacht" gehängt wurde. Das Foto seiner Hinrichtung ist weltweit bekannt - es zeigt ihn, die Schlinge um den Hals, mit emporgehobenen Armen und zum Aufstand aufrufend.
} 
rend ich zum Beispiel den Film einfädelte, protestierten die anderen und verlangten, dass man Licht macht, eine Kerze oder Lampe anzündet, weshalb ich dann nach draußen gehen und das Ganze unter dem Mantel und durch irgendein Vordach geschützt erledigen musste. Sie konnten oftmals nicht nachvollziehen, wie wichtig diese Dokumente nach dem Krieg einmal sein würden. Sie sagten nur: >Du fotografierst, während wir sterben.< Eine bestimmte Menge an Fotomaterial habe ich mitgenommen, als ich mich den Partisanen anschloss, doch zumeist habe ich das den gefangenen deutschen Soldaten sichergestellte Material verwendet. Nach den Kämpfen bei Stolice haben wir eine gewisse Anzahl an Filmen beschlagnahmt und später dann auch, als wir Krupanj einnahmen. In Krupanj sind wir zudem auch zu einem Fotoapparat gekommen, den ich Piperski gegeben habe, damit auch er Bilder macht. Er hat ihn aber beim Rückzug aus Kladanj vergessen. Die Filme habe ich aufbewahrt, indem ich sie in Bogovadja bei der Familie Belić im Stall vergraben habe. Ich habe insgesamt elf Filme mit jeweils 36 Fotos verwendet und sie nach dem Krieg den Kameraden übergeben. Doch all diese Filme sind irgendwie abhandengekommen. Später hat man mir gesagt, ich solle versuchen, sie wiederzufinden und es gelang mir dann tatsächlich, drei oder vier Filme in Zagreb aufzuspüren. Wie sie dorthin gelangt sind, ist mir nicht klar. Heute werden sie im Militärmuseum in Belgrad aufbewahrt. Unter diesen elf Filmen war auch ein Film, den die Deutschen bereits vorher für ihre Bilder verwendet hatten. Und da ich dies nicht wusste, habe ich ihn nochmals für mich genutzt, sodass nach der Entwicklung deutsche und unsere Kolonnen übereinander zu sehen waren. Ich habe auch einen Farbfilm aufgenommen, der ebenfalls verloren gegangen ist. ॥ $^{14}$

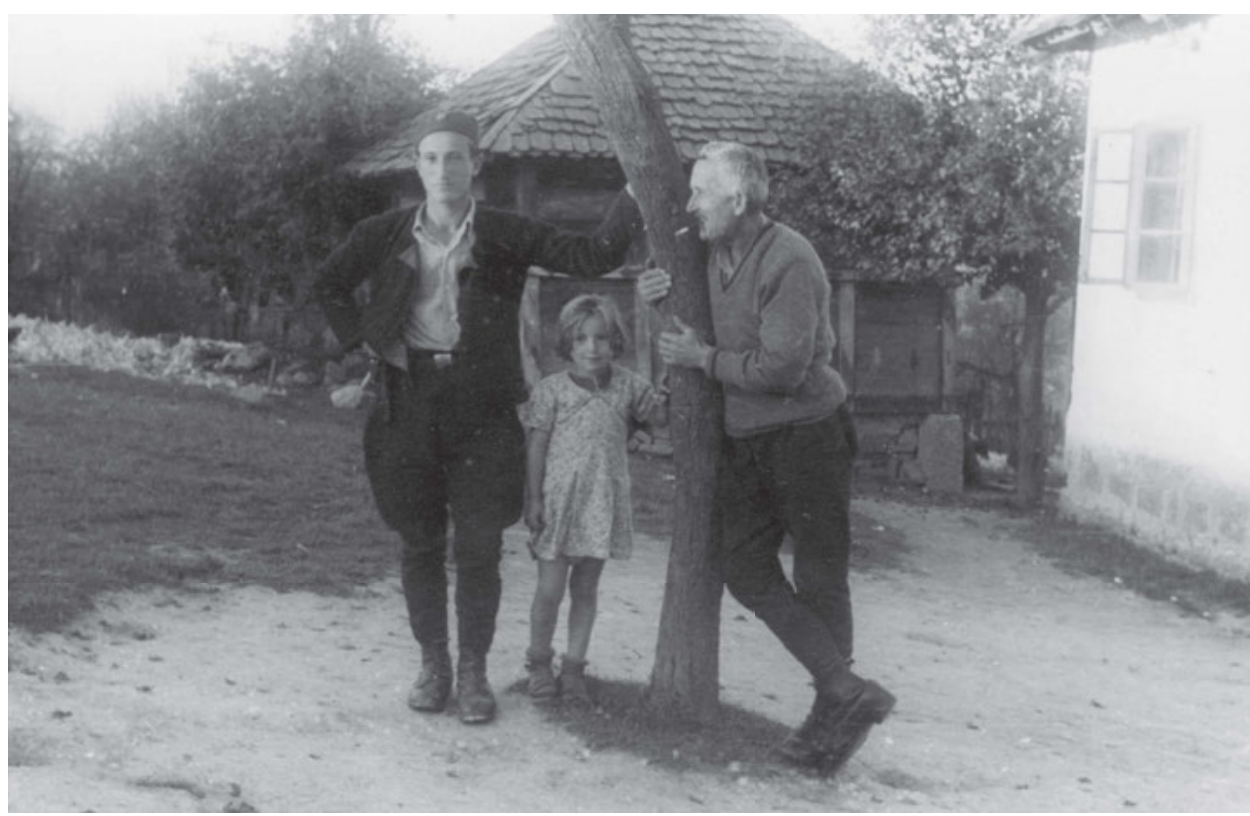

Dragoljub Dudić (rechts) mit seinem Sohn Miša Dudić, Kämpfer der Partisaneneinheit in Valjevo, Valjevska Kamenica, 1941. Foto: Rade Jokić. Branko Matić zufolge sind auf dem Foto abgebildet: Miloš Milićević, Negosava Bojinović und Dragojlo Dudić. Belgrad, Militärmuseum | 992.

13 Matić, Branko. Valjevski partizani 1941-1942 na fotografijama Rada Jokića. Valjevo: Eigenausgabe des Autors 2015, S. 101.

14 Ranković, Zdravko und Jeremić, Miroslav. Kultura u prošlosti Valjevskog kraja. Bd. 2: Slikarstvo, arhitektura, fotografija, skulptura: izbor tekstova emitovanih u emisijama Radio Valjeva.Valjevo: Napred. Vgl. auch Matić, Branko. Valjevski partizani 1941-1942 na fotografijama Rada Jokića. Valjevo: Eigenausgabe des Autors 2015, S. 16-23. 
Neben Jokić fotografierte in der Kolubara-Kompanie auch Sreten Čitaković, der nach den Kämpfen gegen die deutschen Wehrmachtsverbände bei Stolice am 1. September 1941 einen Fotoapparat des österreichischen Herstellers Voigtländer zusammen mit einigen Agfa-Filmen requirierte. Zudem schenkte er seinem Mitkämpfer Miodrag Tatović eine Fotokamera der Marke Rodenstock. Anfangs fotografierten sie in erster Linie mit Hilfe der sichergestellten deutschen Filme, und erst später sollte es ihnen gelingen, Fotomaterial über Partisanenverbindungen in den Städten zu besorgen. ${ }^{15}$

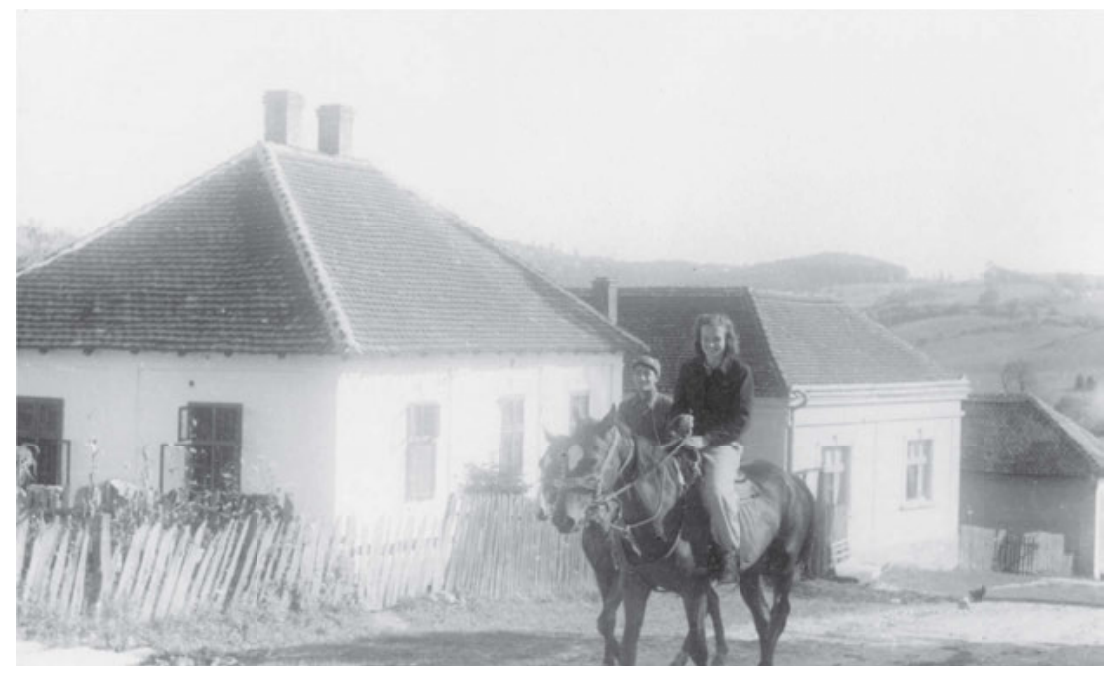

Die Anhänger der Valjevo-Kompanie Miša Veličković und Sofija Stanišić, Valjevska Kamenica, Serbien, September 1941. Foto: Rade Jokić. Belgrad, Militärmuseum | 1004.

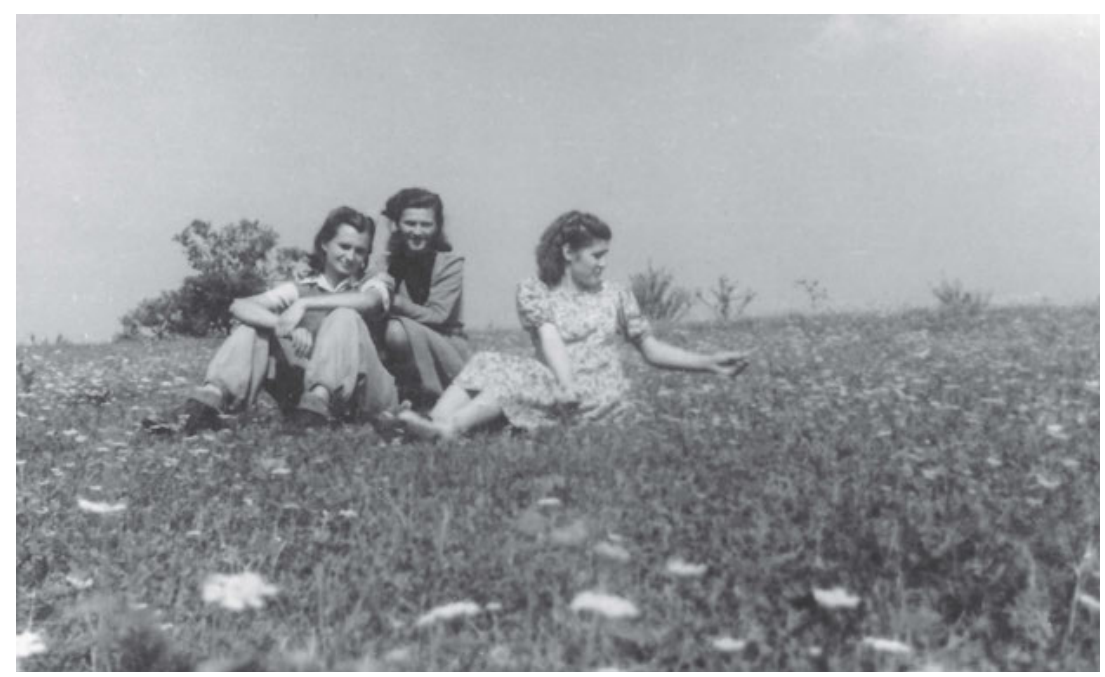

Anhängerinnen der Valjevo-Kompanie, Serbien, 1941. Sofija Stanišić mit zwei unbekannten Freundinnen. Foto: Rade Jokić. Belgrad, Militärmuseum | 1007. 
Neben der Dokumentation offenbarte Čitaković in einigen seiner Fotografien auch die persönlichere Seite seiner Mitkämpfer. Seine Porträts zeigen Stoja Stanišić - eine der ersten Frauen, die an der Seite der zumeist männlichen Kämpfer gegen die deutschen Wehrmachtsverbände aktiv war - oder bekannte kommunistische Politiker wie Ivo Lola Ribar und Aleksandar Ranković auf ihren Pferden. Über die Jungkommunistin Milica Pavlović aus dem Kreiskomitee der Kommunistischen Partei Jugoslawiens in Valjevo versuchte er, seine Fotografien in die »Republik von Užice« zu schicken, um sie dort vervielfältigen und verteilen zu lassen, ${ }^{16}$ doch die Filme sind im Zuge des Vordringens der deutschen Wehrmacht am 29. November 1941 unwiderruflich verloren gegangen. Er schuf auch Aufnahmen für gefälschte Ausweise:

"Unsere Patrouillen erhielten die Aufgabe, in den Gemeinden nicht ausgefüllte Ausweise zu requirieren. Als wir um den 8. Februar herum nach Bukovac und Osečenica kamen, habe ich mich mit einigen meiner Mitkämpfer zu Milomir Uskoković, einem Fotografen aus Osečenica, begeben. Bei ihm habe ich zwei Filme entwickelt und sie trocknen lassen. All dies habe ich alleine getan, sodass Milomir keine einzige Aufnahme sah. Er stellte mir alles Notwendige zur Verfügung und war dabei überaus zuvorkommend. Wir setzten dann unseren Marsch weiter nach Breždje fort, und ich schickte die Fotografien Mirko Tomić, damit er sie Bora Baruh übergibt, der einen deutschen Stempel angefertigt hatte und mit diesen Fotografien gefälschte Ausweise erstellte. « ${ }^{17}$

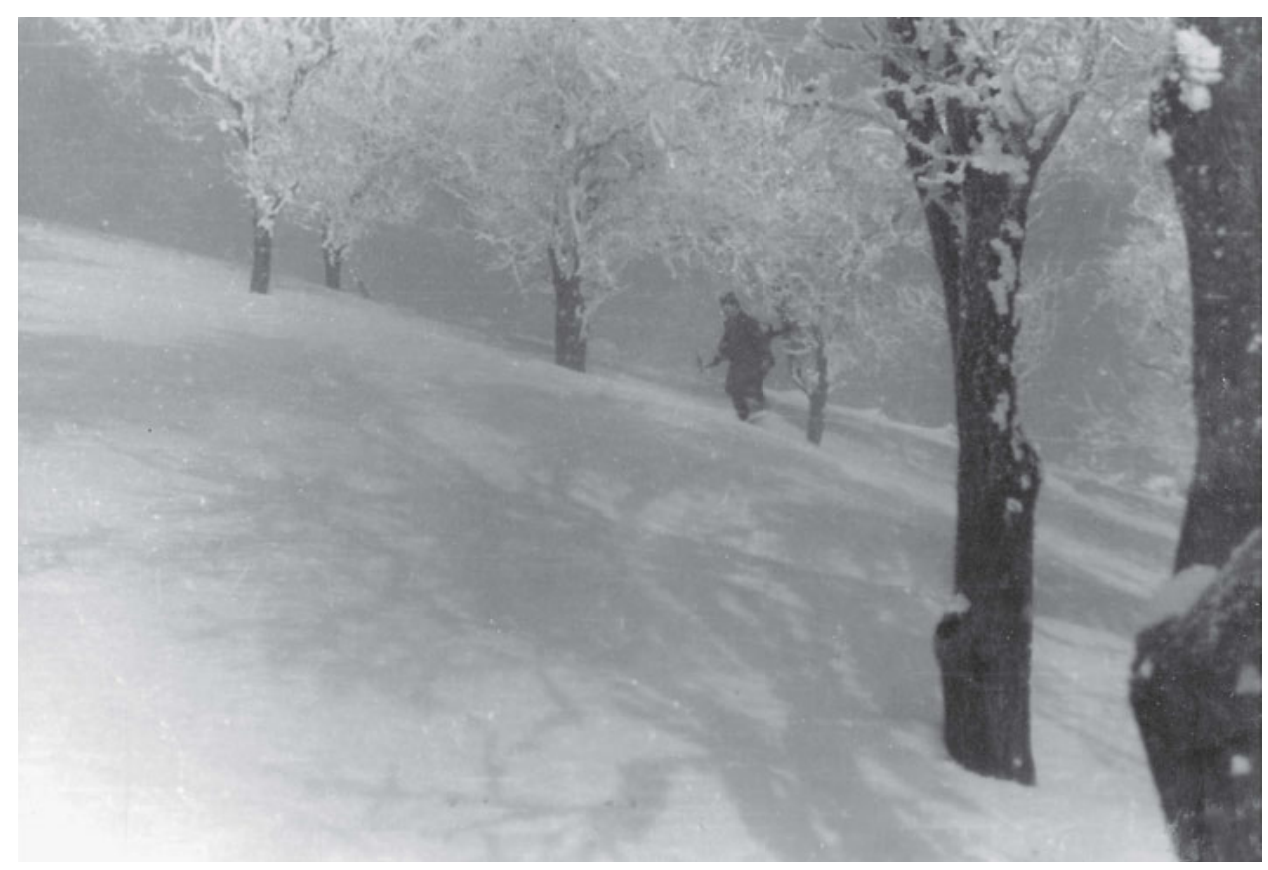

Wachposten bei $-40^{\circ}$ Celsius, Leskovac, Südserbien, Februar 1942. Foto: Rade Jokić. Belgrad, Militärmuseum | 1161. 


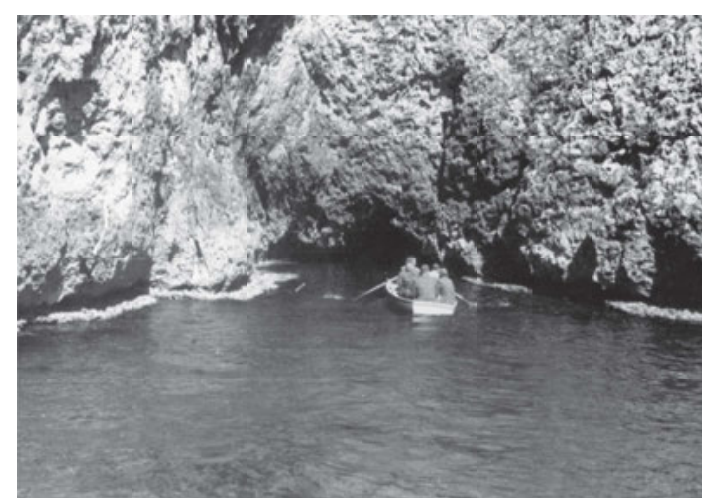

Eingang in eine Grotte auf der Insel Biševo, 1944. Foto: Vladimir Bakarić. Zagreb, Kroatisches Historisches Museum | HPM/MRNH-F-5986.

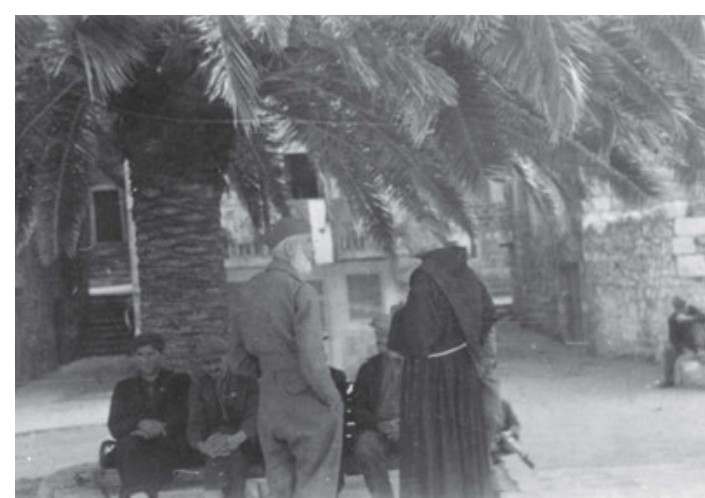

Delegierte auf der regionalen Konferenz der Einheitlichen Volksbefreiungsfront für Dalmatien, Hvar, 10. Oktober 1944. Foto: Vladimir Bakarić. Zagreb, Kroatisches Historisches Museum | HPM/MRNH-F-5993.

In Kroatien entstanden die ersten Partisanenfotografien im Oktober 1941. Nur zwei Monate nach den ersten Aufnahmen in Slowenien machte ein unbekannter Fotograf die ersten Bilder in der Psunj-Partisaneneinheit. ${ }^{18}$ Im Dezember desselben Jahres fotografierte Vladimir Bakarić, Politkommissar und einer der Gründer des Antifaschistischen Landesrats der Volksbefreiung Kroatiens (ZAVNOH), die Flüchtlingskolonne bei Slunj. ${ }^{19}$ Später gelangen ihm als einem der Anführer des Partisanenkrieges einige der geschichtsträchtigsten Fotografien aus der Zeit des Volksbefreiungskrieges, darunter ein Bild, das den Aufenthalt des Obersten Hauptquartiers der Volksbefreiungsarmee auf der Insel Vis im Jahr 1944 dokumentiert.

\section{Die ersten Ausstellungen der Partisanen}

Es ist nicht leicht festzustellen, wann die erste Ausstellung mit Fotografien der Partisanen stattgefunden hat, doch handelt es sich dabei wahrscheinlich um eine Präsentation, die am 7. November 1942 in Bosanski Petrovac organisiert wurde. Diese Ortschaft befand sich auf dem zweiten großen, von den Besatzern befreiten Territorium, der »Republik von Bihać«. Über das Ereignis selbst gibt es nur wenige heute noch erhaltene Aufzeichnungen, allerdings ist bekannt, dass bei der Ausstellung Fotografien von Vili Šimunov-Barba, ${ }^{20}$ einem der ersten und bedeutendsten Partisanenfotografen, zu sehen waren. Zu dieser Zeit war das am 25. Mai 1942 befreite Bosanski Petrovac Mittelpunkt der »Republik von Bihać«. Auf dem Gebiet waren die ersten zivilen Regierungsstrukturen durch die Volksbefreiungsräte geschaffen worden, die mit der Regelung aller zivilen Angelegenheiten, etwa der Organisation von kulturellen Veranstaltungen und Bildungsaktivitäten mit Hilfe einberufener sogenannter Ausschüsse für Kultur und Bildung, betraut waren. Sie waren unter anderem für

18 Ivanuš, Rhea. Fotografski albumi u zbirci fotografija, filmova i negativa Hrvatskoga povijesnog muzeja. Zagreb: Hrvatski povijesni muzej 2006, S. 23.

19 Hlevnjak, Branka und Ivanuš, Rhea. Hrvatska antiratna fotografija: Prvi svjetski, Drugi svjetski i Domovinski rat. Zagreb: Udruga za promicanje oblikovanja i umjetnosti, Design Art d. o. o., Centar za kulturu i obrazovanje 2008, S. 111.

20 Jakšić, Pavle. Nad uspomenama. Bd. I. Belgrad: Izdavačko preduzeće Rad 1990, S. 277. 


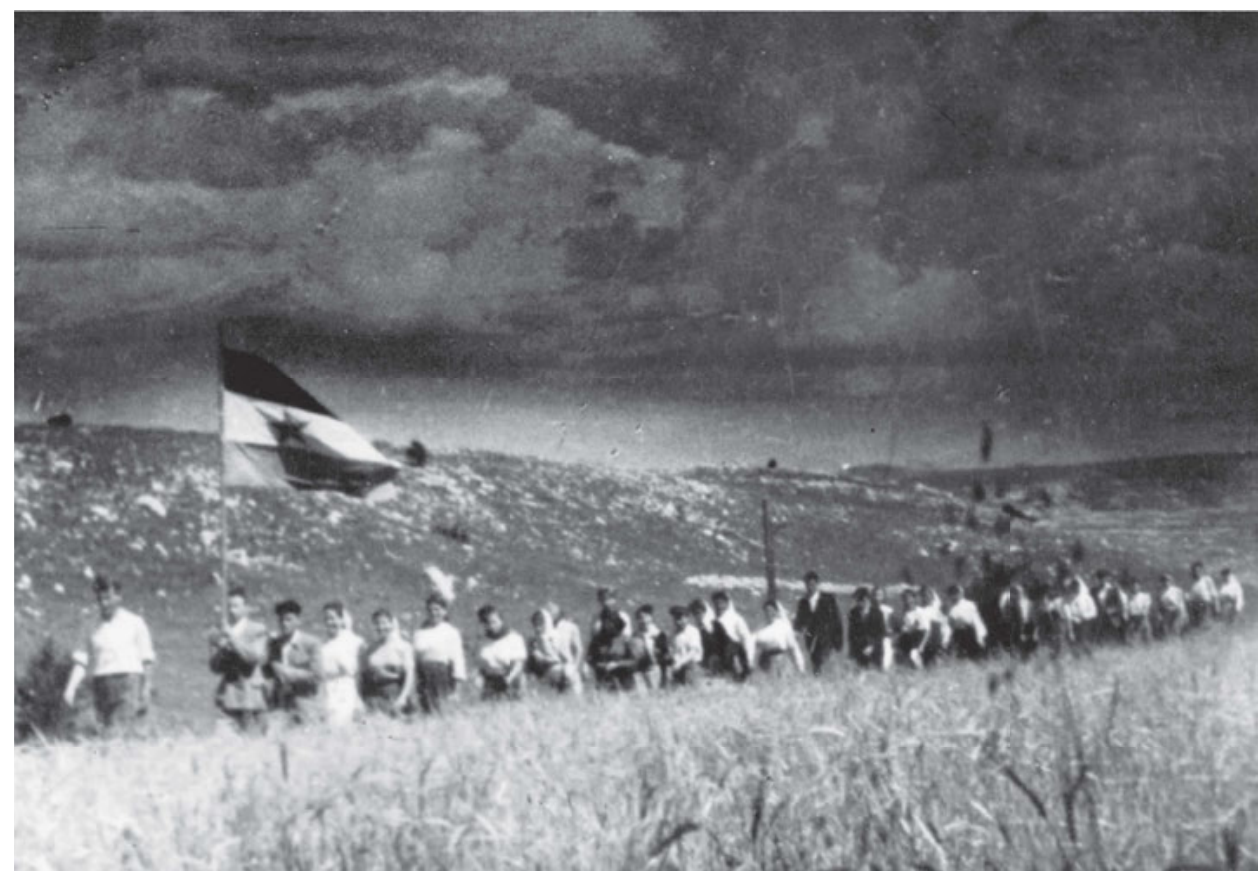

Jugendbataillon aus Bosansko Grahovo, Bosnien-Herzegowina (gegründet 1942, mit 272 Mitgliedern) auf dem Weg zur Kornernte im Sana-Tal. Fotograf unbekannt. Sarajevo, Historisches Museum von Bosnien und Herzegowina | FNOB 10737.

die Organisation des fotografischen Gewerbes auf dem befreiten Territorium zuständig, wie dies im kroatischen Küstenort Selce im Jahre 1943 der Fall war ${ }^{21}$ - was wiederum ein weiterer Beleg dafür ist, dass die Partisanenfotografie während des Krieges auch einen zivilen und künstlerischen Charakter besaß. Während der Dauer der »Republik von Bihać« wurde die erste landwirtschaftliche Arbeitsaktion von Jugendlichen unter der Bezeichnung »Sana-Tal« ausgerichtet. Die fotografisch gute Dokumentation spricht für die hohe Präsenz von Fotografen bei dieser Aktion, an der sich unterschiedlichen Schätzungen zufolge 2.000 bis 3.500 Jugendliche beteiligt hatten. ${ }^{22}$ In Bosanski Petrovac erfolgte am 6. Dezember auch die Gründung der Antifaschistischen Frauenfront, die durch der Kommunistischen Partei nahestehende Aktivistinnen ins Leben gerufen wurde und im Laufe des Krieges zu einer Massenorganisation anwuchs. ${ }^{23}$

Am 20. Oktober 1942, einige Tage bevor Josip Broz Tito als Oberbefehlshaber der Partisanenarmee die Erste Proletarische Brigade - Kommandant war der Belgrader Surrealist und Spanienkämpfer Konstantin »Koča« Popović - zum Eid antreten ließ, erließ er den Befehl an die Brigaden und Partisaneneinheiten, Ausgaben der Partisanenzeitungen sowie dokumentarisches Material über den Volksbefreiungskampf und der Verbrechen der Besat-

21 Antić, Vinko. Vinodoska Selca u borbi. Selca: Udruženje boraca narodnooslobodilačkog rata 1975, S. 623.

22 Trnjaković, Mile. Sjećanja na rad omladinske organizacije na području Bosanskog Petrovca do kraja 1942. godine. In: Čerkez, Vladimir (Hrsg.). Bosanski Petrovac u NOB. Zbornik sjećanja. Bd. IV. Bosanski Petrovac: Opštinski odbor SUBNORA Bosanski Petrovac 1974, S. 155.

23 Zur Antifaschistischen Frauenfront siehe Dugandžić, Andreja und Okić, Tijana. The Lost Revolution. Women's Antifascist Front between Myth and Forgetting. Sarajevo: Crvena 2018. 


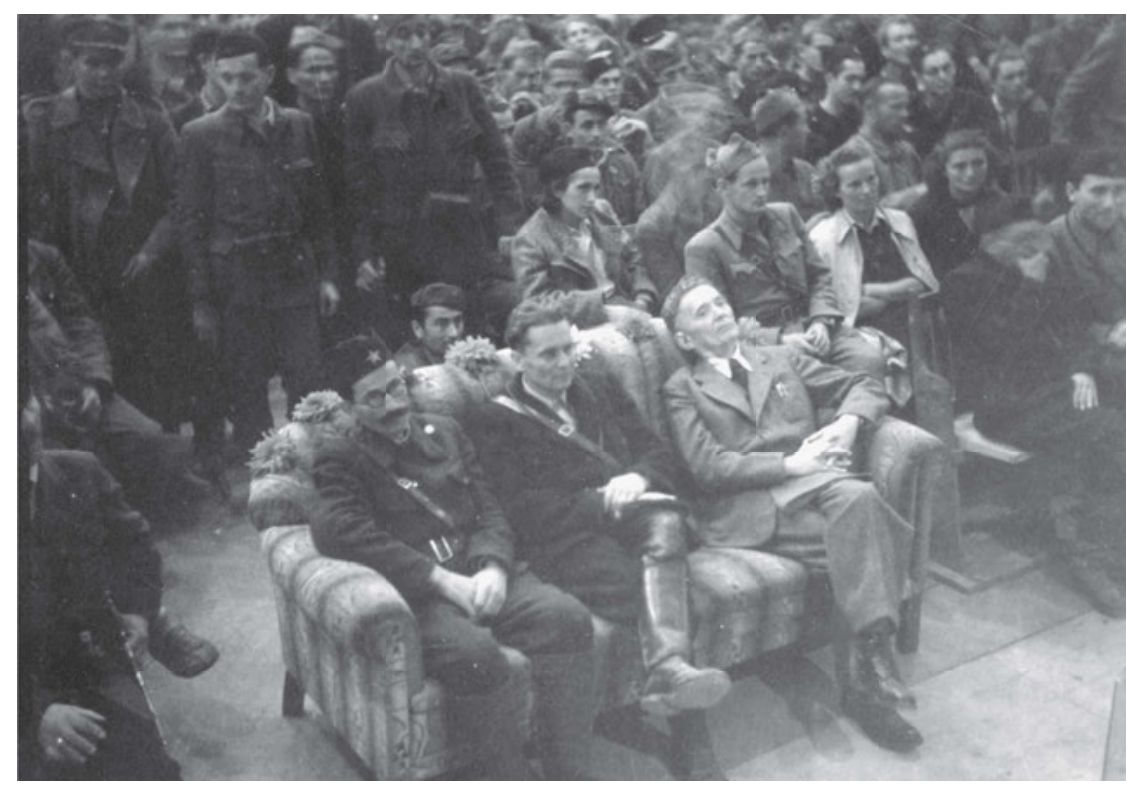

Von links: Ivan Milutinović, Josip Broz Tito, Ivan Ribar bei einer Aufführung des Theaters der Volksbefreiung. Bosanski Petrovac, Bosnien-Herzegowina, 1942. Foto: Vili Šimunov-Barba. Belgrad, Militärmuseum | 4110.

zungsmächte und ihrer Verbündeten an den Generalstab zu schicken. Von allen Einheiten wurde verlangt, einzelne Exemplare aller bis dahin herausgegebenen Zeitungen, Broschüren, Flugblätter und sonstiger Drucksachen sowie feindliche Dokumente zu senden. Gleiches galt für Partisanenfotografien, Texte von Volks- und Partisanenliedern, Namenslisten der Kriegsopfer, Angaben zu den begangenen Verbrechen, Verzeichnisse und Schilderungen der Aktionen sowie Humoristisches und Alltägliches aus dem Leben der Einheiten. Unterzeichner des Befehls war Moša Pijade, Vorkriegskommunist, Journalist und Maler mit dem Pseudonym »Čiča Janko« (Onkel Janko). Interessanterweise waren die Fotografien im Befehl als zweiter Punkt angeführt, was als Beleg dafür angesehen werden kann, dass man sich innerhalb der Partisanenbewegung der Bedeutung von Fotografien durchaus bewusst war. Laut Befehl sollte unter anderem Folgendes zugestellt werden:

»Jeweils ein Exemplar aller Fotografien unserer Kämpfe und der Ereignisse hinter der Front sowie der erbeuteten Fotografien des Feindes (insbesondere Aufnahmen der faschistischen Gräueltaten). Des Weiteren Fotografien unserer gefallenen Helden. Die Rückseite einer jeden Fotografie oder das Blatt Papier, auf dem sie eventuell aufgeklebt ist, soll mit Angaben darüber versehen werden, wo und wann sie entstanden ist und eventuell auch von wem sie aufgenommen worden ist. Dabei sollte es den Kameraden auch dann nicht leidtun, wenn sie ihre einzige Aufnahme dafür hergeben, da diese Fotografien vervielfältigt werden, während die Originale den Kameraden später wieder zurückgegeben werden können, wenn sie das möchten. Bei Fotografien, von denen die Kameraden denken, dass sie es wert sind, vergrößert zu werden, und auch sonst, sollte man der Kopie das Negativ beifügen. ${ }^{24}$ 
Ein Jahr nach der Schau in Bosanski Petrovac wurde am 27. November 1943 im befreiten herzegowinischen Städtchen Livno eine Ausstellung zu Ehren der Zweiten Sitzung des Antifaschistischen Rats der Volksbefreiung Jugoslawiens (AVNOJ) organisiert, über die jedoch nicht viel bekannt ist. ${ }^{25}$ Von der Fotografie und der Atmosphäre in der befreiten Stadt begeistert, schrieb der bekannte slowenische Schriftsteller und Publizist Edvard Kocbek in seinen Tagebucheinträgen über die Ausstellung. Er begann, Filmszenen in seinem Kopf zu kreieren, Regie zu führen und Kamerabewegungen einzubringen - der Kulturwissenschaftler Gal Kirn sieht diese Notizen als Skizze für das erste Partisanendrehbuch. ${ }^{26}$ Bei dem Film handelte es sich allerdings keineswegs um bewegte Bilder, sondern vielmehr um Fotografien, die sich erst dann zu bewegen beginnen, wenn sie sich die Unzulänglichkeiten unseres Auges und Geistes zunutze machen.

In den Republiken von Užice und Bihać liegen die Anfänge kultureller Tätigkeiten der Partisanen und der Ausgangspunkt ihrer organisierten Form. Im Rahmen der Gründungssitzung des AVNOJ am 26. und 27. November 1942 in Bihać erging durch den Exekutivrat der Beschluss, eine Übergangsverwaltung des Theaters der Volksbefreiung einzusetzen und damit die erste Kultureinrichtung des neuen Staates zu begründen. An ihrer Spitze stand der Schriftsteller Ivo Frol, Leiter der Dramensektion war der Schauspieler Vjekoslav Afrić,

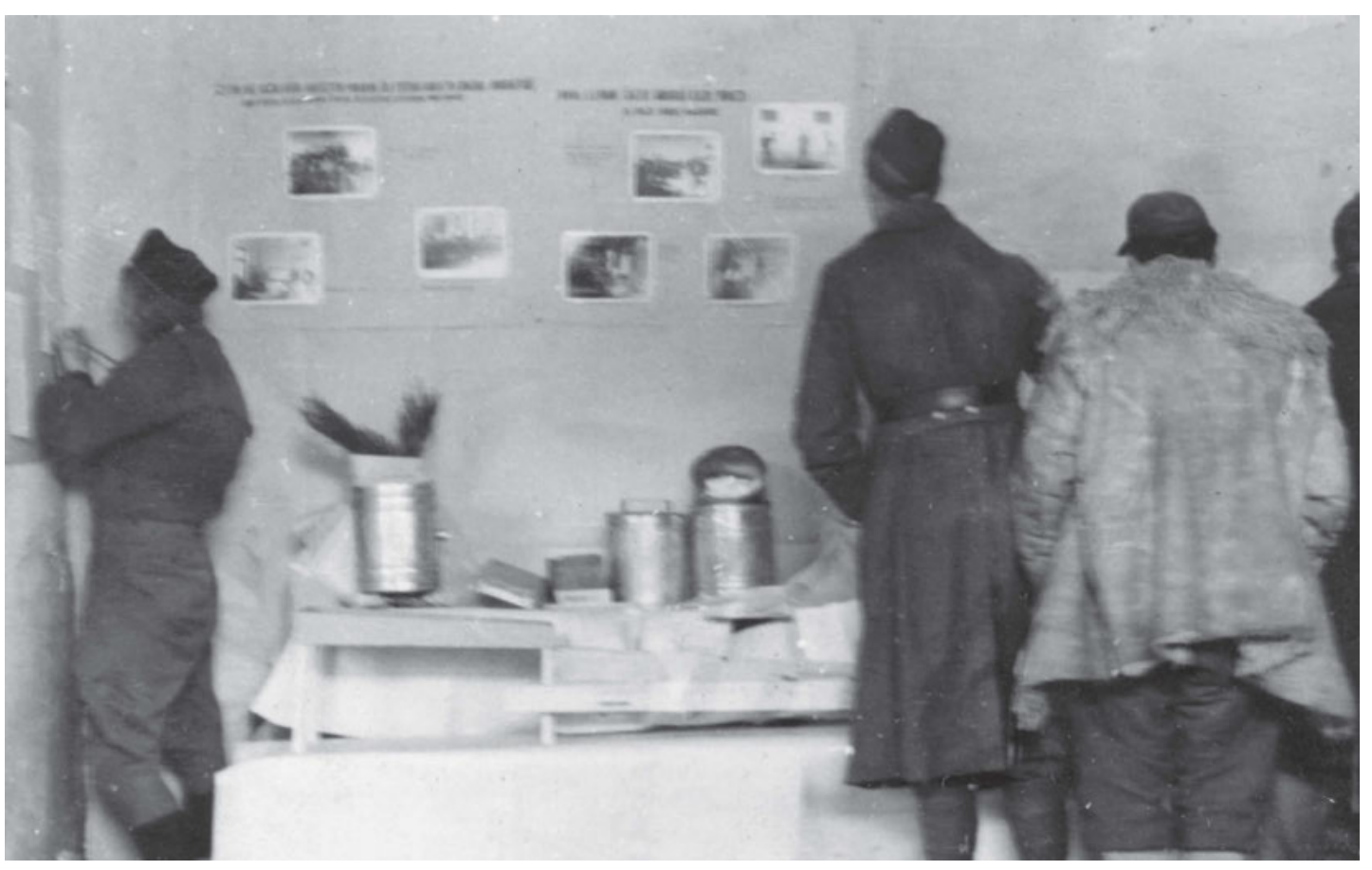

Ausstellung von Partisanenfotografien anlässlich der Zweiten Sitzung des AVNOJ, Livno, Bosnien-Herzegowina, 27. November 1943. Fotograf unbekannt. Zagreb, Kroatisches Historisches Museum I HPM/MRNH-F-5379.

25 Miletić, Miloš und Radovanović, Mirjana. Lekcije o odbrani: Prilozi za analizu kulturne delatnosti NOP-a. In: Dies. (Hrsg.). Lekcije o odbrani, Prilozi za analizu kulturne delatnosti NOP-a. Belgrad: KURS und Rosa-Luxemburg-Stiftung Southeast Europe 2016, S. 31. 26 Kirn, Gal. On the Specific (In)existence of the Partisan Film in Yugoslavia's People's Liberation Struggle. In: Jakiša, Miranda und Gilić, Nikica (Hrsg.). Partisans In Yugoslavia: Literature, Film and Visual Culture. Bielefeld: transcript Verlag 2015, S. 211. 


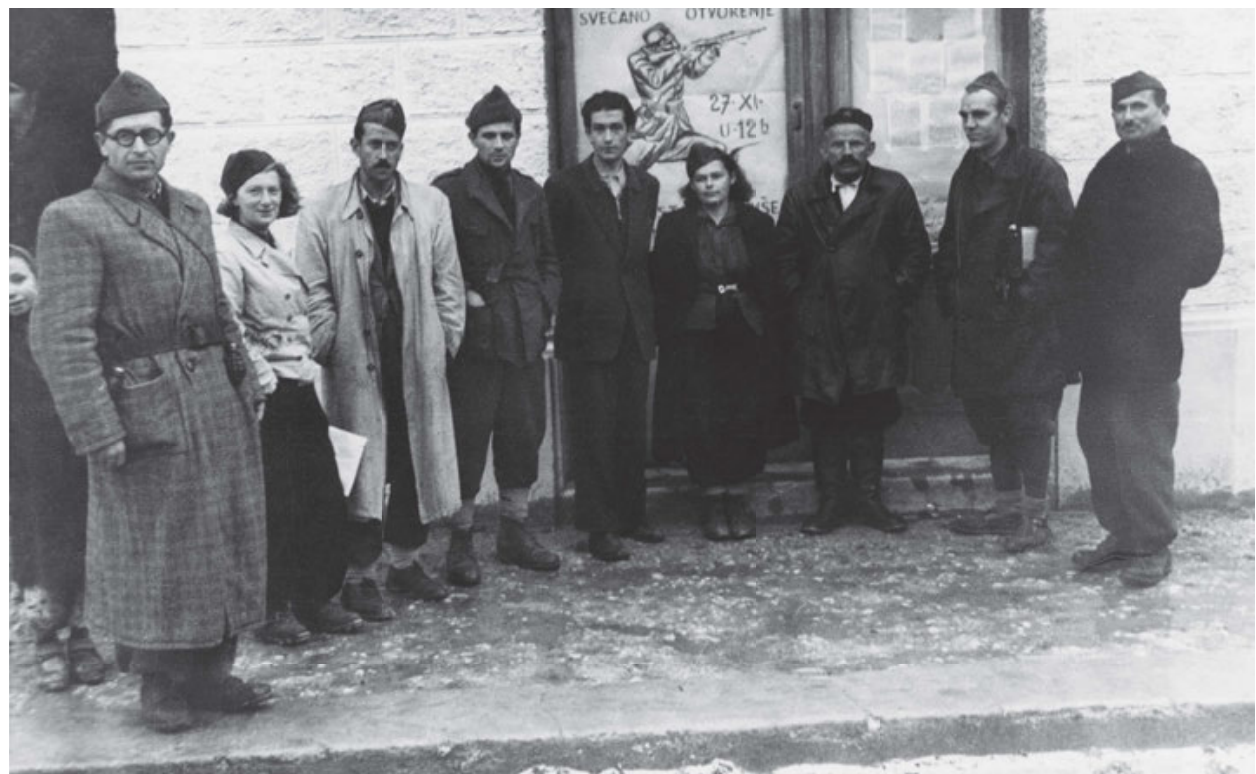

Slowenische Delegierte in Livno, auf dem Weg nach Jajce, November 1943.

Fotograf unbekannt. Sarajevo, Historisches Museum von Bosnien und Herzegowina | FNOB 724.

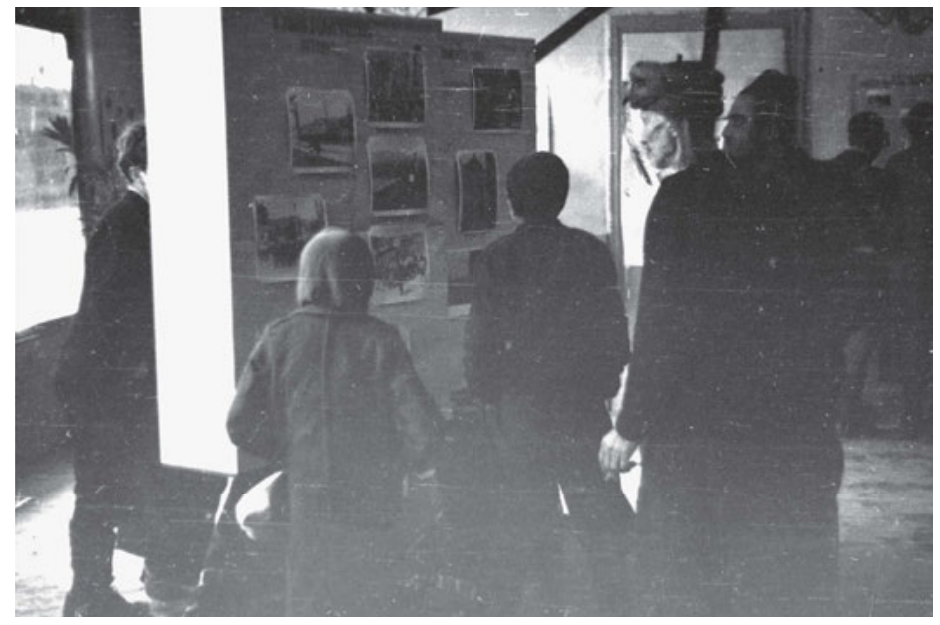

Details der Ausstellung zur Partisanenfotografie in Livno, anlässlich der Zweiten Sitzung des Antifaschistischen Rates der Volksbefreiung Jugoslawiens. Fotograf unbekannt. Fotolabor des Instituts für die Geschichte der Arbeiterbewegung der jugoslawischen Völker | MRNJ III-266./ znaci.net.

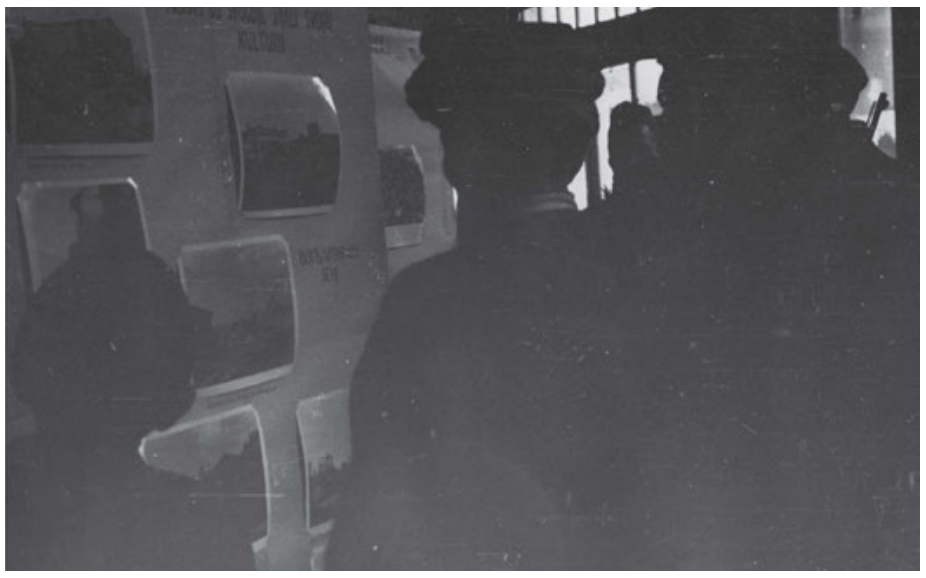

Detail der Ausstellung zur Partisanenfotografie, Livno 1943. Fotograf unbekannt. Fotolabor des Historischen Archivs beim ZK BdKJ | MRNJ III-1807/znaci.net. 


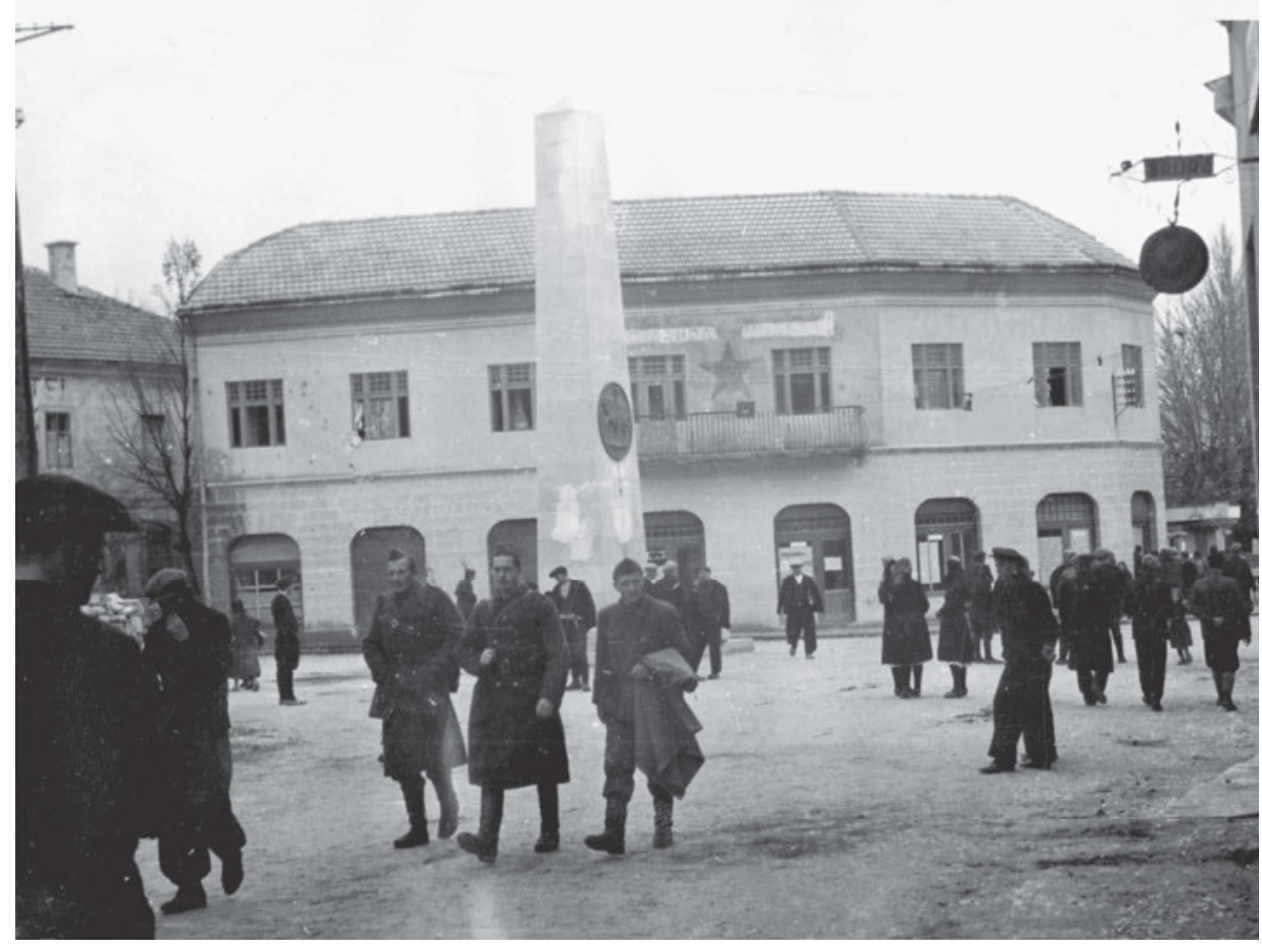

Eine Gruppe von Partisanen in Livno, 1943. Fotograf unbekannt. Fotolabor des Historischen Archivs beim ZK BdKJ | MRNJ III-3116/znaci.net.

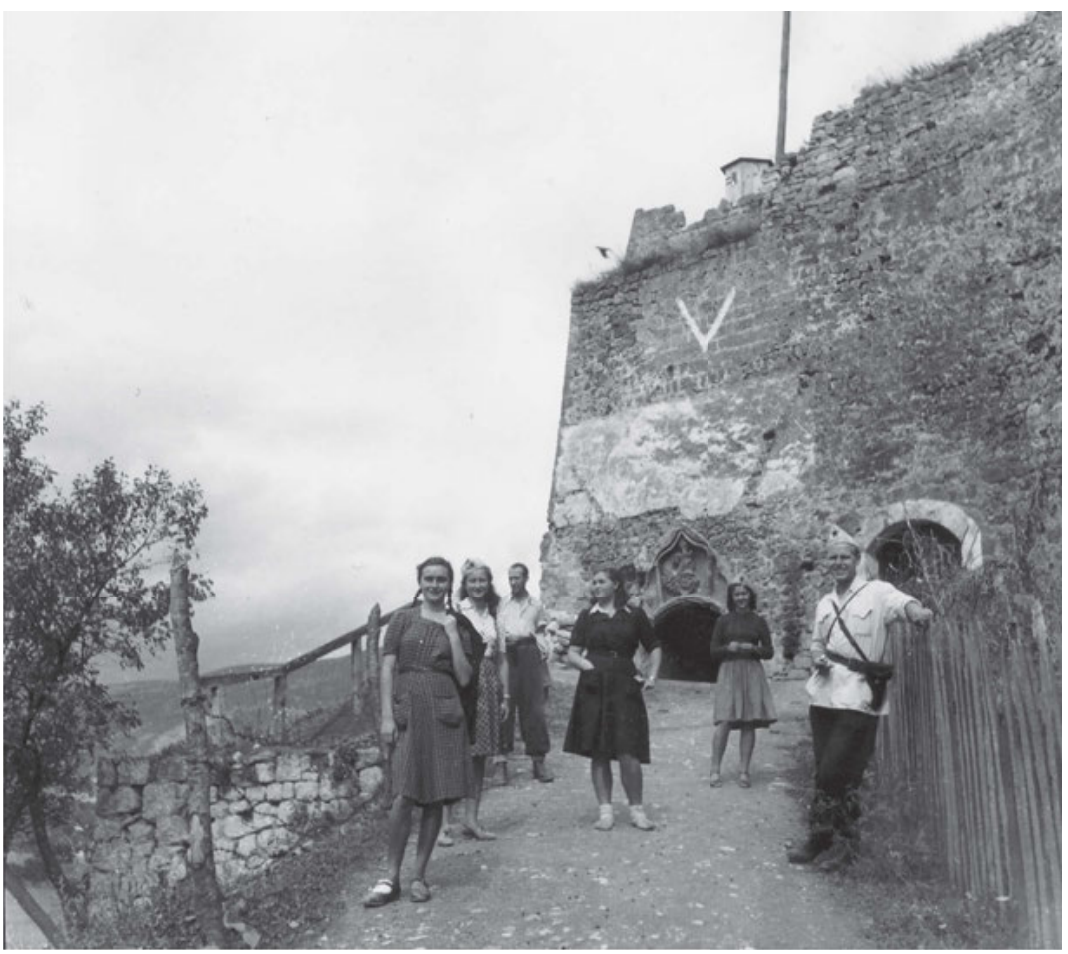

Mitglieder des Theaters der jugoslawischen Volksbefreiung in Jajce, September 1942. Von links nach rechts: Nada Borozan, Mira Afrić, Jože Rutić, Mira Djerić, Dara Lončar, Vjekoslav Afrić.

Foto: Žorž Skrigin. Fotolabor des Historischen Archivs beim ZK BdKJ | MRNJ-III-3459/znaci.net. 
Leiter der Schauspielschule Nikola Popović, während die Ballettsektion der frühere Balletttänzer des Kroatischen Nationaltheaters in Zagreb und einer der bekanntesten Partisanenfotografen, Žorž Skrigin, übernahm. ${ }^{27}$ Die Musiksektion führte Nikola Hercigonja, ihr Dirigent war Oskar Danon. ${ }^{28}$

Entgegen der gängigen Meinung, dass die erste Ausstellung der Partisanenfotografie in Kroatien am 11. Juni 1943 in Otočac veranstaltet wurde, bin ich bei meinen Untersuchungen auf Belege gestoßen, dass die ersten Partisanenfotografien schon am 23. Dezember 1942 im dalmatinischen Städtchen Slunj bei einer Fotografie- und Druckausstellung ${ }^{29}$ gezeigt wurden. Organisiert hatte sie die Agitprop-Abteilung des Kreiskomitees und des Zentralkomitees der Kommunistischen Partei Kroatiens. ${ }^{30}$ Ein Jahr später präsentierte man anlässlich der im Jugendheim in Otočac ausgerichteten Ausstellung Broschüren, Zeitungen im Taschenformat und Karikaturen der Partisanen, Bilder von Vladimir Kristl, Vilim Čerić, Ivo Kušanić sowie Fotografien von Franjo Mosinger. Nach Otočac folgten Ausstellungen in Senj, Novi Vinodolski und Crikvenica, wo die Stücke im Saal des dortigen Falkenhauses zu sehen waren. ${ }^{31}$

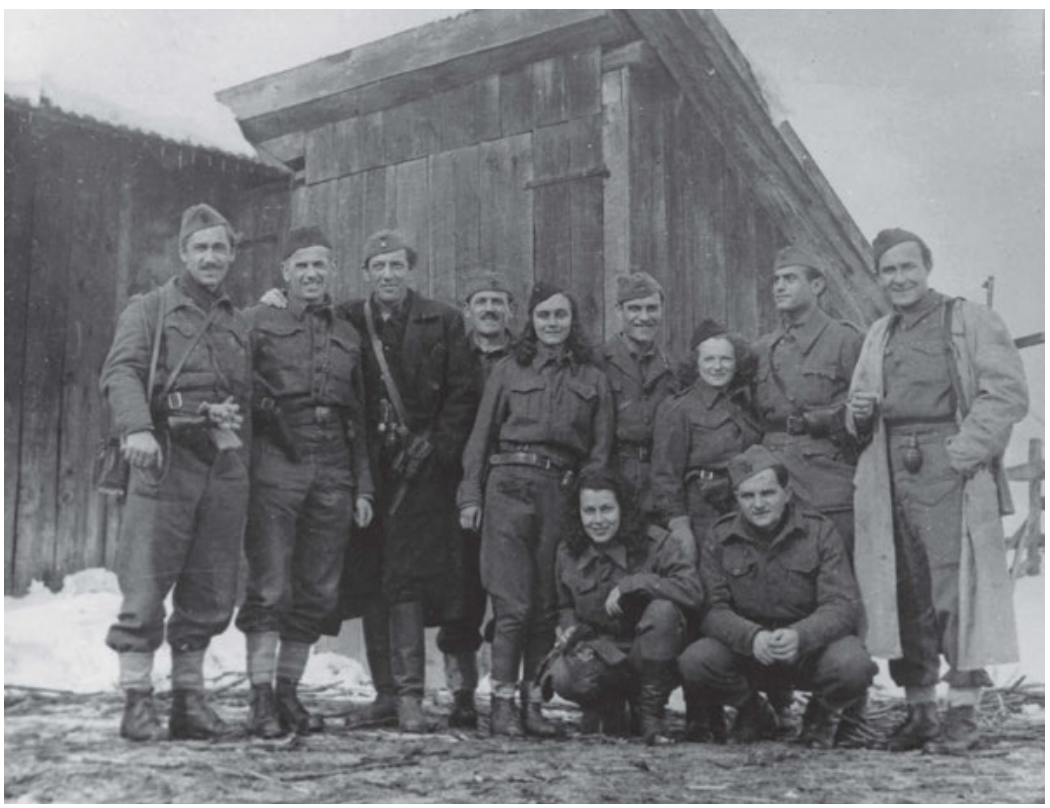

Theater der Volksbefreiung auf dem Berg Kozara, Dezember 1943.

Foto: Žorž Skrigin. Sarajevo, Historisches Museum von Bosnien und Herzegowina | FNOB 6485.

27 Georgij Skrigin wurde am 4. August 1910 in Odessa geboren, doch mit der Zeit war er unter dem Spitznamen Žorž bekannt. Ich habe mich entschieden, inn in diesem Buch Žorž Skrigin zu nennen, da der Autor selbst in der Nachkriegszeit mit diesem Namen unterzeichnete.

28 Petranović, Branko. Istorija Jugoslavije 1918-1988. Bd. 3: Socijalistička Jugoslavija 1945-1988. Belgrad: Nolit 1988 , S. 366.

29 Borcić, Mane. Kulturno-prosvjetna i propagandna djelatnost u kotarevima Slunj i Veljun tokom NOR-a. In: Zatezalo, Djuro (Hrsg.). Kotar Slunj i kotar Veljun u NOR-u i socijalističkoj izgradnji. Bd. II. Karlovac: Historijski arhiv u Karlovcu 1988, S. 758.

30 AlHRPH (Archiv des Instituts für die Geschichte der Arbeiterbewegung Kroatiens), KP-220/4890.

31 Hlevnjak, Branka und Ivanuš, Rhea. Hrvatska antiratna fotografija: Prvi svjetski, Drugi svjetski i Domovinski rat. Zagreb: Udruga za promicanje oblikovanja i umjetnosti, Design Art d. o. o., Centar za kulturu i obrazovanje 2008, S. 117. 


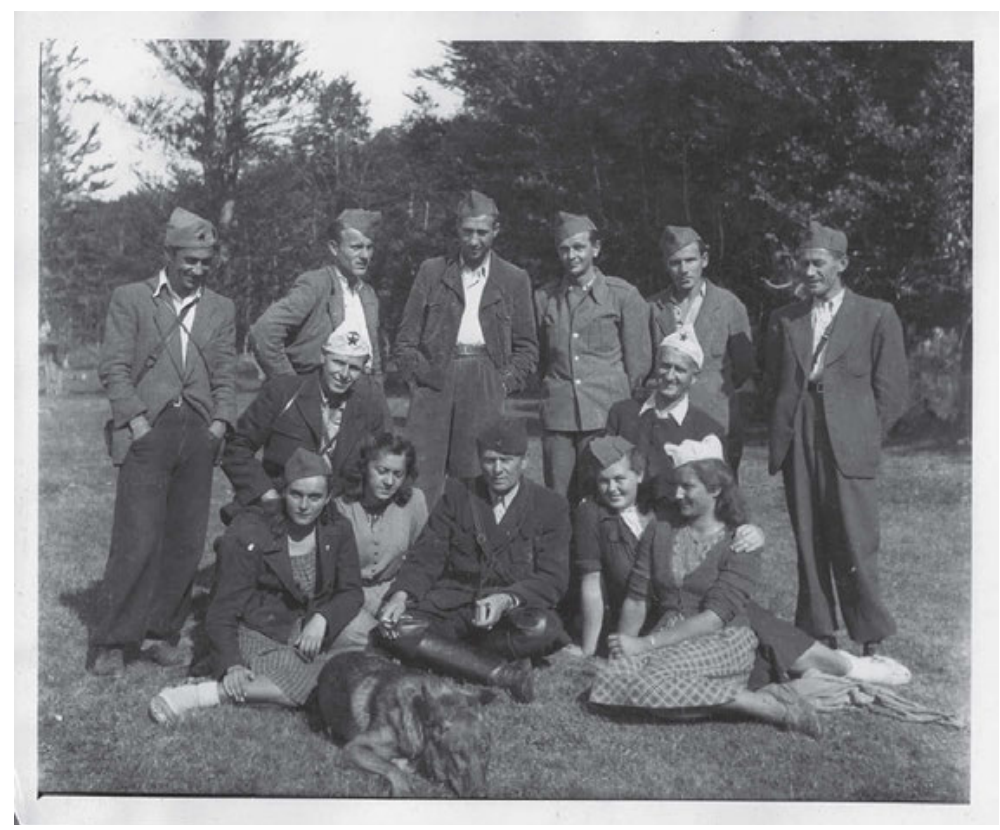

Josip Broz Tito mit Mitgliedern des Theaters der Volksbefreiung in Mlinište, September 1942. Links neben Tito sitzend: Nada Borozan, Dara Lončar. Rechts neben Tito sitzend: Mira Djerić, Mira Afrić. Kniend: Vjekoslav Afrić, Milan Vujković. Stehend: Žorž Skrigin und unbekannte Mitglieder. Belgrad, Museum Jugoslawiens | III-1249.

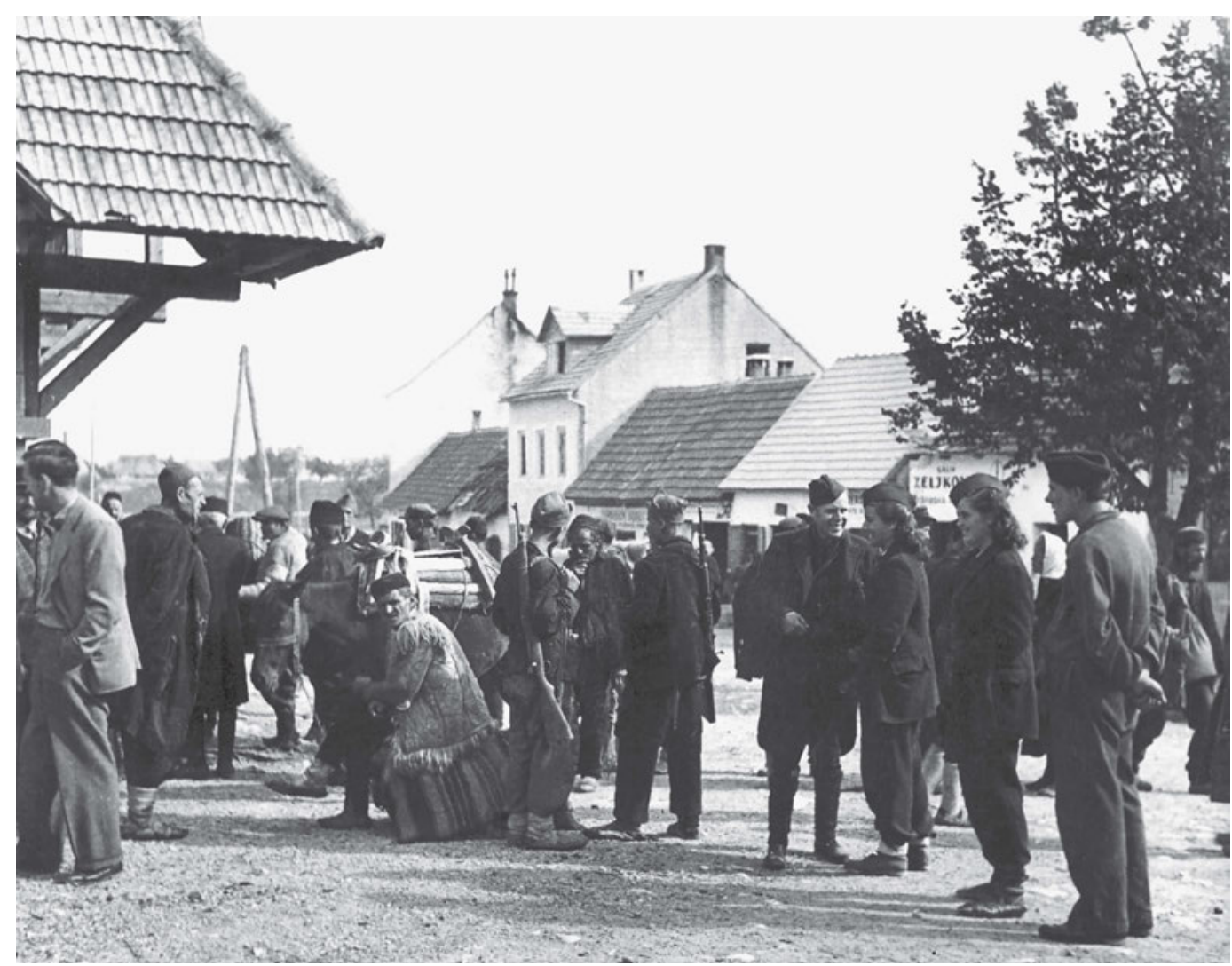

Mitglieder des Theaters der Volksbefreiung im befreiten Glamoč am Markttag, 1942. Auf dem Foto zu sehen sind unter anderem Mira und Vjekoslav Afrić. Fotograf unbekannt. Belgrad, Museum Jugoslawiens | III-3428. 


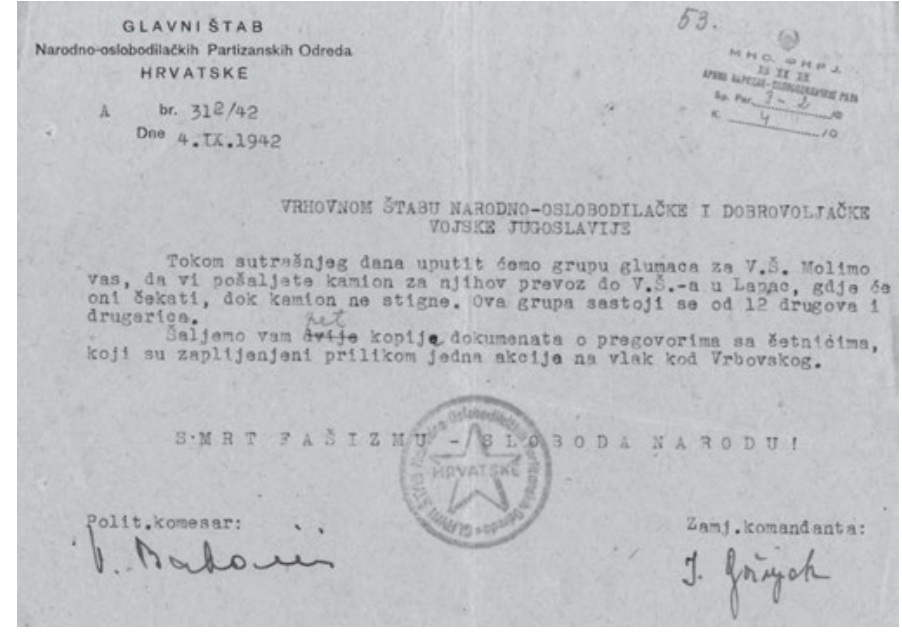

Der Hauptstab der Partisaneneinheiten Kroatiens bittet das Oberkommando um den Transport von Schauspielern. Belgrad, Militärarchiv | K4 F2 3.

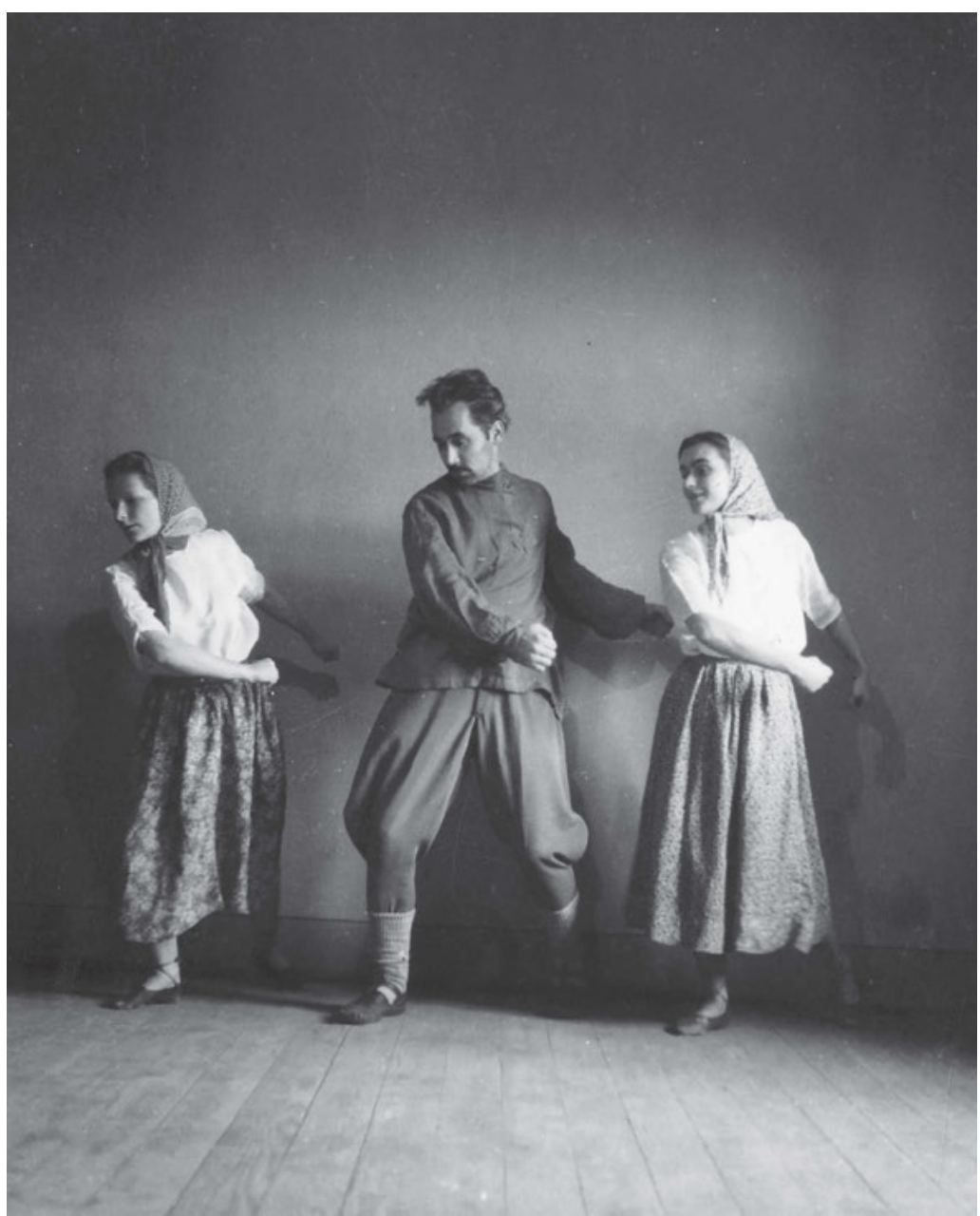

Mitglieder des Theaters der Volksbefreiung während der Proben zur Zweiten Sitzung des AVNOJ in Jajce, 1943. Von rechts nach links: Anika Radošević, Žorž Skrigin, Nada Borozan. Foto: Žorž Skrigin. znaci.net. 


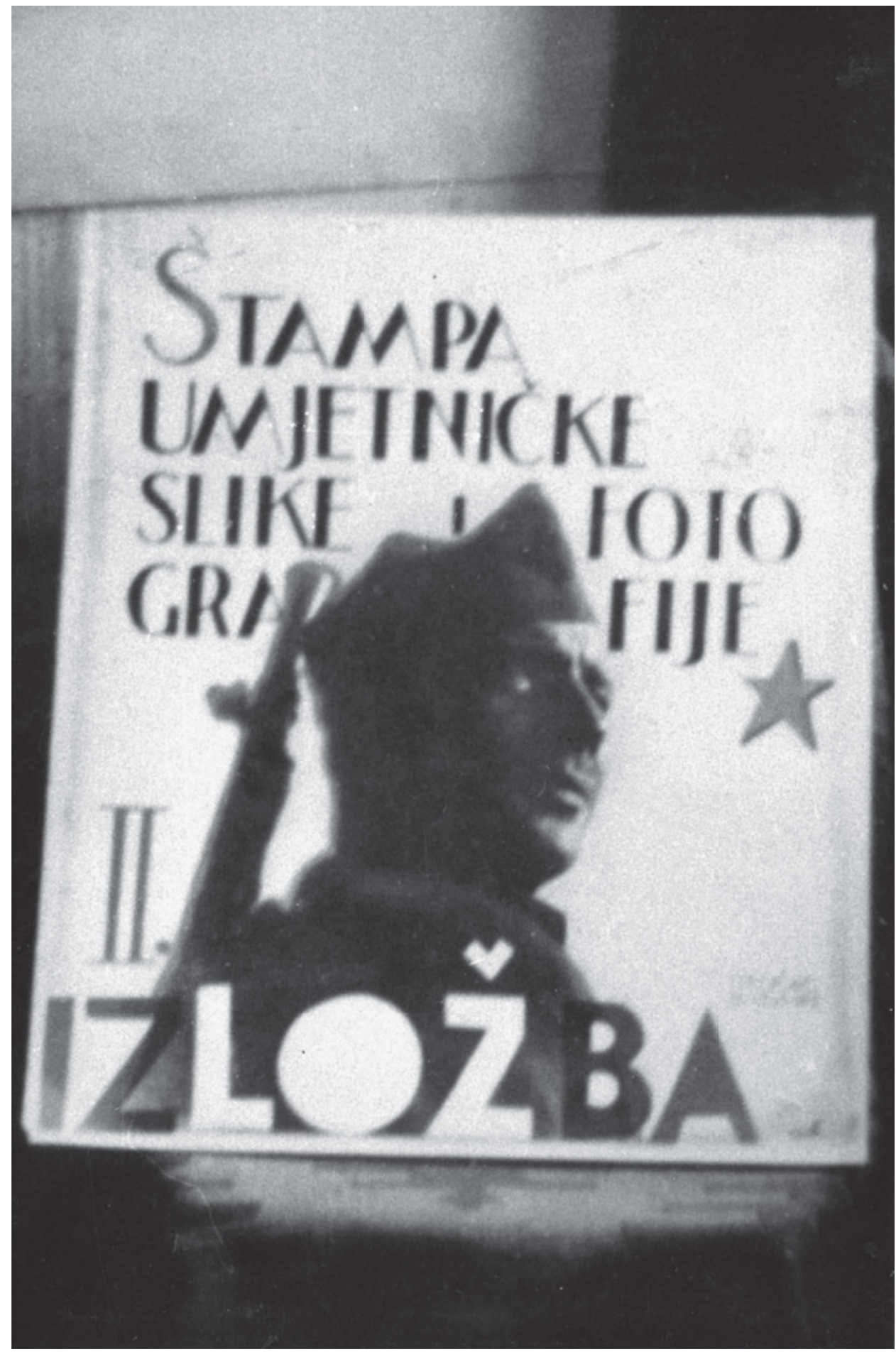

Plakat zur Zweiten Bilder- und Fotoausstellung in Otočac, Kroatien, 11. Juni 1943.

Foto: Franjo Mosinger. Zagreb, Kroatisches Historisches Museum | HPM/MRNH-F-3427. 


\section{Sic transit gloria mundi: Schauspieler und Balletttänzer als Partisanenfotografen}

Die letzte Rolle von Vjekoslav Afrić im damaligen Kroatischen Staatstheater war die Hauptfigur im Faust, und gerade Afrićs Gestalt sollte in den 1980er-Jahren dem kroatischen Regisseur Slobodan Šnajder für die Dramatisierung eines wesentlichen Teils seines Kroatischen Faust dienen; dieses Stück versetzt das kroatische Theaterpublikum auch heute noch in Aufregung und gelangte 1987 am Theater in Mühlheim an der Ruhr unter der Regie von Roberto Ciulliu zur deutschsprachigen Uraufführung. In der Gestalt von Afrić und dem heutigen Kroatischen Nationaltheater, das sich auf dem kürzlich umbenannten Zagreber Marschall-Tito-Platz befindet, überschneiden sich ideologisch potenzierte Erinnerungen und Versuche kollektiven Vergessens erneut. Eine Tagebuchaufzeichnung von Afrić aus dem Jahr 1942 über die gesellschaftliche Rolle des Theaters, das Publikum sowie die emanzipatorische Wirkung der Kunst ist überdies von unveränderter Aktualität:

"Von den Partisanen befreite Gebiete konnte man sich nicht ohne ein intensives Kultur- und Künstlerleben vorstellen. Parallel zu der Formierung der ersten militärischen Einheiten organisierte man auch schon die ersten Kurse für Analphabeten, Schulen, Bibliotheken, mündliche Zeitungen, Grafik- und Fotoausstellungen, verschiedene Kurse, Zeitschriften, und so wollte letztendlich jede größere militärische Einheit ihre eigene Kultur- und Künstlertruppe begründen. In jedem Dorf auf dem von den Besatzern befreiten Territorium war mindestens eine Amateurgruppe im Bereich von Kultur und Kunst aktiv. Man sang Volks- und Partisanenlieder, tanzte Volkstänze, richtete unterschiedliche Veranstaltungen aus, Dramen-, Poesie- sowie Kulturabende und andere gesellige Zusammenkünfte [...]. In Lika war das Interesse des Publikums für unsere Veranstaltungen riesig, oftmals spielten wir vor mehreren Tausend Menschen. Wenn man erfuhr, dass wir in irgendeinem Dorf eine Veranstaltung organisierten, eilten die Bauern auch aus den weit entfernten, umliegenden Ortschaften herbei, um den Schauspielern aus Zagreb zu lauschen. Es gab sogar Zuschauer, die nicht in der jeweils befreiten Gegend lebten, sodass der Besuch unserer Veranstaltungen für sie ein überaus riskantes Unterfangen war. ${ }^{32}$

Im selben Jahr begannen Vjekoslav Afrić und Žorž Skrigin mit den Vorbereitungen für die Theatervorstellung Sumnjivo lice (Verdächtige Person) des serbischen Satirikers Branislav Nušić. Sie inszenierten auch die erste Ballettvorstellung der Partisanen unter dem Titel Okupator, in der neben Skrigin auch Nada Borozan, Dara Tatalović und die wunderschöne, herausragende Berufstänzerin Anika Radošević tanzten, während der Dichter Junus Medjedović als Schauspieler auftrat. Die eigene Geistesstärke, den mentalen Zustand der Kollegen, die Position der Kulturschaffenden, die die Sicherheit der Städte aufgaben und sich den Partisanen in den Wäldern anschlossen, thematisiert ein Tagebucheintrag Afrićs vom 23. November 1942 nach der Vorstellung von Sumnjivo lice. Das Publikum setzte sich aus insgesamt siebzig gefangengenommenen Mitgliedern der kroatischen Heimwehr zusammen. In dieser Situation war die Realität im Grunde weitaus interessanter als die Kunst 
selbst, hatten das Theater und das Leben die Positionen getauscht und dem Künstler blieb nichts anderes übrig, als über die eigene Rolle nachzudenken und sich mit jenen zu konfrontieren, die statt eines Engagements zu einem Kompromiss bereit waren:

"Sie jubelten und applaudierten so, als wären sie Partisanen. Unter innen befanden sich auch einige uns bekannte Bürger aus Zagreb, die uns nach der Vorstellung detailliert über die Vorkommnisse in Zagreb, insbesondere im Zagreber Theater, informierten. Eine dieser uns vertrauten Personen war der Bruder einer uns allen bekannten Balletttänzerin, der selbstverständlich über jeden Klatsch, jede Intrige und Pikanterie in den Theaterkreisen bestens Bescheid wusste. So berichtete er uns bis ins kleinste Detail über die Zustände im Zagreber Theater seit unserem Weggang. Später habe ich viel über all seine Informationen nachgedacht und mich darüber gewundert, wie fremd mir doch das Umfeld geworden ist, das ich verlassen hatte und das mir bis vor einigen Monaten so vertraut war. Ist es denn möglich, dass es auch heute noch mitten im grausamsten Krieg und der Revolution Menschen geben kann, die im Restaurant sitzen, zu Hause Feiern organisieren, im Theater für ein Publikum spielen können, in dem Besatzer des Landes anwesend sind, darüber hinaus aber auch noch mit ,fröhlichen Abenden und Kabarettvorstellungen nebenbei etwas hinzuverdienen, über das Getratsche und die Intrigen im Theater erzählen, Liebesabenteuer erleben, im Radio Gedichte sprechen können, und zwar im selben Radio, das die infamsten Lügen und Dreistigkeiten verbreitet, schamlos das gesamte Volk belügt und beschwindelt, aus dem Stimmen schreien, um sich möglichst laut mit der eigenen Unmenschlichkeit und den begangenen Gräueltaten zu rühmen. Kann ich und darf ich das alles überhaupt verstehen? Wenn ich es verstehen könnte, müsste ich das auch vergeben können. Und was sollte ich überhaupt verstehen? Sind sie denn aus einem anderen Stoff zusammengesetzt als wir, sodass sie sich einfach nicht für das Leben entscheiden können, das wir führen? [...] Ich schaue mir diese Mitglieder der Heimwehr an und was dann? Soll ich sie bemitleiden? Sie verachten? Sie verstehen? Was soll ich über meine guten und unbescholtenen Kollegen in Zagreb denken? Und je mehr ich über sie nachdenke, desto mehr fühle ich, wie sich dieser gesamte psychologische Prozess in mir kopfüber dreht. Wie in einer Fotokamera. Anstatt sie zu verstehen, um sie lieben zu können, liebe ich sie, wodurch ich sie zu verstehen beginne. Wenn dieser Krieg einmal zu Ende geht und wir am Leben bleiben und sie auch, werden wir gemeinsam in irgendeinem Restaurant oder bei einem geselligen Abend bei jemandem zu Hause sitzen und über die eigenen Erlebnisse erzählen. Sie über ihre Erfolge als Schauspieler, ihre Abenteuer und das Getratsche und wir über unsere Erlebnisse im Krieg [...] und das war's dann auch. Wir werden uns wieder gegenseitig interessant sein. 'Sic transit - Gloria Swanson!«, wie mein Freund Dubajić zu sagen pflegte. «33

Sic transit gloria mundi (So vergeht der Ruhm der Welt) bedeutet Afrićs Vergebung gegenüber seinen Kollegen, seine Aussöhnung - die große Geste eines Intellektuellen, Künstlers und Revolutionärs, der Privilegien ausschlägt, um seinem politischen Wesen und Wirken treu zu bleiben, indem er Antonio Gramscis Hass gegenüber der Unentschlossenheit überwindet. Afrić betrachtet auch die Rolle der Kunst und im Besonderen die Rolle des Theaters der 


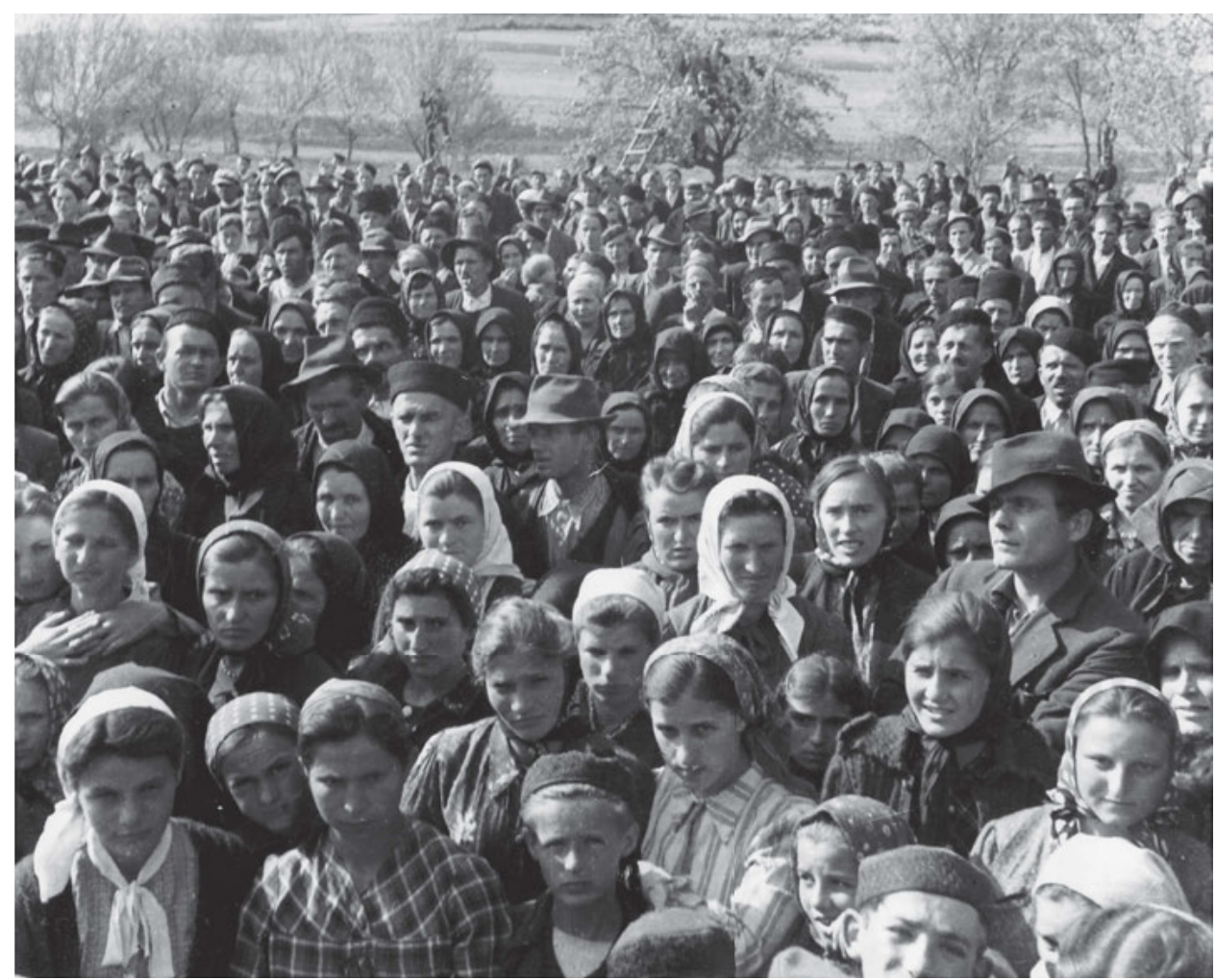

Publikum bei einer Aufführung des Theaters der Volksbefreiung in Lika, Kroatien, 1942.

Foto: Žorž Skrigin. Fotolabor des Historischen Archivs beim ZK BdKJ | MRNJ III-3716/znaci.net.

Volksbefreiung kritisch. Er verweist darauf, dass innerhalb der Partisanenbewegung unterschiedliche, oftmals gegensätzliche Auffassungen von Kunst geherrscht haben. ${ }^{34}$ Befreit von Dogmatik und Moralismus - mit denen auch heute, nur mit umgekehrten Vorzeichen, der gesamte Zeitraum des Partisanenkampfes dargestellt wird - führt uns Afrić das Dilemma vor Augen. Zwar zeigt er kein Interesse für den grellen Schein des Scheinwerferlichtes und den Schauspielruhm, doch wird er nicht zum Zyniker, sondern vielmehr zum engagierten Kulturschaffenden, der auch weiterhin die Bedingungen, unter denen er wirkt, zu hinterfragen wagt. Aus dem Tagebuch geht gleichermaßen hervor, dass Afrić während seiner Zeit als Partisanenkämpfer fotografierte und seinen Fotoapparat sowie einige Filme aus Zagreb mitgenommen hatte, als er am 22. April 1942 mit einer Gruppe von Kollegen die Stadt verließ. In der ersten Gruppe befanden sich neben Afrić noch Ivka und Joža Rutić sowie Salko Repak, während die zweite Gruppe aus Milan Vujnović, Zvonimir Cvija und Žorž Skrigin bestand, die am selben Tag Zagreb den Rücken kehrten. ${ }^{35}$ Bevor er seine Wohnung in Zagreb zurückließ, vernichtete Žorž Skrigin einen Teil seiner Fotografien, weil er befürchtete, dass nahestehende Menschen aufgrund der Bilder bei den Ustascha kompromittiert werden könnten. Lediglich ein paar Filme und seinen Fotoapparat der Marke Rolleiflex behielt er, um Aufnahmen während seiner Zeit als Partisanenkämpfer zu machen.

34 Ebd., S. 525.

35 Afrić, Vjeko. Umjetnici u redovima boraca. In: Malić, Josip (Hrsg.). Zbornik sjećanja: Zagreb 1941-1945. Bd. III. Zagreb: Gradska konferencija SSRNH, Institut za historiju radničkog pokreta Hrvatske und Školska knjiga 1984, S. 237. 
Žorž Skrigin gehörte vor dem Krieg zu den namhaftesten Mitgliedern des Fotoklubs Zagreb und war einer der am häufigsten ausgezeichneten Fotografen im In- und Ausland. In der Partisanenbewegung schuf er einige der wichtigsten Fotografien. Während des Marsches des Ersten Kroatischen Proletarierbataillons in Richtung Adriaküste machte Skrigin piktorialistische Fotografien an den Plitvicer Seen, später die ersten Bilder der Kämpfe. Auf der Straße, die Senj und Novi Vinodolski verband, bereiteten die Partisanen einen Hinterhalt genau an jenem Punkt vor, an dem die Straße zwischen den Bergen und dem Meer verlief. Der Kommandant des Bataillons, Milan Žeželj, wählte zusammen mit den übrigen Partisa-

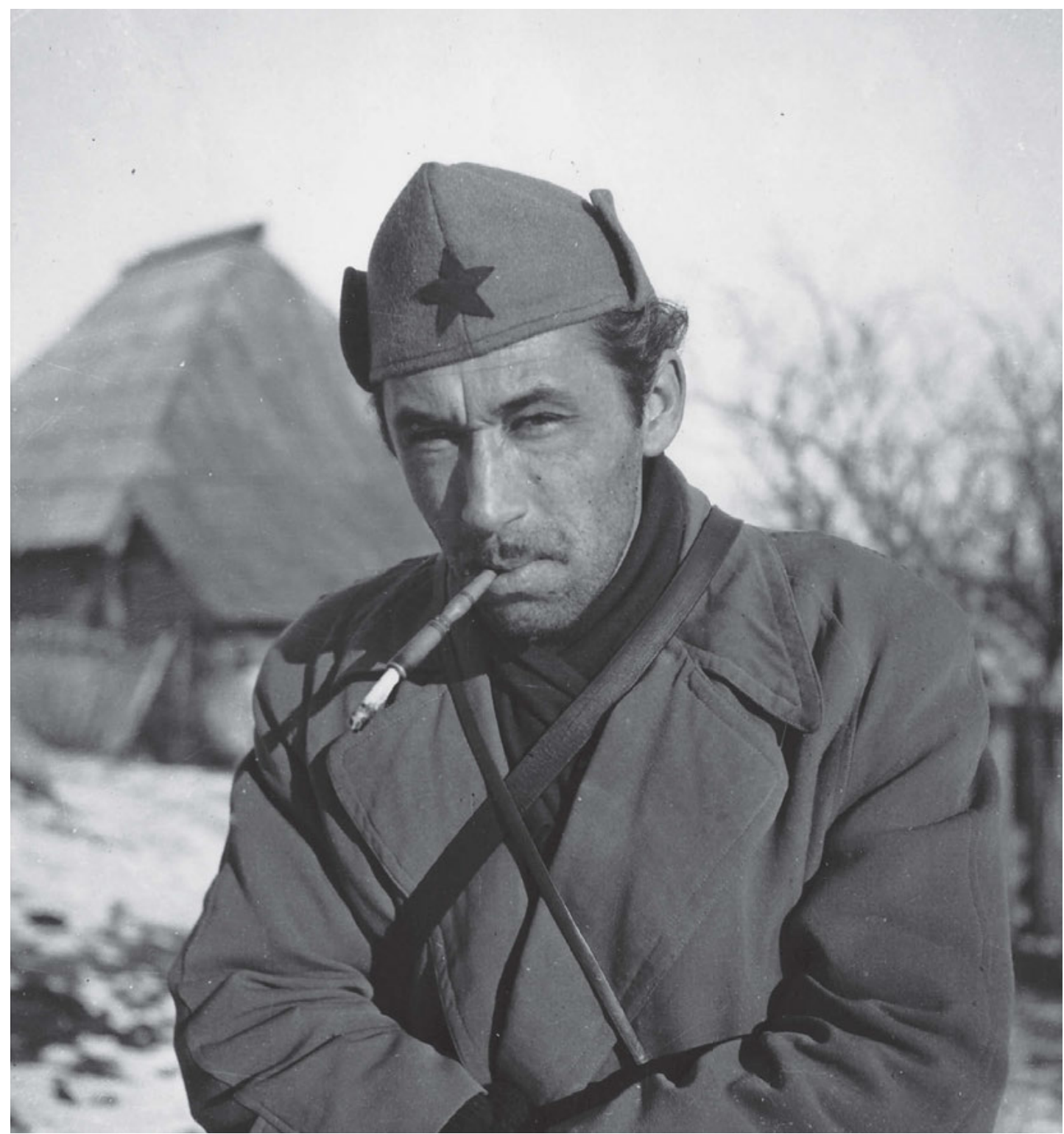

Žorž Skrigin, Mitglied des Theaters der Volksbefreiung. Foto: Žorž Skrigin. Fotolabor des Historischen Archivs beim ZK BdKJ | znaci.net. 
nen den besten Platz aus, um die Aktion zu filmen. Skrigin beschrieb diese Augenblicke mit folgenden Worten:

»Ich stellte schnell meinen Fotoapparat ein und fand einen Platz, um möglichst gute Aufnahmen machen zu können. Der Feind war schon sehr nahe, kam auf der Straße an mir vorbei - warum schießen wir nicht? Ich weiß, dass abgesprochen war, Banina würde mit einem Schuss aus seinem Revolver das Zeichen für den Angriff geben. An mir fuhr die Artillerie vorbei, gefolgt von gepanzerten Wagen und ich fragte mich, warum unsere Verbände nicht angreifen, da ja dies der beste Moment war, um gute Aufnahmen zu machen. Ich lag regungslos am Boden, damit mich die italienischen Flankenverbände nicht sahen, man hörte keine menschlichen Stimmen, sondern nur das Brummen der Motoren. All dies löste bei mir eine ungeheure nervliche Angespanntheit aus. Ich begann mich leicht hin und her zu bewegen, doch dann - man hörte den Revolverschuss, und vom Meer, das von der Sonne beschienen und durch die Windstille aalglatt war, erschallte ein starkes Echo. Dann entstand ein heilloses Durcheinander. Ich hörte laute Rufe: 'Los, Proletarier! ... Angriff! ...! Kaum hatte ich meinen Fotoapparat auf die angreifenden Truppen gerichtet, da hörte ich schon über meinen Kopf das Rattern des schweren Maschinengewehrs, das nur ein paar Meter von mir entfernt platziert war. Dies war meine Feuertaufe im Krieg. Die Kugeln zischten über meinen Kopf hinweg, ich hörte dieses Geräusch zum ersten Mal in meinem Leben und der Geruch des Pulvers stieg erstmals in meine Nase hoch. Instinktiv zog ich meinen Kopf ein und versuchte, mich noch mehr auf den Boden zu pressen, während mir folgender Gedanke durch den Kopf schoss: Soll ich denn direkt beim ersten Mal mein Leben verlieren, und das auch noch durch Beschuss aus den eigenen Reihen? Doch dann wurde meine Eitelkeit geweckt - sollte ich wirklich nichts von dem aufnehmen, was sich da unten auf der Straße abspielte? Ich drehte meine Rolleiflex auf den Kopf, streckte meine Arme in die Höhe und schaute mir das Geschehen unten auf der Straße im Spiegel des Fotoapparats an. Dabei sagte ich zu mir selbst, dass es sicherlich besser sei, wenn die Kugeln aus unserem Maschinengewehr meine Arme und nicht meinen Kopf treffen! ${ }^{36}$

Die Partisaneneinheit erlitt bei diesem Kampf keine Verluste, die italienische Einheit verlor zwei Kanonen, und in die Hände der Partisanen gelangten drei leichte Maschinengewehre, zahlreiche Gewehre, einige Tausend Gewehrkugeln und ein Revolver, den Skrigin erhielt. ${ }^{37}$ Als Mitglied des Theaters der Volksbefreiung, das dem Oberkommando der Volksbefreiungsarmee und der Widerstandsbewegung Jugoslawiens unterstand, hatte Skrigin als Fotograf eine gute Position inne. Er war nicht den Kämpfen an vorderster Frontlinie ausgesetzt und mit Fotomaterial besser ausgestattet. In Mlinište war er einer der ersten Fotografen, die Josip Broz Tito aufnahmen. Ständig gemeinsam mit dem Haupttross der Volksbefreiungsarmee unterwegs, befand sich Skrigin oftmals in Gesellschaft des bekannten Dichters Ivan Goran Kovačić, den er auch unmittelbar vor seinem Tod in Ostbosnien nach der Fünften Offensive fotografierte. ${ }^{38}$ Vjekoslav Afrić rettete die Verse von Kovačićs wohl berühmtesten Gedicht Jama (Grube), das er als Erster den Verwundeten der Ersten Proletarischen Brigade öffentlich vorlesen sollte. Das Gedicht beschreibt die Gräuel des Krieges und den Schmerz, in den Versen schien der Dichter den eigenen Tod vorauszuahnen:

\footnotetext{
36 Skrigin, Žorž. Rat i pozornica. Belgrad: Turistička štampa 1968, S. 22-23.

37 Ebd., S. 163.

38 Ebd.
} 


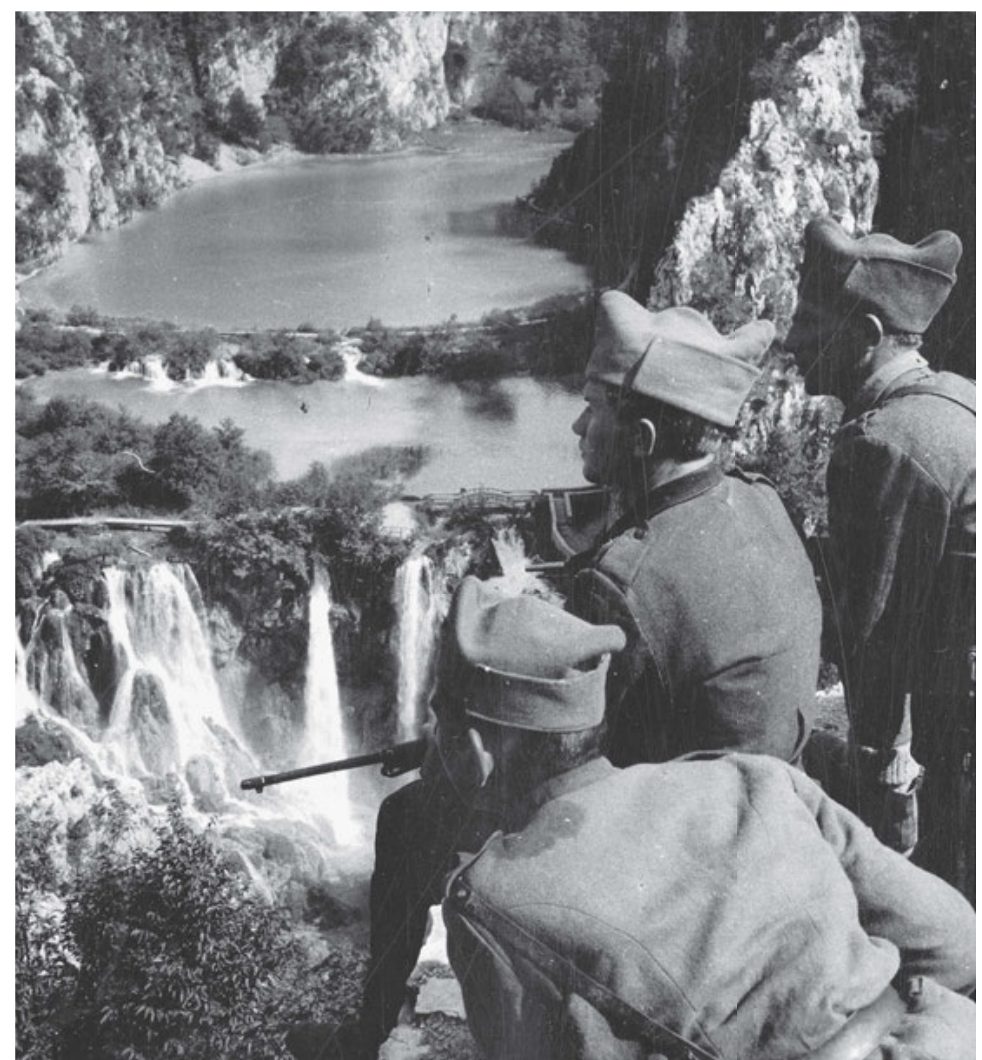

Partisanen an den Plitvicer Seen, 1942. Foto: Žorž Skrigin. znaci.net.

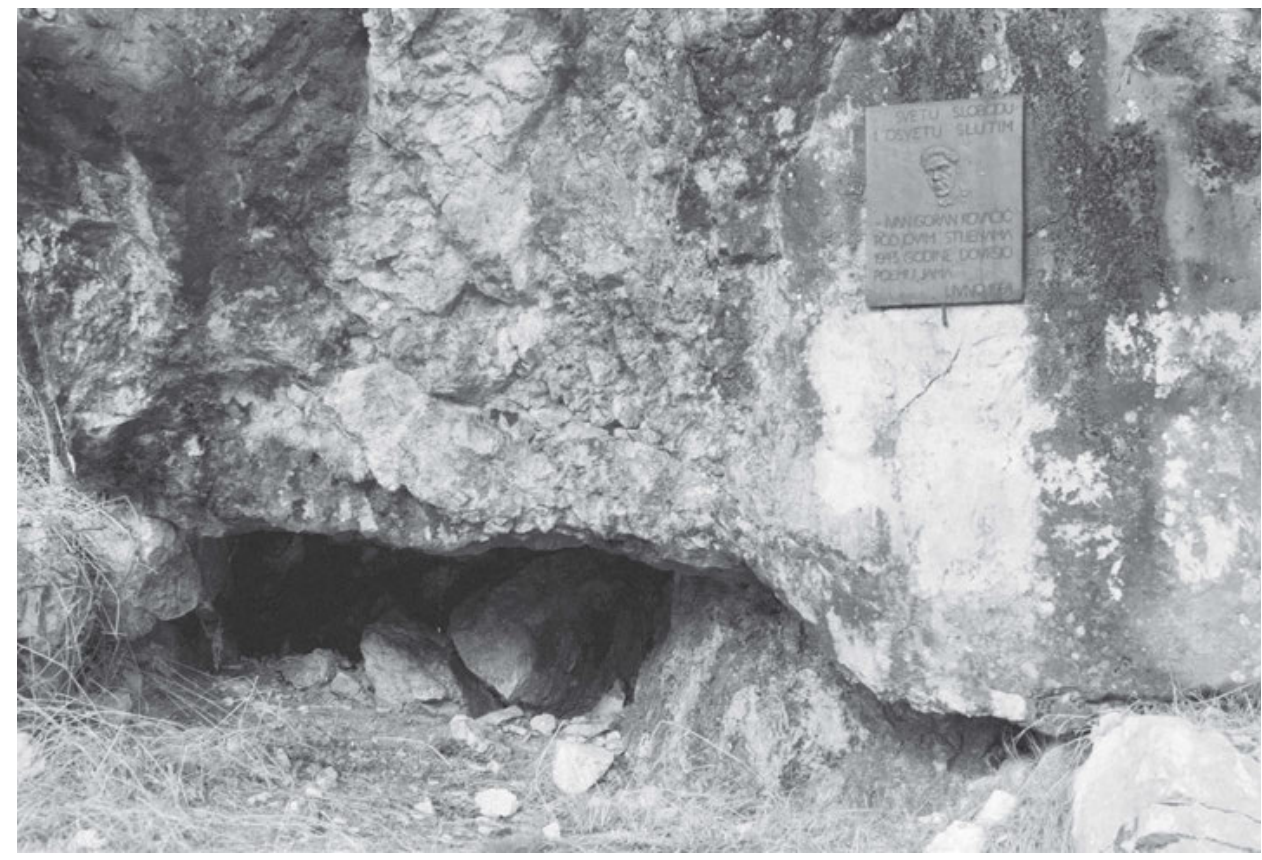

Ort, an dem Ivan Goran Kovačić sein Gedicht Grube verfasst hat. Livno, Bosnien und Herzegowina, 2017. Foto: Davor Konjikušić. 
Ich begann zu schluchzen und hörte nie auf

Nur mit der Kehle, da ich keine Augen mehr habe,

Nur mit dem Herzen, da meine Tränen das Messer

Der Mörder das letze Mal fließen ließen. Ich habe

Keine Augen, um euch zu sehen und auch keine Kraft,

Doch ich würde so gerne - mit euch in den Kampf ziehen.

Wer seid ihr? Woher kommt ihr? Ich weiß es nicht, doch

Ich wärme mich in eurem Licht. Singt. Denn ich schweige,

Endlich lebe ich, obwohl ich vielleicht sterben werde.

Die heilige Freiheit und Rache ahne ich ...

Euer Gesang bringt mir das Augenlicht zurück,

Mächtig wie das Volk, strahlend wie die Sonne.

\section{Die erste Tagung der Kulturschaffenden im besetzten Europa}

Obwohl bereits ein Jahr zuvor geplant, fand der Erste Kongress der Kulturschaffenden und Öffentlichen Arbeiter Kroatiens wegen der feindlicher Angriffe erst 1944, vom 25. bis zum 27. Juni, im Örtchen Topusko statt. Diese wahrhaft einzigartige Tagung im besetzten Europa war für die Entwicklung der Partisanenfotografie von besonders großer Bedeutung. Im Rahmen der Konferenz wurde am Abend des 26. Juni eine Gemälde- und Fotoausstellung ausgerichtet. $^{39}$

In Otočac hatte Hugo Fischer Ribarić, ein Fotograf aus Crikvenica, zusammen mit Elvira Kohn und Djurdja Koren (geb. Šipušić) - die zu den wenigen Fotografinnen gehörten - die Fotosektion der Propagandaabteilung des Antifaschistischen Landesrats der Volksbefreiung Kroatiens (ZAVNOH) begründet. ${ }^{40}$ Die übrigen Mitglieder der Sektion waren der Journalist und Publizist Mahmud Konjhodžić, die Fotolaborantin Slavica Biluš und der Grafiker Karlo Nadj. ${ }^{41}$ Ribarić oblag gleichzeitig die Leitung der Propagandaabteilung des ZAVNOH.

Der bekannte Jurist und Mitglied der Kommunistischen Partei Jugoslawiens Mladen Iveković, der zugleich einer der Gründer der Zeitschrift Pregled und Redaktionsmitglied der Zeitungen Novi list, Odjek und Naše novine war, dokumentierte die Sitzung in Topusko fotografisch. Zu Beginn des Zweiten Weltkriegs war er von Januar bis September 1942 im Konzentrationslager Jasenovac inhaftiert, doch den Partisanen gelang es, ihn im Zuge eines Gefangenenaustauschs zu befreien. Als Mitglied des Exekutivrats des AVNOJ, verantwortlichem Redakteur der Zeitung Vjesnik und Leiter der Propagandaabteilung des ZAVNOH war

39 Prvi kongres kulturnih radnika Hrvatske. Topusko, 25.- 27.VI.1944. In: ČSP, 8, Nr. 2/3, 1976, S. 16-17. Siehe Roksandić, Drago. Prvi kongres kulturnih radnika Hrvatske (Topusko, 25.-27. lipnja 1944.): Iskustvo i aproprijacije. In: Ders. und Cvijović Javorina, Ivana (Hrsg.). Intelektualci i rat 1939. -1947. Zbornik radova s Desničinih susreta 2011. Zagreb: Plejada d. o. o. 2012 , S. 112.

40 Graovac, Dušan. Organizacija i djelatnost NOO-a u Lici između Drugog i Trećeg zasjedanja ZAVNOH-a. In: Zatezalo, Djuro (Hrsg.). Treća godina Narodnooslobodilačkog rata na području Karlovca, Korduna, Like, Pokuplja i Žumberka. Karlovac: Historijski arhiv u Karlovcu 1977, S. 745.

41 Hlevnjak, Branka und Ivanuš, Rhea. Hrvatska antiratna fotografija, Prvi svjetski, Drugi svjetski i Domovinski rat. Zagreb: Udruga za promicanje oblikovanja i umjetnosti, Design Art d. o. o., Centar za kulturu i obrazovanje 2008, S. 113. 


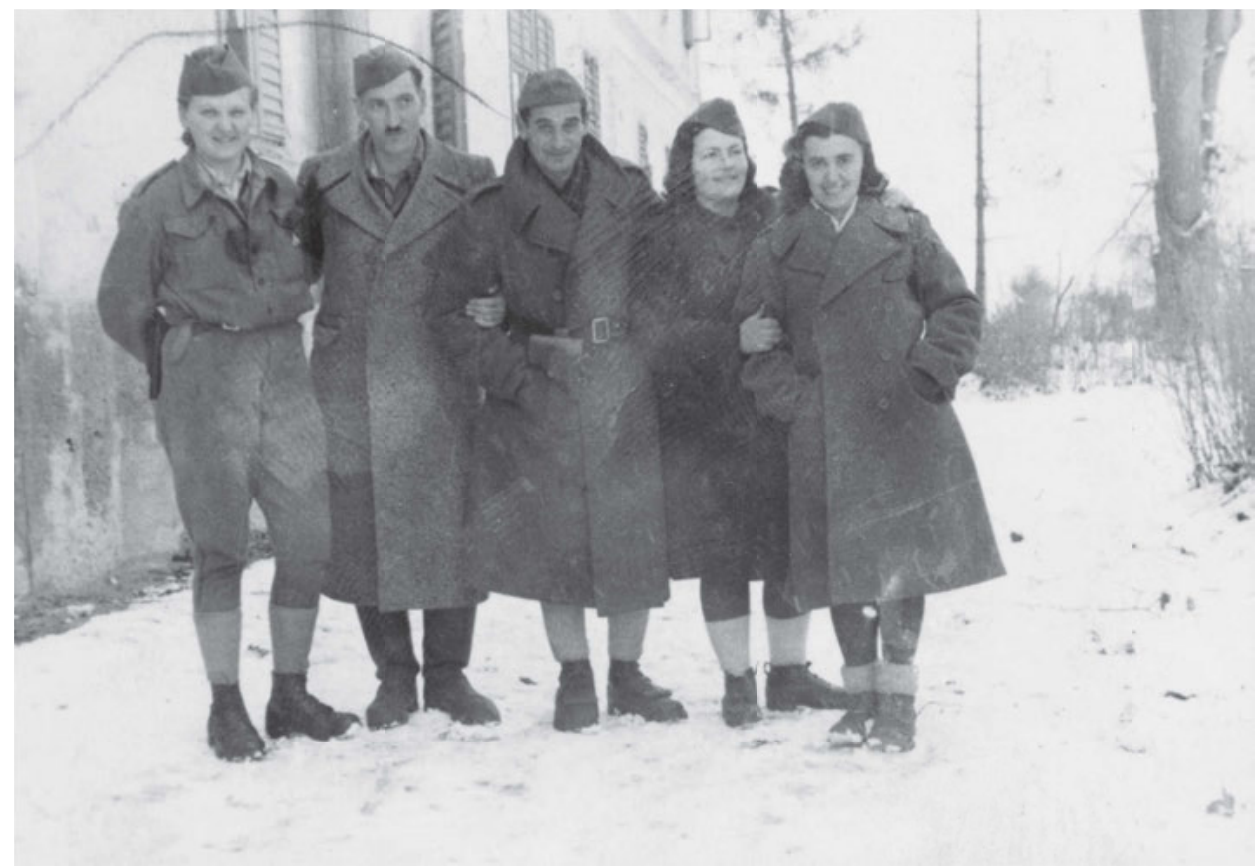

Mitglieder der Fotosektion der Propagandaabteilung des Antifaschistischen Landesrates der Volksbefreiung Kroatiens. Fotograf unbekannt. Von links nach rechts: Djurdja Koren, Karlo Nadj, Hugo Fischer Ribarić, Slavica Biluš und Elvira Kohn. Topusko, Kroatien, Herbst 1944. Zagreb, Kroatisches Historisches Museum I HPM/MRNH-A2602-f33-27a.

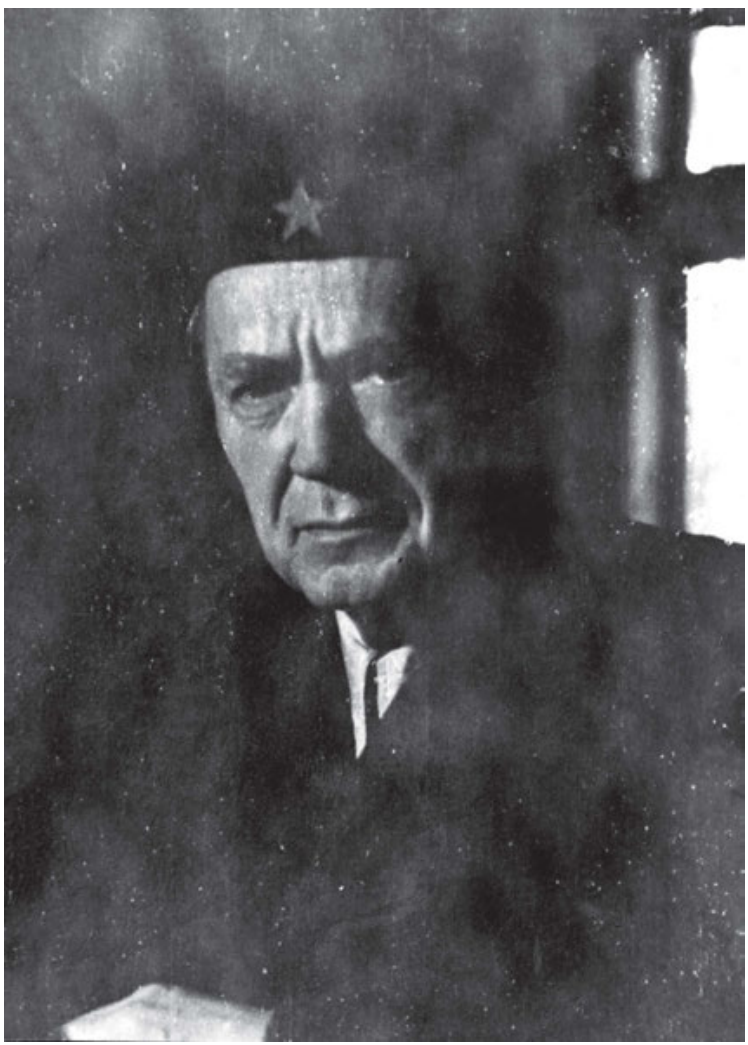

Ivan Ribar, Vorsitzender des Antifaschistischen Rates der Volksbefreiung Jugoslawiens, Otočac, Kroatien, 1943.

Foto: Fotosektion des Landesrats der Volksbefreiung Kroatiens. Zagreb, Kroatisches Historisches Museum I HPM/MRNH-A-2601-f90-30. 
es Iveković möglich, in ganz Kroatien und Bosnien-Herzegowina zu fotografieren, wobei vor allem seine Porträts des Volksdichters Vladmir Nazor, des bekannten Politikers Dr. Ivan Ribar sowie des bereits erwähnten Dichters Ivan Goran Kovačić hervorzuheben sind. Bei den Vorbereitungen für die Fotoausstellung in Topusko gab es zahlreiche Probleme, weil die Fotografien thematisch nicht geordnet waren, Titel fehlten und die Fotografien überwiegend bei den früher abgehaltenen Sitzungen des ZAVNOH und der Einheitlichen Volksbefreiungsfront (JNOF) gemacht wurden. Man konnte weder bestimmtes Fotomaterial noch den Bildvergrößerungsapparat finden, den Hugo Fischer Ribarić angeblich in einem in der Erde ausgehobenen Versteck zurückgelassen hatte. ${ }^{42}$

Eine ähnliche Versammlung fand schon zwei Jahre zuvor auf der Adriainsel Hvar statt. Die Konferenz der Kulturschaffenden Dalmatiens, an der Schriftsteller, Komponisten, Architekten und bildende Künstler teilnahmen, wurde am 19. Dezember 1942 abgehalten. Im Zuge der weiteren Entwicklung des ZAVNOH wurden bei seiner dritten Sitzung Abteilungen für Verwaltung und Justiz, Volksgesundheit, Wirtschaft, Schulwesen, Sozialpolitik und Propaganda organisiert. Auf diese Weise gestaltete man auch die Ordnung der Volksbefreiungsräte von der Bezirksebene aufwärts. ${ }^{43}$ Ebenso die Basis für die Gründung des Museums der Volksbefreiung wurde geschaffen, nachdem am 3. September 1944 alle Kreis- und Bezirksräte der Volksbefreiung den Befehl erhielten, mit der Sammlung von Objekten, einschließlich jener Fotografien, denen man besondere Bedeutung zuschrieb, zu beginnen. ${ }^{44}$ Cvito Fisković, namhafter Kunsthistoriker und damaliger Kustos des Archäologischen Museums in Split, rief in der Zeitung Slobodna Dalmacija (Freies Dalmatien) die Bürger auf, von Wasserrohren und Sanitätsmaterial bis hin zu Fotografien alles zu sammeln. ${ }^{45}$

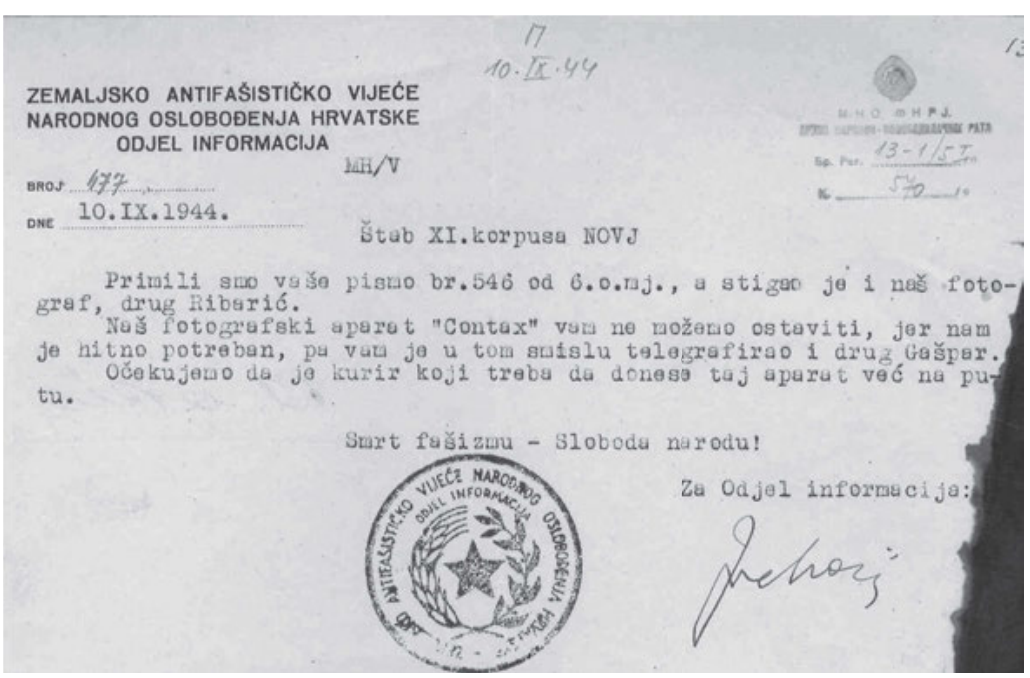

Schreiben des Landesrates der Volksbefreiung Kroatiens an das Sechste Korps der Volksbefreiungsarmee Jugoslawiens über die Schwierigkeit, der Einheit einen Fotoapparat zu überlassen. Belgrad, Militärarchiv | NOVJ-K570 F5i 13.

42 HDA (Kroatisches Staatsarchiv), ZAVNOH II/Propagandaabteilung (Informationsabteilung): 1944.: 6. Schachtel 30/206, NV32/2905, Siehe Roksandić, Drago. Prvi kongres kulturnih radnika Hrvatske (Topusko, 25.-27. lipnja 1944.): Iskustvo i aproprijacije. In: Ders. und Cvijović Javorina, Ivana (Hrsg.). Intelektualci i rat 1939. -1947. Zbornik radova s Desničinih susreta 2011. Zagreb: Plejada d. o. o. 2012, S. 115.

43 Sabor u Topuskom. Treće zasjedanje Zemaljskog antifašističkog vijeća narodnog oslobođenja Hrvatske. Zagreb 1975, S. 51.

44 Zemaljsko antifašističko vijeće narodnog oslobođenja Hrvatske, zbornik dokumenata 1944. Zagreb 1975.

45 Dedijer, Vladimir. Dnevnik III 1941-1944. Rijeka: GRO Liburnija, Zagreb: Mladost 1981, S. 204. 


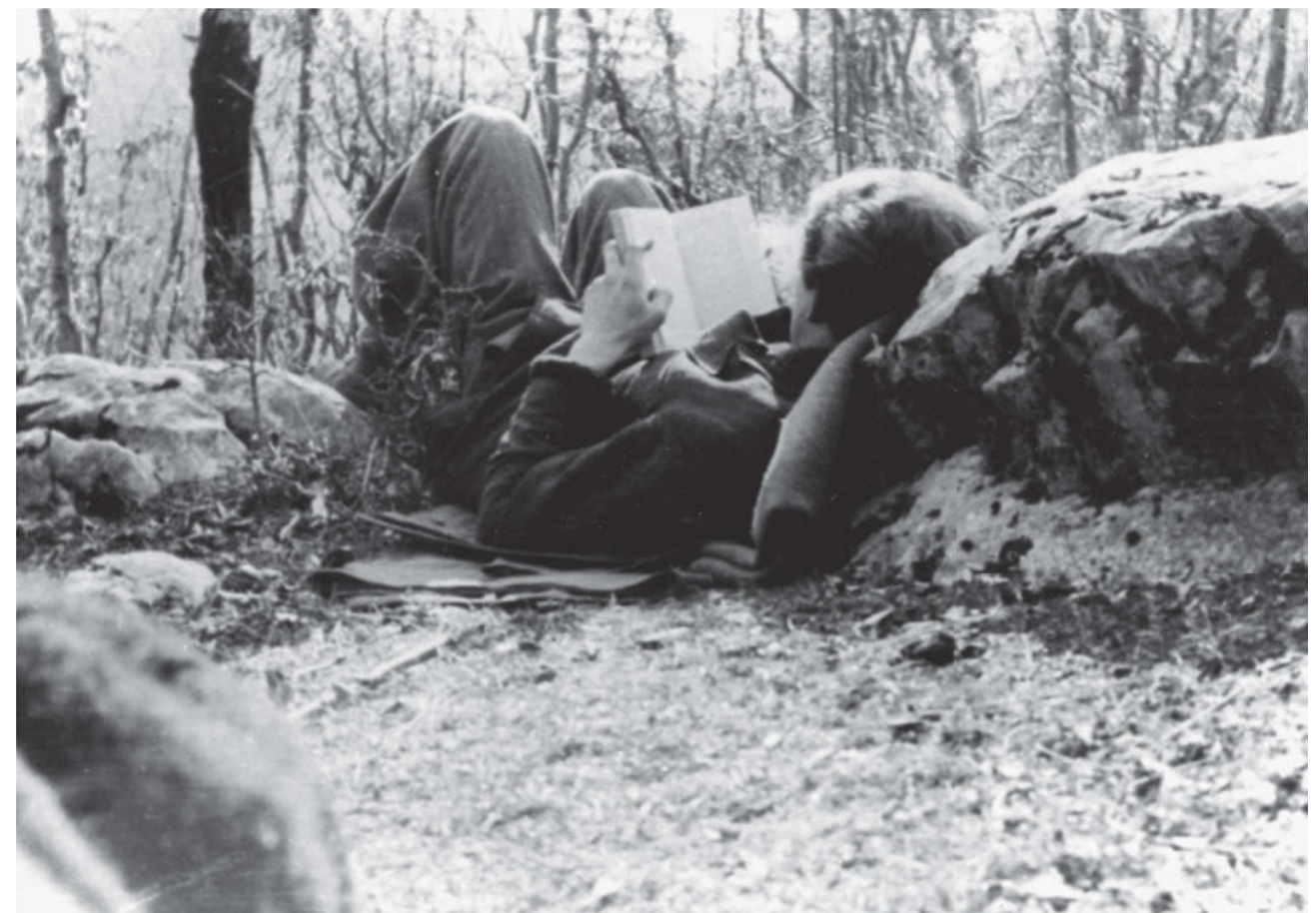

Der Dichter Ivan Goran Kovačić. Foto: Mladen Iveković. Sarajevo, Historisches Museum von Bosnien und Herzegowina | FNOB 6440.

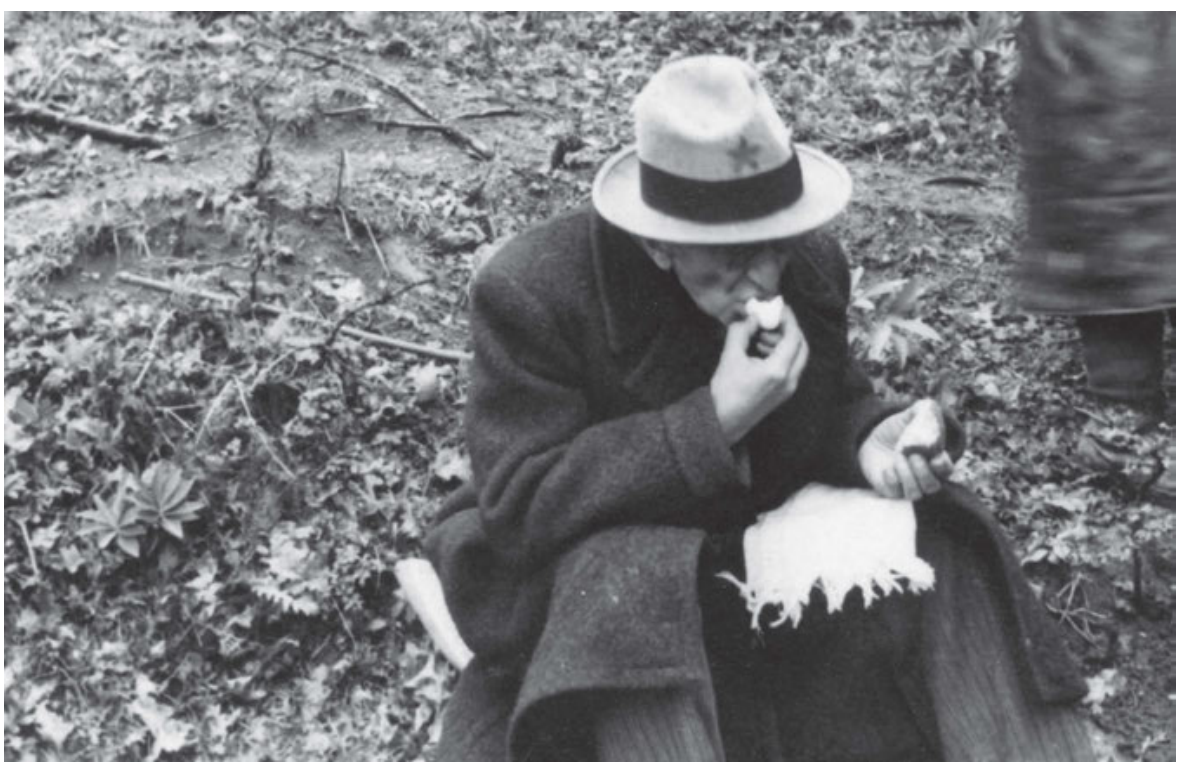

Der kroatische Volksdichter Vladimir Nazor. Foto: Mladen Iveković. Zagreb, Kroatisches Historisches Museum | HPM/MRNH-A-6337/135. 


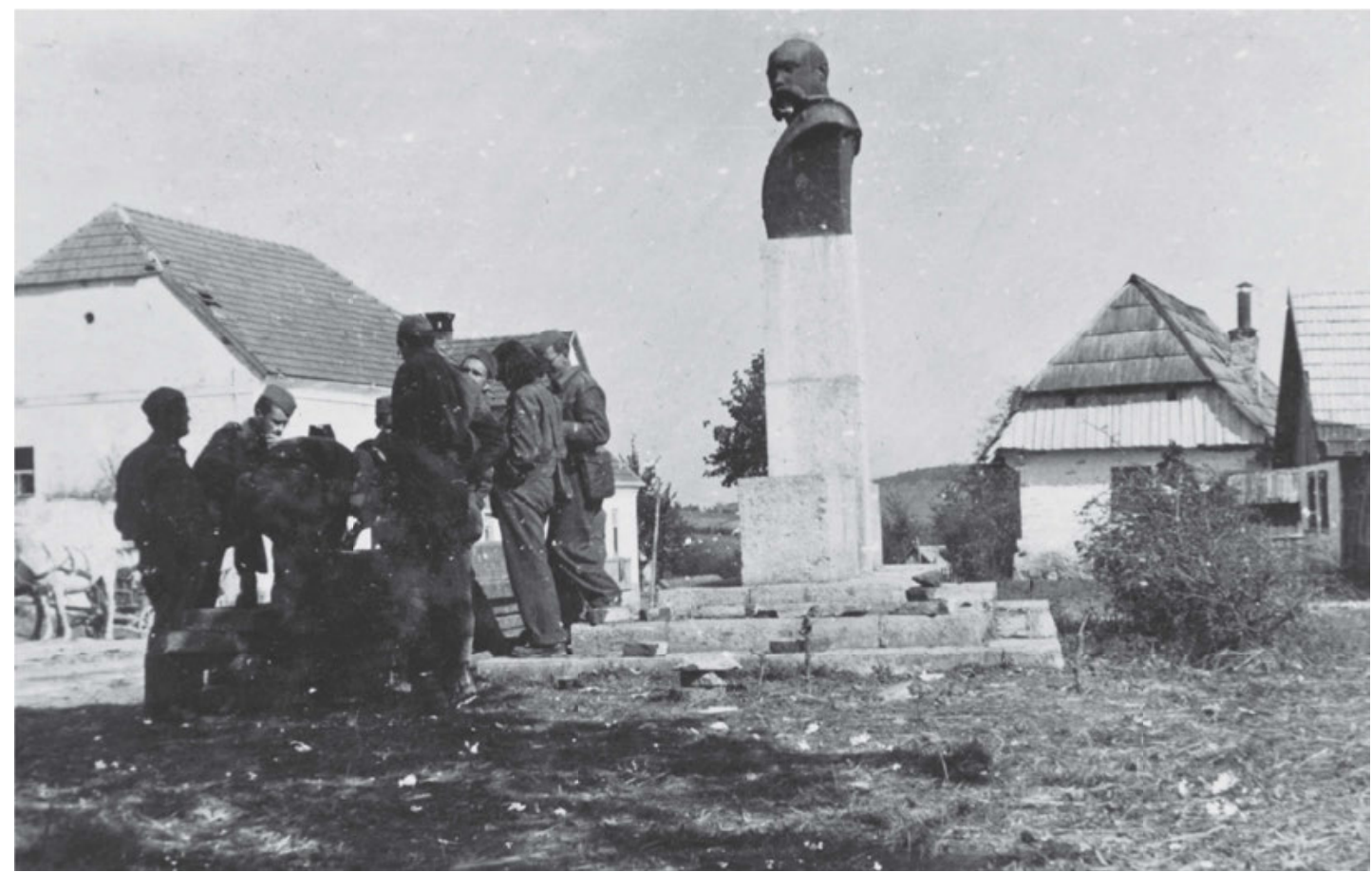

Eine Gruppe von Partisanen am Denkmal des österreichisch-ungarischen und jugoslawisch-königlichen Militärbefehlshaber Eugen Kvaternik, Rakovica, Sommer 1944. Foto: Fotosektion des Landesrates der Volksbefreiung Kroatiens. Zagreb, Kroatisches Historisches Museum | HPM/MRNH-A-2601-f129-7.

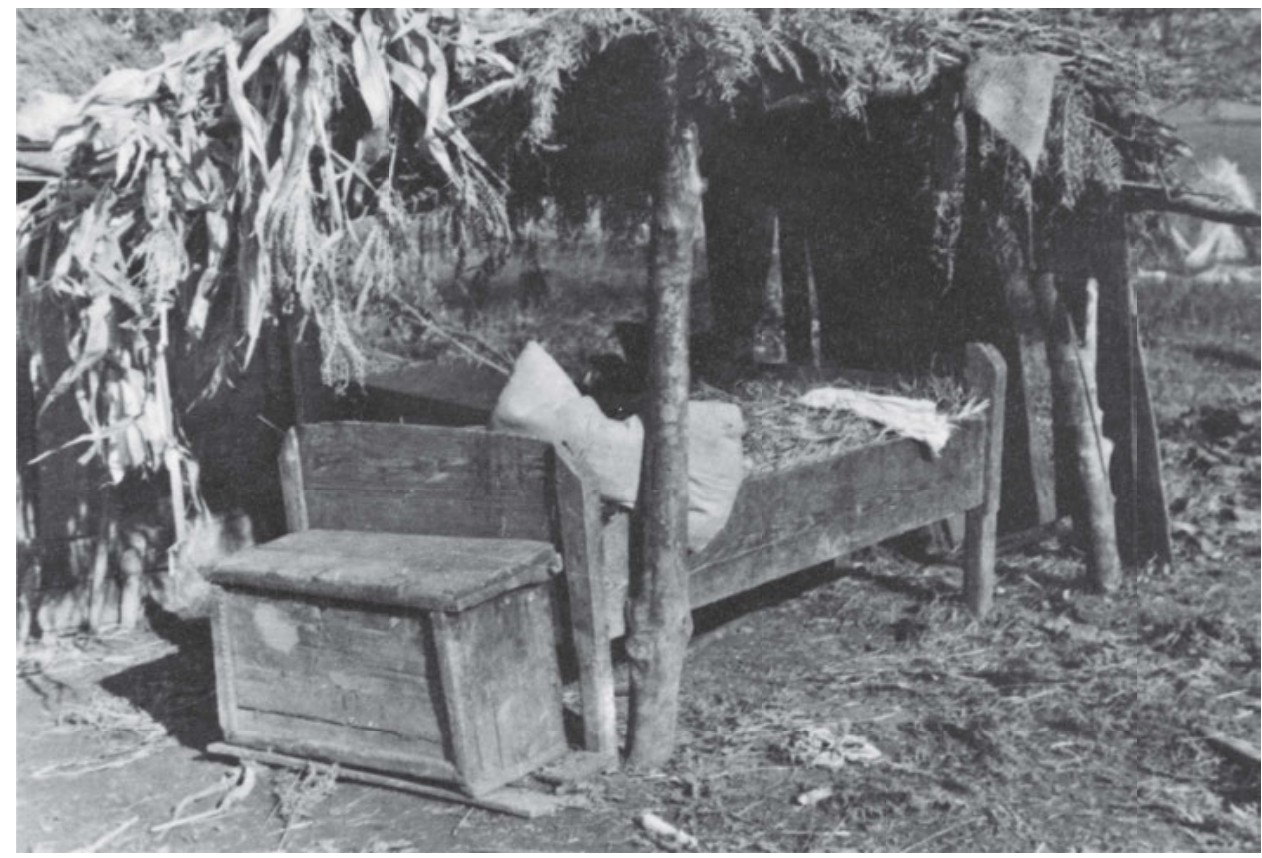

Improvisiertes Haus in Kordun, Kroatien, 1944. Foto: Fotosektion des Landesrates der Volksbefreiung Kroatiens. Zagreb, Kroatisches Historisches Museum I HPM/MRNH-2602 f88-34a. 


\section{IZLOŽBA UMJETNIKA PARTIZANA}

\section{A N K E T A}

U ciljursto aže suradnje Izmedju umjetnika i šrokih narodnih slojeva, molimo vas, da octgovorite na slijedeca pitanja:

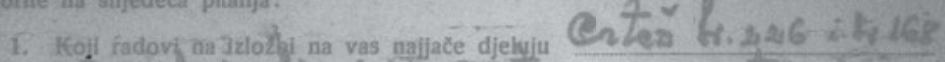

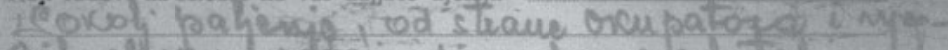

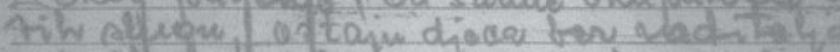

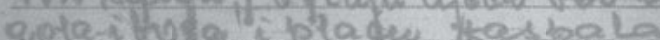
Geta ma nom

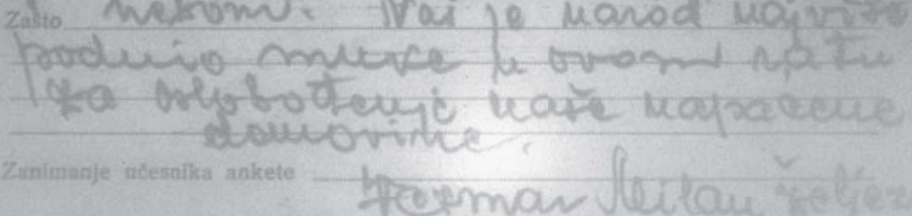

Umfrage, welche Werke einer Ausstellung den Besuchern aus welchem Grund am besten gefallen haben.

Kroatisches Staatsarchiv. Ohne Inv.-Nr.

\section{ZEMALJSKO ANTIFAŠISTIČKO VIJECE}

364

\section{Glovnom Štabu Hrvateke}

\section{) Ze druge Juru - . . . Vorszin.}

Woli se drugerski neslov, de pošalje radiogrem:

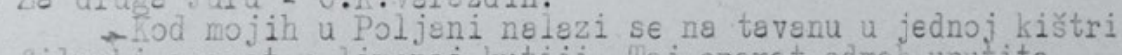

filmski eperet u limenoj kutiji. Tejeperet odmel uputite

po kuriru ze Propegendni odje1 Zỉivol-a.

Pustek Wertin

Smrt fasizmu - Sloboda naroduI

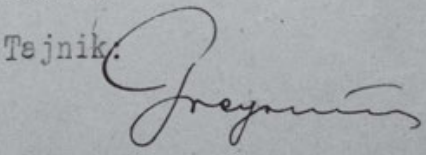

Ein Schreiben an den Generalstab Kroatiens, das auf die Entdeckung eines Fotoapparates auf einem Dachboden hinweist und den Auftrag enthält, diesen direkt an die Propagandaabteilung des Antifaschistischen Rates der Volksbefreiung Kroatiens zu schicken. Kroatisches Staatsarchiv. Ohne Inv.-Nr. 


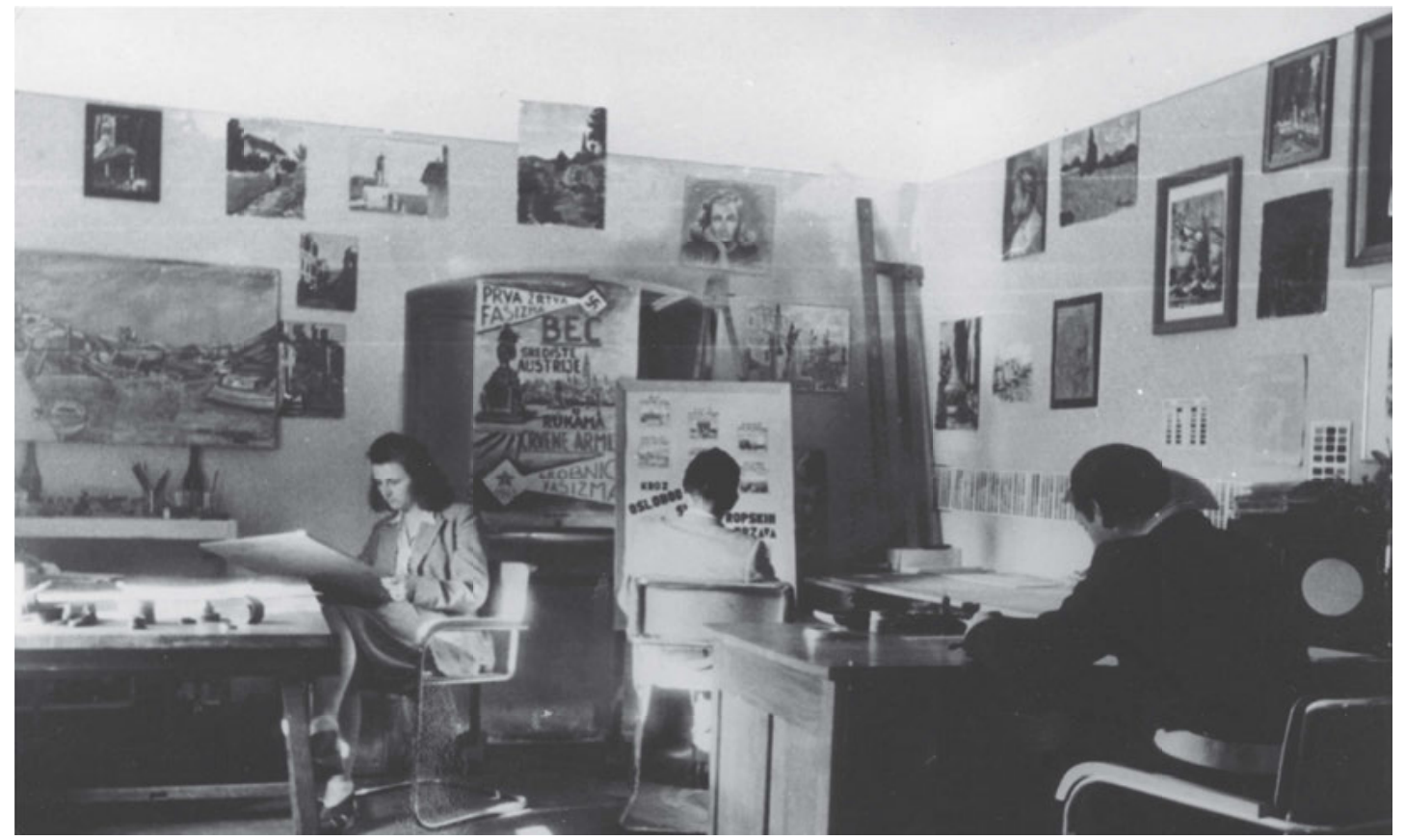

Informationsbüro in Dubrovnik, 1945. Foto: Nikola Rubčić. Zagreb, Kroatisches Historisches Museum | HPM/ MRNH-F-8259.

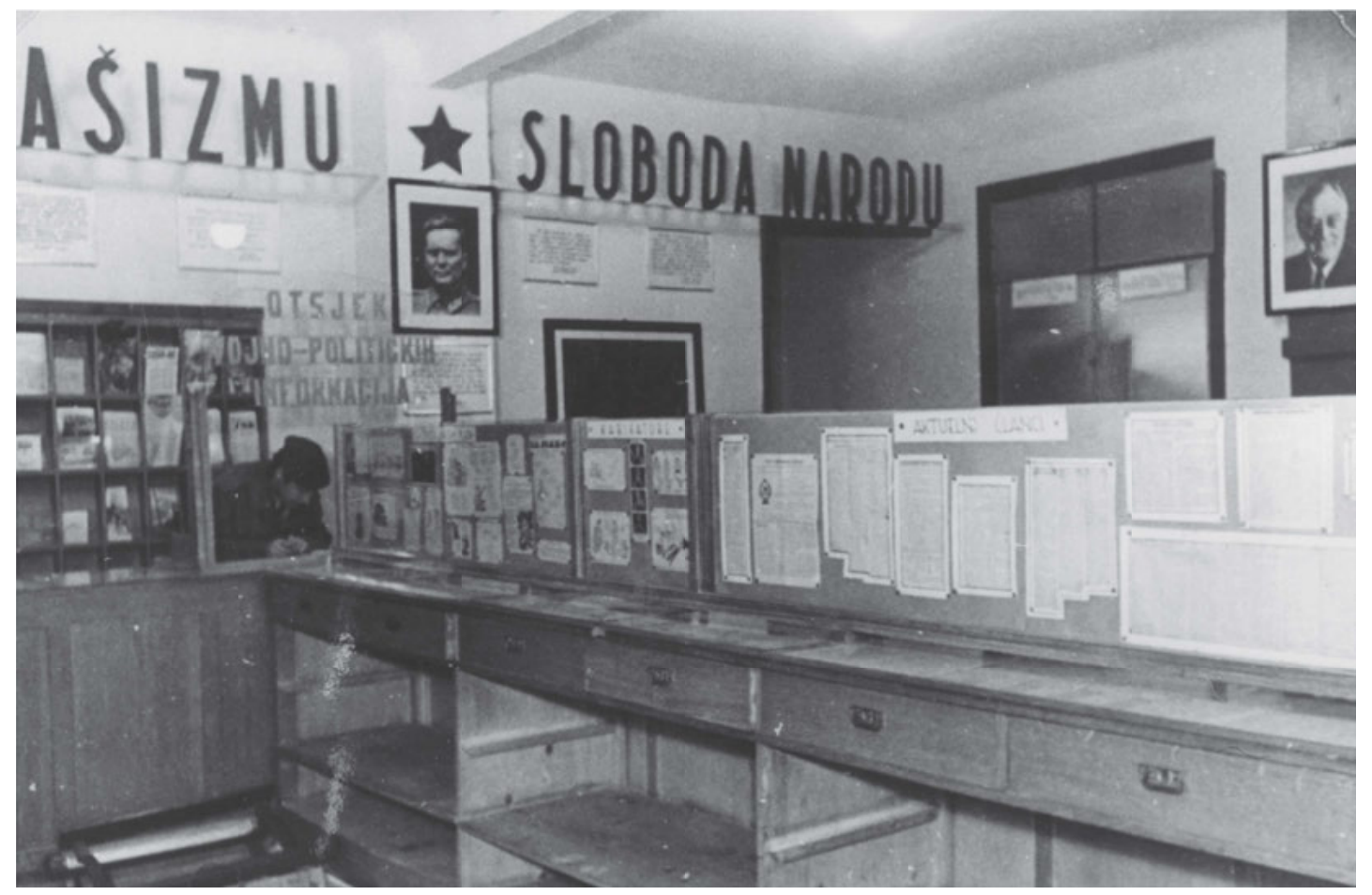

Informationsbüro in Dubrovnik, 1945. Foto: Nikola Rubčić. Zagreb, Kroatisches Historisches Museum | HPM/MRNH-F-8247. 


\section{Fotografisches Tagebuch von Franjo Mosinger}

Nach dem Krieg blieb eine Vielzahl der Fotografien in Fotoalben erhalten, wie zum Beispiel im Album von Nikola Rubičić mit dem Titel Rad odjela informacija u Dubrovniku (Tätigkeit der Informationsabteilung in Dubrovnik), ${ }^{46}$ während der Zagreber Fotograf und Partisan Franjo Mosinger ein persönliches Fototagebuch anlegte, in dem er Fotografien und Texte kombinierte. Hierbei handelt es sich um ein einzigartiges und erschütterndes Zeugnis, das uns seinen Weg und sein Werk als Partisanenfotograf verfolgen lässt:

»In den ersten Frühlingstagen des schicksalhaften Jahres 1943 brachte mich der Genosse Jovica Trzun zu den Partisanen. [...] Aus dem Dorf Borčec in der Nähe von Stenjevac begaben wir uns über Sesveta zum Fuß des Bergs Zagrebačka gora. Richtiges Lager - ich lernte den Wald kennen, seine schönen und schrecklichen Seiten. [...] Das Haus in Turopolje, in dem wir auf unserem weiteren Weg Unterschlupf gefunden haben. Der Bauer, unser treu ergebener Freund, begab sich dadurch in Lebensgefahr. [...] Versteckt auf dem Dachboden, warten wir auf unseren Verbindungsmann. Hinter uns molk die Bäuerin die Kuh. Ständig in Angst, verraten zu werden. [...] Wie es der Zufall so will, kam drei Stunden nach unserer Ankunft eine Einheit der Ustascha in das Dorf. Deren Kommando befand sich im benachbarten Haus. Wir saßen in der Falle. Acht Tage lang lagen wir unter Heuhaufen begraben. Wir warteten, dass die Ustascha den Stall betreten, der unter uns lag. Und am dritten Tag kamen sie dann auch, um die Kuh zu beschlagnahmen. Sie bemerkten uns nicht. Die Bäuerin traute sich von da an kaum, den Stall zu betreten. Sie stand Todesängste aus. Wir konnten nicht ewig bleiben. Der achte Tag... [...] Als Bauern verkleidet, begaben wir uns in den Wald des Bauern. So kamen wir problemlos am Wachposten der Ustascha vorbei. Von der kleinen Öffnung auf dem Heuboden aus fotografierte ich kurz vor dem Aufbruch diese Szene. Die Tochter des Hausherrn war sich der Gefahr nicht bewusst, der die gesamte Familie ausgesetzt war, und spielte sorglos. [...] Nachts marschierten wir weiter. Unsere Führer waren junge Knaben. Alle fünf Kilometer wechselten sie sich ab. In der Abenddämmerung brachten sie uns zu der Truppe im Wald. Kaum zehn Kilometer von Zagreb entfernt, also im Herzen des Unabhängigen Staates Kroatien, begegneten wir einem Dutzend Partisanen (Diversanten). Ihr Kommandant begrüßte uns freudig. ।In zwei bis drei Stunden wird es hier hoch hergehen<, sagte er uns. 'Wir werden zu tun haben, ihr werdet es schon sehen! Wir nahmen auf dem Waldboden Platz. Um uns herum lagen Papierpakete, Schreibmaschinen, Bleistifte. Am Tag zuvor wurde all das im nahe gelegenen Gemeindehaus sichergestellt. Um zehn Uhr brachen wir auf und gelangten nach zwei Kilometern zu Eisenbahnschienen unweit von Odra. Der Kommandant befestigte Drähte an den Schienen. Der Zug kam, und dann sprangen unter lautem Getöse die Lok, der Beiwagen und zwei Waggons seitlich aus den Schienen. Aus den Waggons schauten angstverzerrte Gesichter hervor. [...] Ein Monat ist vergangen. Otočac ist zur Hauptstadt des befreiten Territoriums geworden. Es wurde eine Gruppe von Kriegsmalern unter meiner Leitung gegründet. « ${ }^{47}$

\footnotetext{
46 Hlevnjak, Branka und Ivanuš, Rhea. Hrvatska antiratna fotografija: Prvi svjetski, Drugi svjetski i Domovinski rat. Zagreb: Udruga za promicanje oblikovanja i umjetnosti, Design Art d. o. o., Centar za kulturu i obrazovanje 2008, S. 114.

47 Text aus dem Fototagebuch von Franjo Mosinger, das im Kroatischen Historischen Museum verwahrt wird.
} 


\section{Partisanenfotografinnen}

In Kroatien wirkte auch Elvira Kohn, eine der wenigen Partisanenfotografinnen. Ihre Karriere als Fotografin begann 1932 im von Miho Ercegović geführten Fotoatelier Jadran in Dubrovnik, wo sie kommerzielle Fotografien aufnahm. Ihre künstlerische Arbeit stand indes unter dem Einfluss der Neuen Sachlichkeit. Nach der Gründung des Unabhängigen Staates Kroatien wurde sie unter dem Druck des Geschäftspartners von Ercegović aufgrund ihrer jüdischen Abstammung entlassen, doch sie war auch weiterhin heimlich für ihn tätig. ${ }^{48}$
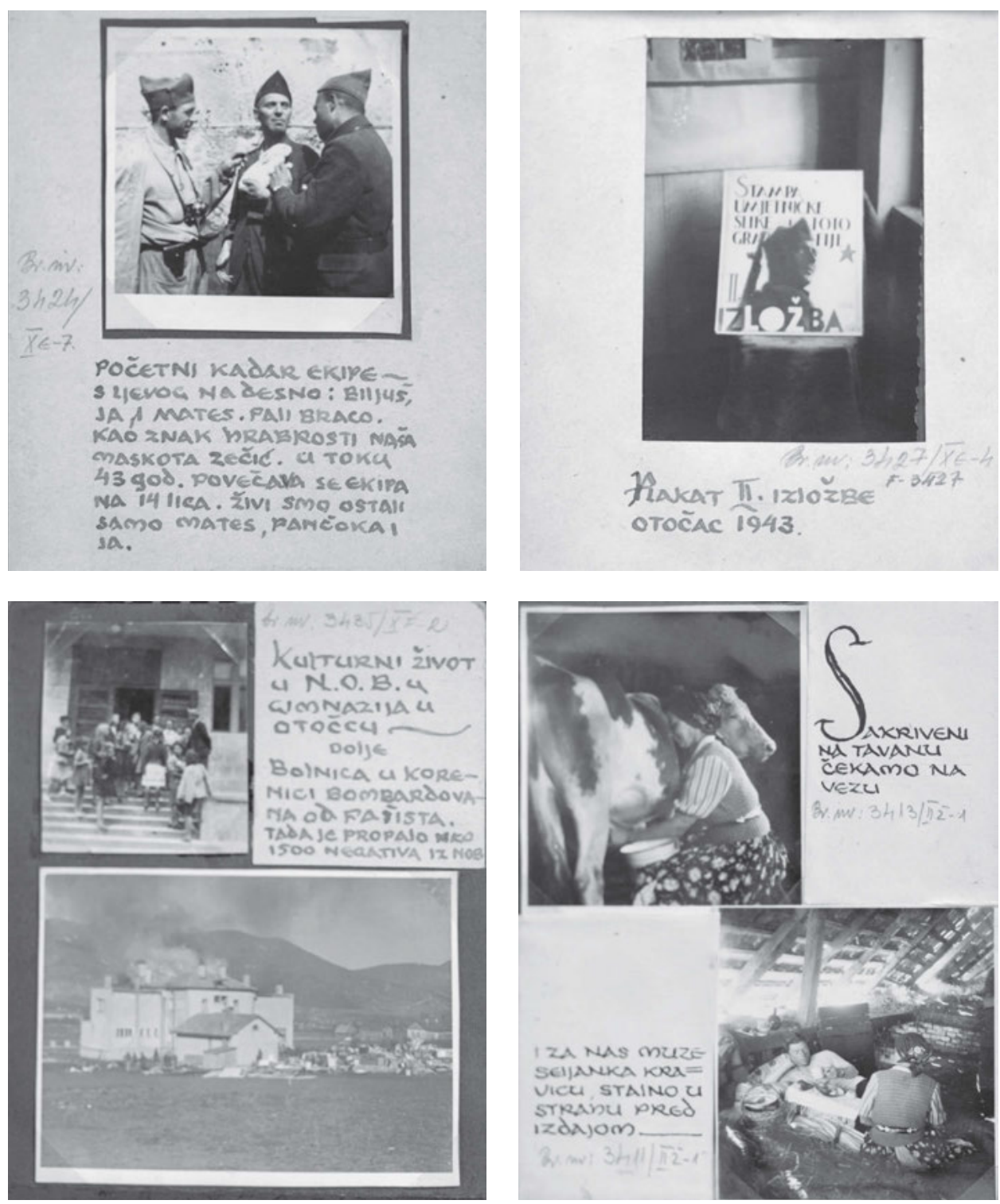

Seiten aus dem Tagebuch von Franjo Mosinger. Zagreb, Kroatisches Historisches Museum. Ohne Inv.-Nr.

48 Šiljak, Lea. Elvira Kohn. In: Centro, Mai 2003. Siehe http://www.centropa.org/biography/elvira-kohn\#During\%20the\% 20War. [Abruf am 30.01.2021]. 
Unmittelbar vor ihrem Tod im Jahr 2003 gab Elvira Kohn ihr letztes Interview für das Jüdische Museum Wien, in dem sie Folgendes sagte:

„Neben der Verpflichtung zum Tragen des Abzeichens war es uns verboten, in staatlichen und öffentlichen Einrichtungen zu arbeiten, und auch unsere Bewegungsfreiheit war eingeschränkt. Es war gestattet, zum Strand oder auf den Markt nur bis zu einer bestimmten Uhrzeit am Tag zu gehen; für uns galt die Polizeistunde. In Dubrovnik lag die Staatsgewalt in den Händen der Kroaten, das heißt der Ustascha, während die Militärgewalt in den Händen der Italiener lag. Unser Glück war, dass die Italiener die Macht innehatten. Die Deutschen haben versucht, uns in Zusammenarbeit mit den Ustascha in ihre Konzentrationslager abzutransportieren, doch die Italiener gaben ihnen unmissverständlich zu verstehen, dass sie in Dubrovnik das Sagen hatten und dass es italienisches Recht sei, mit uns zu tun, was sie wollten. [...] Sie brachten uns auf ein großes italienisches Passagierschiff und viele Einwohner aus Dubrovnik kamen, um uns zu sehen. Unter innen war auch mein Chef Miho Ercegović. Als ich ihn sah, ging ich auf ihn zu und gab ihm die Kamera zurück. Doch er sagte nur: ’Nein, behalte sie, und alles was geschieht, wird auf Film festgehalten werden. ¿ Zuerst brachte man uns ins Hotel Vrek in Gruž, einige Kilometer von Dubrovnik entfernt. Dort blieben wir zwei Monate, wonach man uns Anfang Januar 1943 nach Kupare brachte. Wir waren etwa 1.200 Juden. « ${ }^{49}$

Im Mai desselben Jahres wurden sie, wie viele andere Juden auch, in das Lager auf der Insel Rab gebracht, das nach der Kapitulation Italiens aufgelöst wurde. Nach der Befreiung aus dem Lager schloss sich Elvira Kohn mit ihrer Leica, die es ihr während des Lageraufenthalts zu behalten gelang, den Partisanen an. Und obwohl die Partisanen überrascht waren, eine professionelle Fotografin vor sich zu sehen, boten sie ihr sofort an, der Fotoabteilung des ZAVNOH mit der Aufgabe beizutreten, alle Ereignisse auf Filmen festzuhalten. Kohn berichtet:

»lch war die einzige Fotografin im ZAVNOH. Es gab noch zwei weitere männliche Fotoreporter, die man gelegentlich auch mit anderen Ämtern und Tätigkeiten betraute, sodass ich manchmal als Einzige im ZAVNOH fotografierte. Nachdem das Hauptkommando eine eigene Abteilung für Öffentlichkeitsarbeit gegründet hatte, begann ich für sie zu arbeiten und blieb dort bis Kriegsende. [...] Nach Zagreb kamen wir am 9. Mai 1945 so gegen 17 Uhr. Wir überquerten die SaveBrücke und gelangten auf den Hauptplatz. Der Empfang war einfach unbeschreiblich. Die Menschen säumten die Straßen in ganz Zagreb, warteten darauf, dass wir vorbeikommen, sie klatschten, schwenkten Fahnen. Die Atmosphäre war feierlich, emotionsgeladen und die Menschen waren begeistert und aufgeregt. Alle wussten, dass der Krieg nun vorbei war, dass die Ustascha und die Deutschen die Stadt verlassen hatten und das Zagreb befreit war. Nach der Feier auf dem zentralen Platz der Stadt gingen wir, eine Gruppe von Partisanen, die zusammen im Krieg war, in die Zvonimir-Straße, wo sich einst der Sitz von Ante Pavelić befand. Wir beschlossen, als Zeichen des Sieges über die Ustascha im Hauptquartier von Pavelić zu übernachten. Man warnte uns davor, irgendetwas anzufassen, da die Gefahr bestand, dass die Ustascha dort Sprengkörper und Munition zurückgelassen hatten. Im Hof des Gebäudes war immer noch Brandgeruch zu 
vernehmen; höchstwahrscheinlich hatten die Ustascha Dokumente und Papiere verbrannt, nur einen Tag bevor man sie vertrieben hatte. Meine erste Nacht in Zagreb schlief ich auf dem Tisch im Hauptquartier von Pavelić, im Soldatenmantel und mit einer Pistole im Anschlag unter mir. « ${ }^{50}$

In der Partisanenbewegung in Serbien wirkte ebenfalls eine Fotografin - Slavka Abramović. Das fotografische Handwerk erlernte sie unmittelbar vor dem Zweiten Weltkrieg. Vor Ausbruch des Krieges internierten ungarische Faschisten sie mit ihrer Familie in ihrer Heimat Senta in ein Lager, in dem sie die drei darauffolgenden Monate zubrachte. Nach der Entlassung aus dem Lager ging sie zunächst nach Belgrad, später nach Valjevo. Mit ihrer Schwester Zora trat sie 1944 dem Ersten Montenegrinischen Bataillon der Ersten Proletarischen Brigade bei. Von dort aus wurde sie in die Kultur- und Propagandaabteilung der Brigade abkommandiert, in der sie bis Ende September 1945 als Fotografin tätig war. ${ }^{51}$

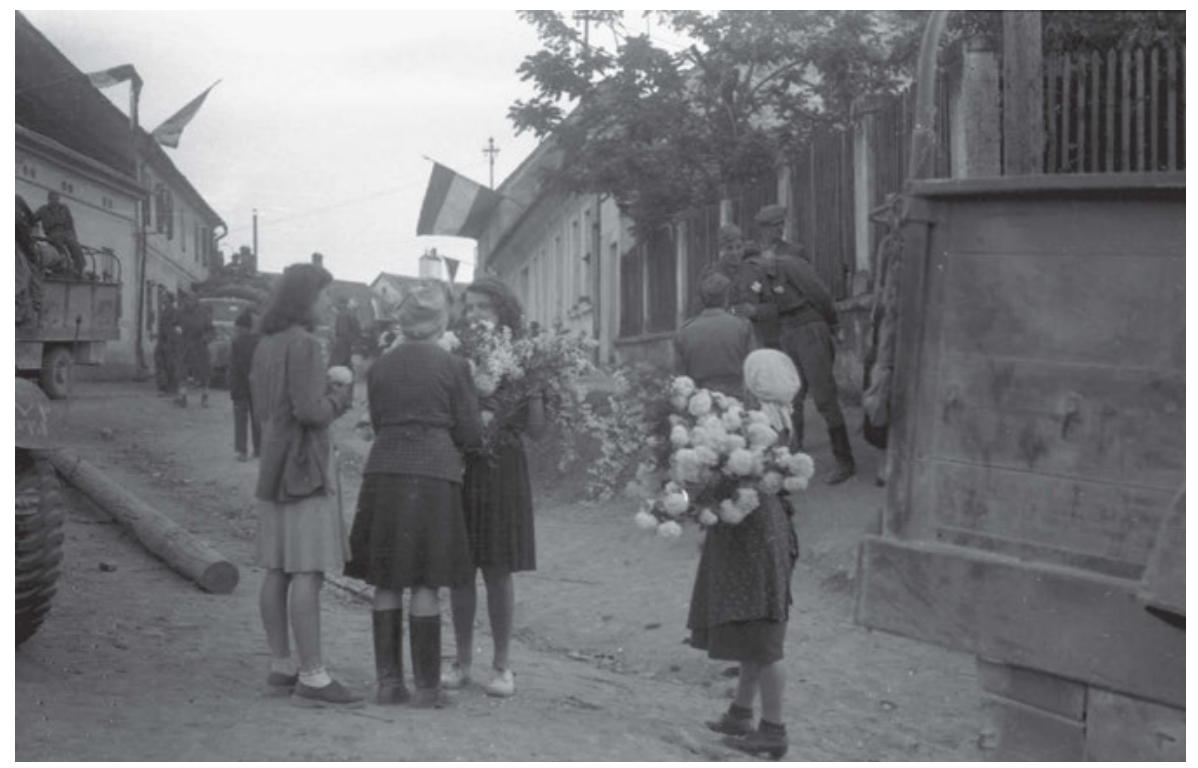

Karlovac, Kroatien, nach der Befreiung im Mai 1945. Foto: Elvira Kohn. Zagreb, Kroatisches Historisches Museum I HPM/MRNH-11474/18a.

\section{Gattin und Bernstein: Dalmatinischer Fotograf und amerikanischer Journalist}

In Dalmatien wirkte die Agitprop des Regionalen Volksbefreiungsrates für Dalmatien, deren Fotosektion Živko Gattin zusammen mit den einstigen Kriegsreportern Slavko Zalar, Jure Ruljančić und Andjelko Batinić gegründet hatte und auch leitete. ${ }^{52}$ Er war der einzige Partisanenfotograf, dem es in Kroatien gelungen war, Farbfotografien zu machen. Nach der Befreiung der Stadt Split organisierte seine Fotosektion am 5. November 1944 im dortigen Kino

\footnotetext{
50 Ebd.

51 Čukić, Milorad und Lagator, Špiro. Partizanke prve proleterske. Belgrad: NIP 1978, S. 161.

52 Mataušić, Nataša. Koncentracioni logor Jasenovac. Zagreb: Spomen područje Jasenovac 2008, S. 46.
} 
Eden eine Fotoausstellung, bei der die Entwicklung des Volksbefreiungskampfes, die Verbrechen der Faschisten, die Befreiung von Split und das Leben in der befreiten Stadt gezeigt wurden. ${ }^{53}$ Die Ausstellung eröffnete Cvito Fisković, der damalige Leiter der Bildungsabteilung des Regionalen Volksbefreiungsrates, mit folgenden Worten:

»hr werdet hier die Verbrechen der Besatzer sehen, Erschießungen unserer Kinder, unsere brennenden Dörfer, unsere gequälten, aber unerschütterlichen Krieger. Mit diesen Fotografien werdet ihr nochmals die schweren und großen Tage des Kampfes um Freiheit erleben. Diese Fotografien zeigen, wie unser Volk gequält wurde, wie hart es kämpfen musste [...]. Und es verwundert nicht, dass gerade hier, in dem alten Gabinetto di lettura bzw. in Wirklichkeit dem Gabinetto di delitto die Wahrheit ans Tageslicht kommt. Unter diesem Dach sind die Autonome und Ausgeburten zu Faschisten geworden, hier haben sie unsere Galgen errichtet, hier taten sie vor Europa so, als würden sie Barbaren kultivieren. ${ }^{54}$

In Gattins Aufzeichnungen, die von seiner Familie zur Verfügung gestellt wurden, ist verzeichnet, dass für seine Liebe zur Fotografie sein Vater Ivan, Überseekapitän und Vertreter des amerikanischen Unternehmens Standard Oil, verantwortlich war, der auch die Fotosektion im kroatischen Bergsteigerverein Mosor leitete. Als junger Mann sog Gattin die damals erscheinende Foto reviju (Fotorevue) förmlich in sich auf. Seine Vorbilder waren Tošo Dabac, Milan Pavić, Franjo Fuis, Žorž Skrigin und Mladen Grčević, durch die er Techniken und Rezepturen für Filmvergrößerungen lernte. In seinen Notizen ist Folgendes festgehalten:

»Bis heute erinnere ich mich an das in dieser Zeitschrift abgedruckte Rezept für die feinkörnige und weiche Filmentwicklung, mit dem man brillante Negative für starke Vergrößerungen erzielte: Metol $6 \mathrm{~g}$, Natriumsulfat $150 \mathrm{~g}$, Borax $6 \mathrm{~g}$, destilliertes Wasser $1 \mathrm{l}$; bei exakt $20^{\circ} \mathrm{C}$ dauerte die Entwicklung sechs Minuten. Immer wenn ich in meinem Leben Schwarz-Weiß-Filme entwickelt habe, verwendete ich jedes Mal diese hervorragende Entwicklungslösung. [...] Als ich mich Ende des Sommers 1942 den Partisanen anschloss, habe ich meine Plaubel Makinette und einen Bestand an Agfa-Isopan-ISS-Filmen mitgenommen. Zu Beginn habe ich das Partisanenlager in Moseć, unsere Gastgeber in Milešina am Fuße des Svijala-Gebirges, die Familien Tokić und Miletić sowie die sich gerade formierende Dritte Dalmatinische Brigade fotografiert. « ${ }^{55}$

Das Fotolabor seines Vaters, das sich auf dem Dachboden ihres Familienhauses befand, sollte zum ersten Fotolabor der Partisanen in Klis Kosa, in der Nähe von Solin werden. Gattin schloss sich direkt nach der italienischen Okkupation dem Verband der Kommunistischen Jugend Jugoslawiens (SKOJ) an, doch er entschied zugleich, erst nach dem Abitur den Partisanen zu folgen:

»Bis dahin haben wir Parolen in ganz Split geschrieben, politische Literatur verteilt, die Widerstandbewegung in den Wäldern unterstützt. An jenem Tag kam mich beim Mahl ein Mann abho-

53 Arhiv VII, arhiv NOB-a (Archiv des Volksbefreiungskampfes), CS K16, Reg.-Nr. 34/1.

54 Antifašistički Split, ratna kronika 1941.-1945: Listopad 1944. - svibanj 1945. Od oslobođenja grada do kraja rata. Odricanja i muke okrunjeni pobjedom. Siehe http://www.ratnakronikasplita.com/kronika/1944-2. [Abruf am 30.01.2021].

55 Aufzeichnungen von Živko Gattin, die freundlicherweise von Ingrid Gattin Pogutz zur Verfügung gestellt wurden. 
len, der vor dem Haus in der Kukuljićeva-Straße, der heutigen Triester Straße, pfiff. Ich ließ die halbe Mahlzeit stehen, sagte zu Hause niemandem etwas und folgte ihm in einer Entfernung von etwa fünfzig Metern. Als wir nach Sitnica kamen, ruderte ein Mann aus Vranjica zu uns, steckte mir eine Angelschnur mit Haken in die Hand, so als würden wir Fische fangen, und wir ruderten zur Insel Barbarinac. Dort nahm mich ein dritter Mann in Empfang, wir gingen durch einen Weingarten und stiegen entlang der alten Straße nach Klis den Berg hinauf. In einem Pinienhain warteten zwei Milchfrauen aus Solin auf mich und führten mich nach Blace unterhalb des KozjakGebirges. [...] Als wir nach Muć kamen, schloss ich mich der Moseć-Einheit an, deren Kommandant der aus Solin stammende Duje Bašić war. Doch just zu jener Zeit suchte Mirko Marasović, ebenfalls Mitglied des Provinzkomitees, jemanden, den er für die Arbeit mit einer Vervielfältigungsmaschine ausbilden wollte, um Flugblätter zu drucken. Damals begannen wir die Zeitung Naš glasnik [Unser Bote] zu drucken, die der aus Sarajevo kommende jüdische Journalist Eli Finci als Redakteur leitete. Man fragte mich, doch ich wollte unbedingt ein Gewehr haben. Marasović sagte mir aber: `Wenn du Flugblätter und Zeitungen druckst, bist du genauso viel wert wie vier Gewehre! ‘ Ich hatte ja meine Plaubel Makinette mitgenommen und begann sofort zu fotografieren, obwohl es damals noch nicht möglich war, auch Fotografien zu drucken. Recht bald gesellte sich die Agitprop-Abteilung des Provinzkomitees von Dalmatien zu uns, die die Deutschen aus Livno vertrieben hatten. Dies war in Mosar, auf dem Feld unterhalb der Siedlung Sitno Gornje. Damals wurde der Beschluss gefasst, eine Zeitung ins Leben zu rufen, die wir Slobodna Dalmacija [Freies Dalmatien] nannten, da sie auf freiem Territorium gegründet wurde. $\aleph^{56}$

Diese Art von Belegen ist außerordentlich wichtig angesichts der Tatsache, dass ein Großteil der Fotografen und Zeugen verstorben ist und über die Fotografie nur wenige Aufzeichnungen existieren. Im Interview für Slobodna Dalmacija erzählte Živko Gattin, wie er seine Kollegen, die Fotografen Jure Ruljančić und Slavko Zalar, um sich versammelte:

»Ich verlangte vom Stabskommandanten Maks Baće, ihn [Slavko Zalar - Anmerkung D. K.] zu uns abzukommandieren, doch er wollte nicht. Wir stritten, ja schlugen uns fast, doch am Ende bekam ich ihn. Er war die Nummer zwei. Der nächste war Jure Ruljančić, der das bekannte Fotoatelier in der Marulić-Straße betrieb. Er schloss sich uns in Split an, als Italien kapitulierte. Bei Slobodna Dalmacija war er als Schriftsetzer beschäftigt. Auch inn habe ich nur mit Mühe und Not bekommen. Bis zum Ende des Krieges waren wir zu sechst. Einer von innen war Hrvoje Vidović, Student der Elektrotechnischen Fakultät in Zagreb. Während die Fotoreporter mit den militärischen Verbänden zogen, musste jemand auf das Fotoarchiv aufpassen. Es war ja nicht wie heute, der Feind konnte mit Hilfe von Fallschirmjägern und Schiffen jederzeit einen Angriff starten und alles würde verloren gehen, wie dies mit dem Fotoarchiv des Hauptstabs in Drvar beim Angriff der deutschen Wehrmacht geschah. [...] Die erste Ausgabe der Zeitung Slobodna Dalmacija mit unseren Fotografien erschien, als wir uns auf der Insel Vis befanden, wobei die Zeitung mit Hilfe der Vervielfältigungsmaschine gedruckt wurde, die Jure Kaštelan und ich aus der Wüste Blace auf die Insel Brač brachten. Die Zinkografie, das heißt die Anfertigung von Zink-Klischees mittels Übertragung des Bildes auf Zink- oder Kupferplatten, erfolgte im befreiten Bari. Dort wurden Plat-

56 Šarac, Damir. Dr. Živko Gattin: Za čitanje »Slobodne« se strijeljalo!. In: Slobodna Dalmacija, Juni 2013. Siehe https://www.slobodnadalmacija.hr/scena/kultura/clanak/id/204129/dr-zivko-gatin-za-citanje-slobodne-se-strijeljalo [Abruf am 30.01.2021]. 
ten mit Fotografien erstellt und wieder zurückgeschickt. [...] Die Verbreitung und das Lesen der antifaschistischen Propaganda wurde bei den Italienern mit einer Haftstrafe und bei den Deutschen mit der Erschießung bestraft. Und dennoch haben die Menschen sie gelesen und allerorts verbreitet. ${ }^{57}$

Sie fotografierten auf dem befreiten Territorium in Livno und Split sowie auf den Inseln Čiovo, Hvar und Vis, wo sie Ausstellungen organisierten und Wandzeitungen gestalteten. Im Februar 1944 realisierten die Mitglieder der Fotosektion auf der Insel Vis ihre erste Ausstellung unter dem Titel Narod Dalmacije u borbi za oslobodjenje (Das Volk Dalmatiens im Kampf um die Befreiung). ${ }^{58}$ Die Präsentation wurde danach auf der Insel Lastovo in der dortigen Schule den Besuchern vorgestellt und anschließend in der Stadt Drvar im Rahmen des am 2. Mai 1944 ausgerichteten Zweiten Kongresses des Vereinigten Verbands der Antifaschistischen Jugend Jugoslawiens (USAOJ) gezeigt. Gattin zufolge haben Slavko Zolar und er die Ausstellungsstücke in Taschen gepackt, zu Fuß transportiert und über das Küstenhinterland Ravni kotari nach Drvar gebracht. Für die Ausstellung nutzten sie eine der dortigen Hallen des holzverarbeitenden Unternehmens Šipad. Danach verlegte man die Ausstellung anlässlich des Kongresses der Volksbefreiungsräte Dalmatiens in die befreite Stadt Hvar sowie in der Folge wie erwähnt in das Kino Eden in Split, schließlich nach Šibenik und nach Belgrad, wo die dalmatinischen Fotografen das Ende des Krieges erlebten.

Gattins Episode der Reise nach Drvar gibt auch die faszinierende Geschichte des amerikanischen Journalisten Walter Bernstein preis, dem Gattin als Begleiter zugeteilt war und der neben den gemeinsamen Reisen zu Fuß auch beim Tragen der Taschen mit dem Ausstellungsmaterial half. Seine Geschichte ist vor allem deshalb interessant, weil er sich als Leutnant der amerikanischen Armee ohne Wissen seiner Vorgesetzten auf das befreite Territo-

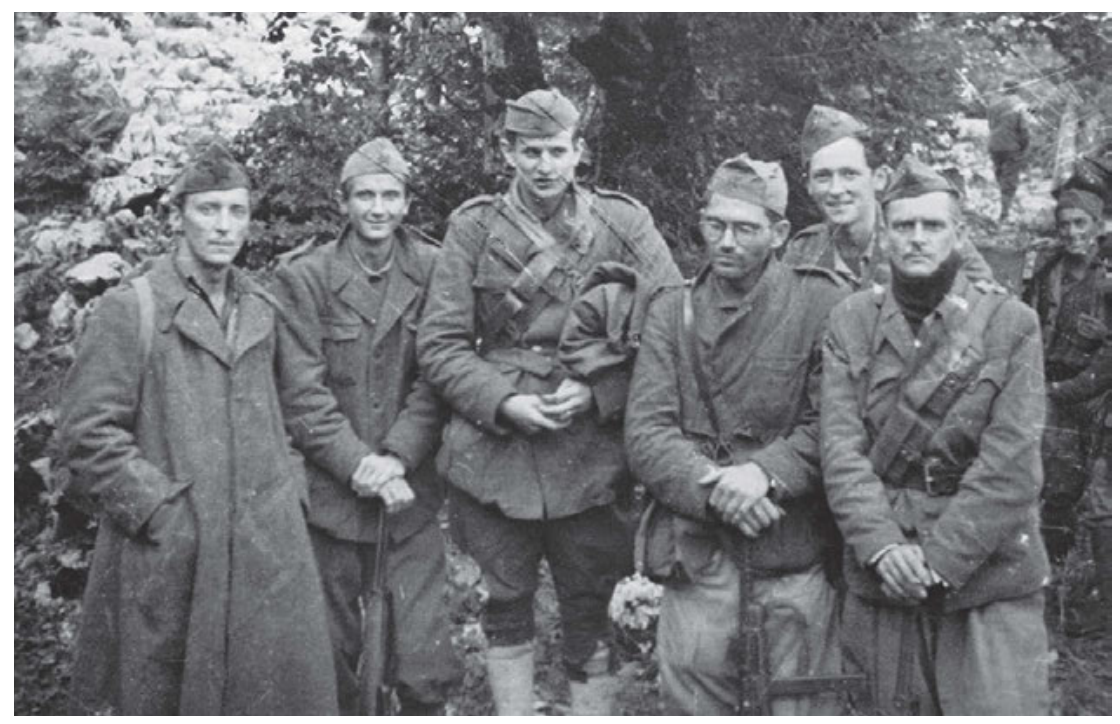

Erster Fotodienst der Zeitung Slobodna Dalmacija: Ruljančić, Zalar, Kohn, Batinić, Gattin und Klišmanić, Insel Vis, 1944. Foto: Fotodienst Slobodna Dalmacija. Privatarchiv von Ingrid Gattin Pogutz.

57 Ebd.

58 Hlevnjak, Branka und Ivanuš, Rhea. Hrvatska antiratna fotografija: Prvi svjetski, Drugi svjetski i Domovinski rat. Zagreb: Udruga za promicanje oblikovanja i umjetnosti, Design Art d. o. o., Centar za kulturu i obrazovanje 2008, S. 113. 
rium schleusen ließ und als erster westlicher Journalist ein Interview mit Josip Broz Tito führte. Das Interview wurde im Wochenmagazin Yank veröffentlicht. ${ }^{59}$

Bernstein wurde 1941 im Alter von zwanzig Jahren in die amerikanische Armee einberufen, in der er schon bald als Berichterstatter aus dem Nahen Osten zu arbeiten begann. Zu jener Zeit bis einschließlich 1944 unterlag die jugoslawische Partisanenbewegung durch die Alliierten einer strengen Zensur - insbesondere von britischer Seite, da deren Regierung
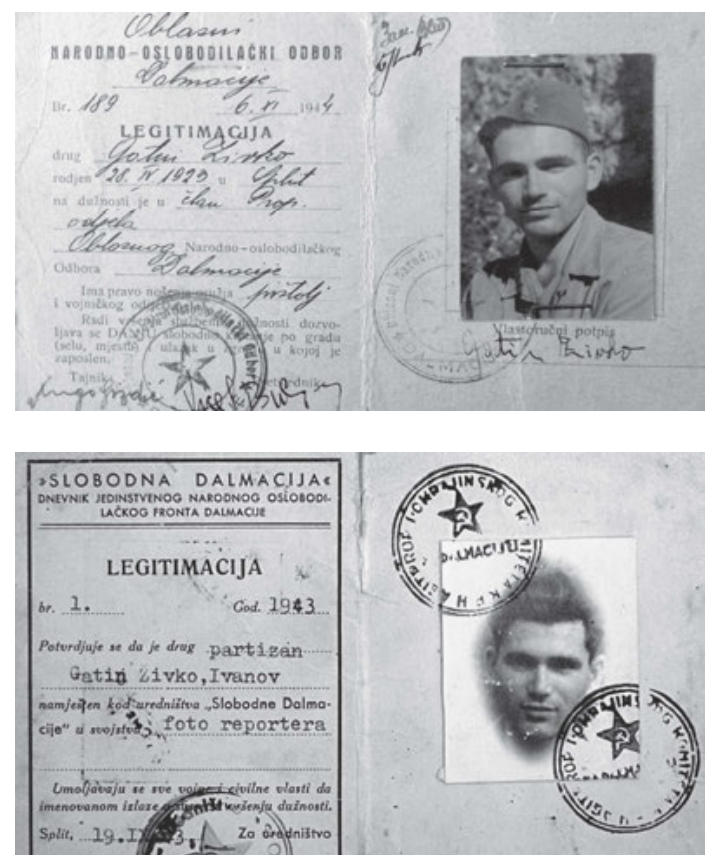

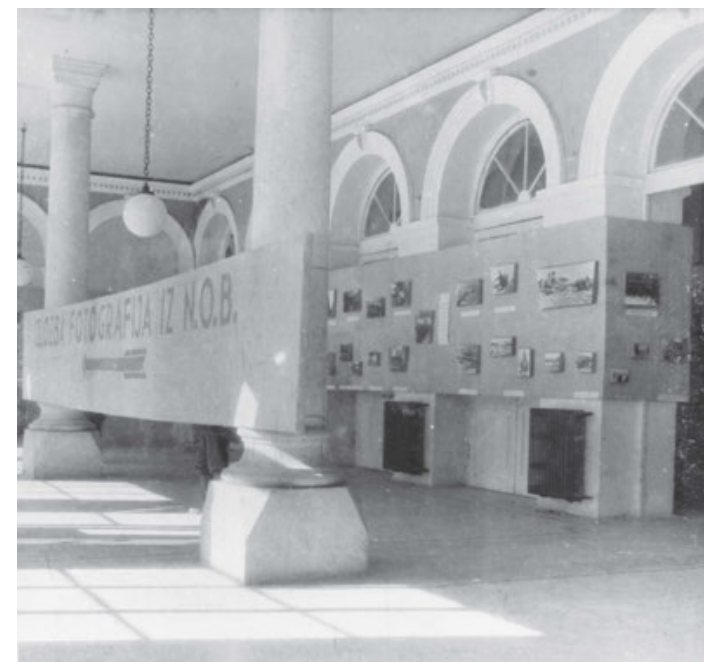

Fotoausstellung zum Volksbefreiungskampf. Insel Hvar, Kroatien, 12.-13. Oktober 1944. Autor: Miloš Žanko. Zagreb, Kroatisches Historisches Museum I HPM/MRNH-F-43.

Ausweise von Živko Gattin.

Privatarchiv von Ingrid Gattin Pogutz.

auch weiterhin den geflüchteten jugoslawischen König Petar II. Karadjordjević und seine Exilregierung unterstützte. Obwohl die Volksbefreiungsarmee Hilfe in Form von Waffen und sonstigem Material erhielt, war die Blockade von Informationen allgegenwärtig. Ihre Durchbrechung war von immenser Wichtigkeit, weil sie die Voraussetzung für die Anerkennung der Partisanenbewegung als einzig legitimer, antifaschistischer Bewegung in Jugoslawien bildete. Die Akzeptanz wiederum war für die internationale Anerkennung des neuen Staates nach dem Krieg erforderlich.

Der im Jahr 2021 verstorbene Walter Bernstein hatte sich 2017 zu einem Gespräch für dieses Buch bereit erklärt. Über die beiden bekannten jugoslawischen Politiker Vladimir Dedijer und Milentije Popović, die er in Kairo kennengelernt hatte, gelang es Bernstein, eine Einladung nach Jugoslawien auf das befreite Territorium zu erhalten. Kurze Zeit später reiste er selbstständig nach Bari, wo auch das amerikanische Kommando stationiert war. Sein erklärtes Ziel war es, nach Jugoslawien weiterzureisen: 

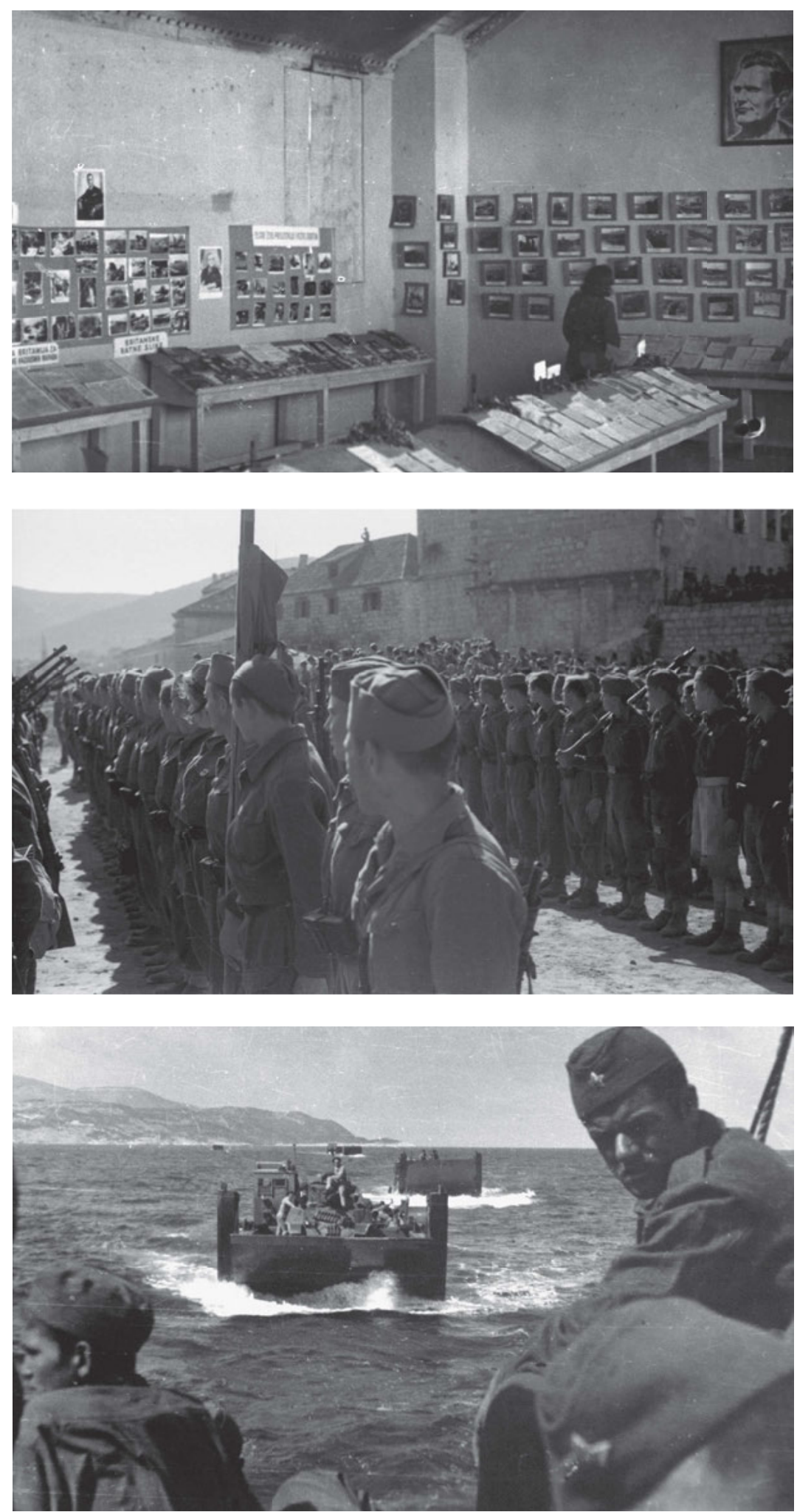

Fotoausstellung zur Zeit des Zweiten Kongresses der Vereinigten Antifaschistischen Jugendfront Jugoslawiens in Drvar, Bosnien und Herzegowina, Mai 1944. Foto: Živko Gattin. Zagreb, Kroatisches Historisches Museum I HPM/MRNHA-11701/52.

Vereidigung der Ersten Dalmatinischen Brigade auf der Insel Vis, September 1944. Foto: Živko Gattin. Zagreb, Kroatisches Historisches Museum | HPM/ MRNH-A-2602-f146-69

Kriegsschiff auf der Insel Vis, Kroatien, 1944. Foto: Živko Gattin. Privatarchiv von Ingrid Gattin Pogutz. 


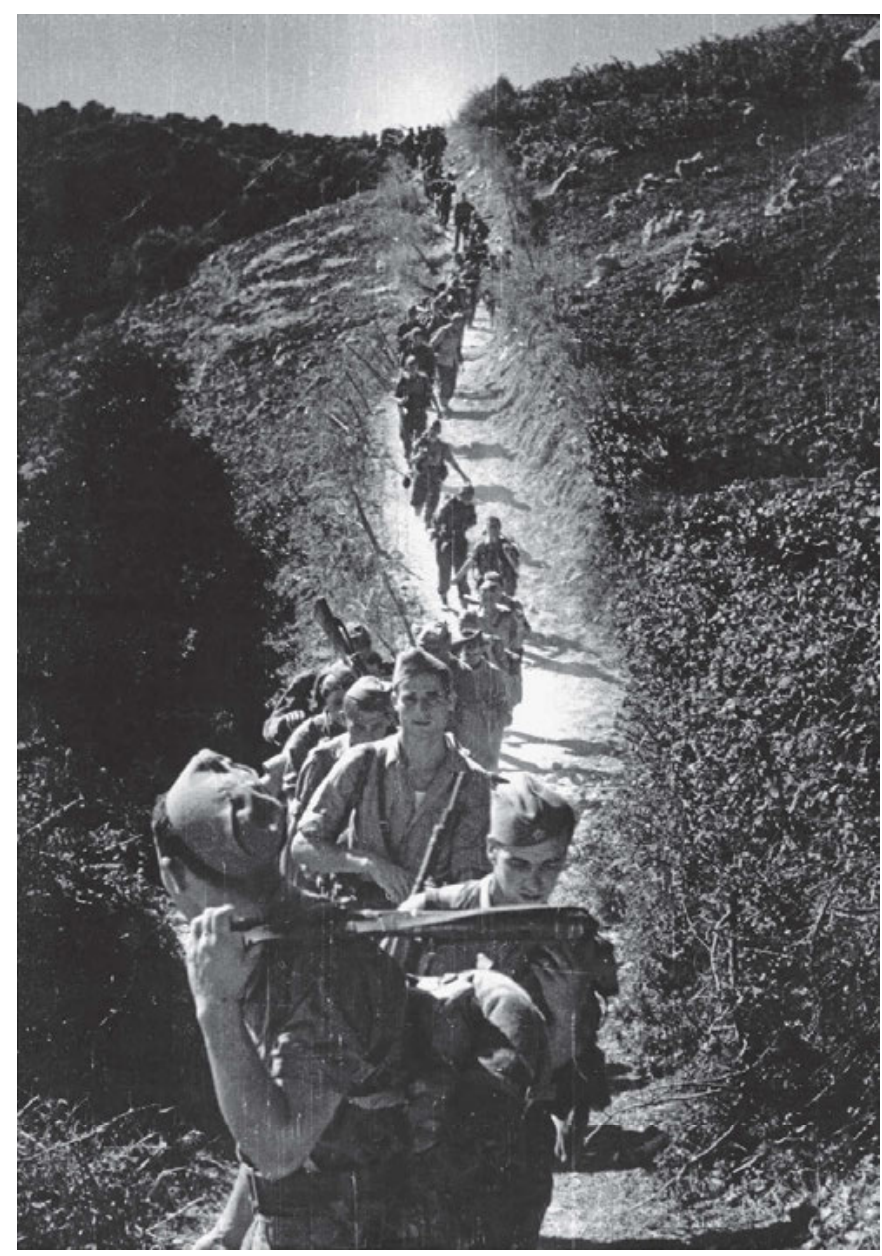

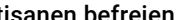

die Insel Hvar, Kroatien,

September 1944. Foto:

Živko Gattin. Privatarchiv von Ingrid Gattin Pogutz.

»lch kam in die Balkanspezialeinheit der amerikanischen Armee, die die Partisanen mit Waffen versorgte. Ich ging zum amerikanischen Offizier und sagte ihm, dass ich nach Jugoslawien reisen wollte. Dieser lächelte nur und gab mir zu verstehen, dass es niemanden erlaubt wäre, zu den Partisanen zu reisen. Er sagte zu mir: >Bleib hier und schreib Texte über uns. ८ Daraufhin sagte ich Dedijer, dass es mir nicht erlaubt sei, nach Jugoslawien zu reisen, woraufhin er mir nur antwortete: >Pfeif auf inn, das ist unser Staat und wenn du kommen möchtest, mach es ruhig, wir werden dich dorthin bringen. « $^{60}$

Auf der Reise nach Drvar wurde Bernstein nachts die Tasche mit all seinen persönlichen Sachen und einem Fotoapparat gestohlen. Gattin gab ihm daraufhin die Filme, die er während der Reise von der Insel Vis aufgenommen hatte, weil ihm die Veröffentlichung der Fotografien in der amerikanischen Presse wichtig war. Nach der Ankunft in Drvar wurde für Bernstein die erste Begegnung mit Tito organisiert: 


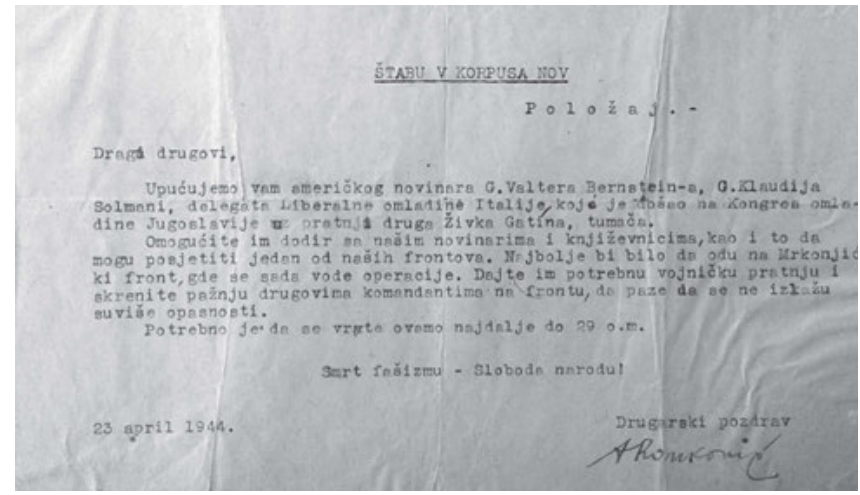

Passierschein für Walter Bernstein, ausgestellt von Aleksandar Ranković, Mitglied des Zentralkomitees der Kommunistischen Partei Jugoslawiens. Privatarchiv von Ingrid Gattin Pogutz.

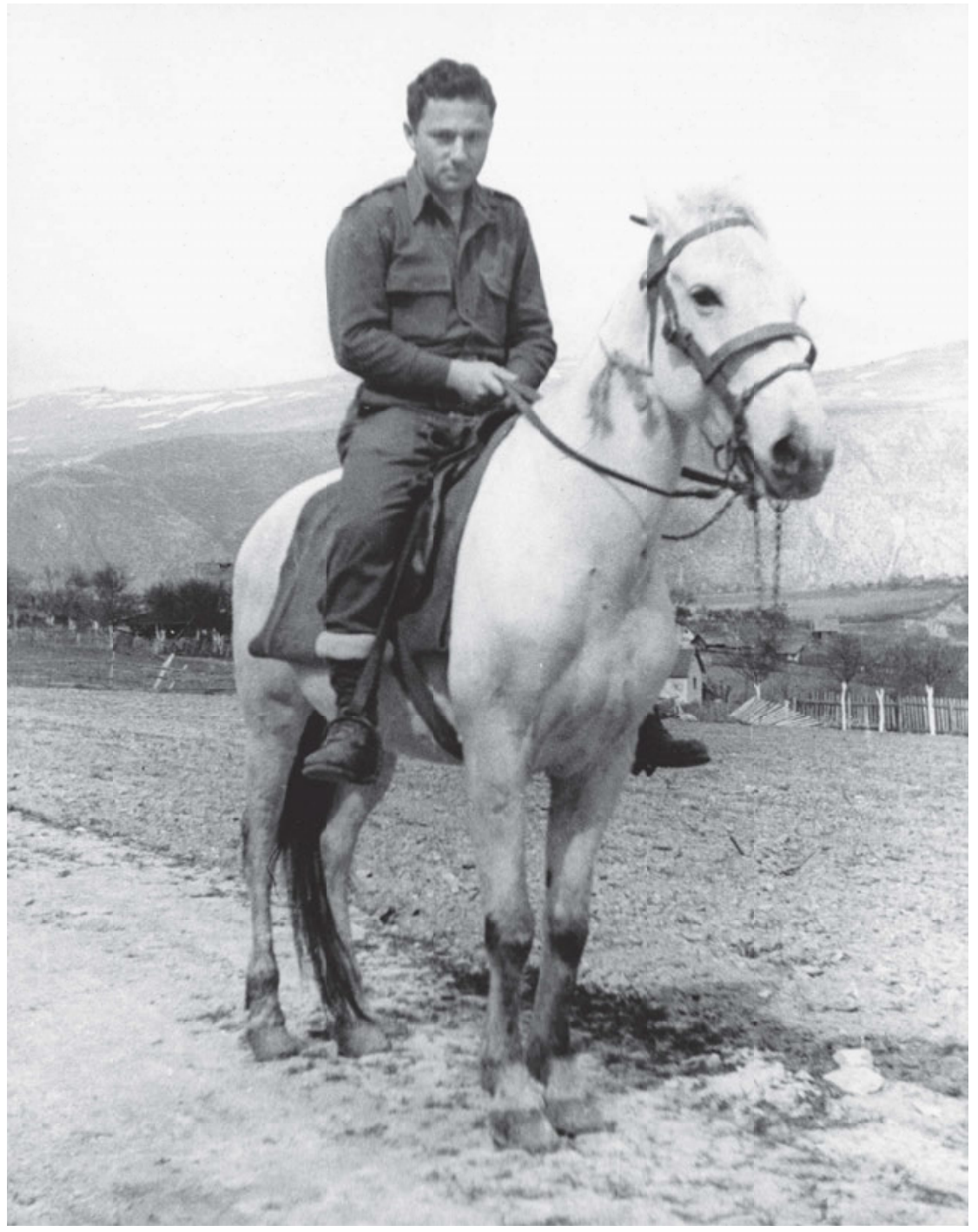

Walter Bernstein auf dem Weg nach Drvar, Bosnien-Herzegowina. Foto: Živko Gattin. Privatarchiv von Ingrid Gattin Pogutz. 
»Ich erinnere mich daran, dass er sich in einer großen Höhle befand, einer Höhle, die das Haus schützte, in dem er untergebracht war. Ich erinnere mich auch daran, dass er einen großen Hund hatte. Hinter einem großen Tisch sitzend, empfing er mich, und das erste Mal sah ich inn nur kurz. Ich glaubte an all das, was ich bei den Partisanen gesehen habe, es inspirierte mich und ich wollte unbedingt Teil all dessen werden. Aus der heutigen Perspektive betrachtet, denke ich, dass ich damals noch sehr jung war und meine Fragen naiv waren. Seine gesamte Gestalt wirkte außerordentlich imposant. Er war nicht dick, so wie er es später geworden ist. Ich wusste, dass er vor dem Krieg illegal reiste und dabei einen reichen Unternehmer spielte. Ich hatte das Gefühl, dass er dazu in der Lage war, und alles was er tat, war für mich unheimlich wichtig. « ${ }^{61}$

Das Gespräch zwischen Bernstein und Tito wurde in englischer Sprache geführt und von einer Frau namens Olga übersetzt. Am darauffolgenden Tag sollte für den jungen amerikanischen Leutnant ein zweites Treffen organisiert werden, zu dem es aber leider nicht gekommen ist.

»Nach diesem ersten einleitenden Gespräch mit Tito war für den nächsten Tag noch ein weiteres, längeres Gespräch vereinbart. An jenem Abend beschloss ich, einen kleinen Spaziergang zu machen, bei dem ich einem britischen Offizier begegnete, der sehr überrascht war, jemanden in der Uniform der Alliierten zu sehen. Es handelte sich um einen unbedeutenden Offizier der britischen Mission beim Hauptstab. Er sah mich neugierig von Kopf bis Fuß an und fragte, wer ich denn sei. Ich erklärte ihm, was ich hier tat, woraufhin er mir sagte, dass ich gegen alle möglichen Befehle verstoßen hätte und mit ihm kommen müsste. Er brachte mich zur britischen Mission, in der sich Randolph Churchill, der Sohn von Winston Churchill, befand. Er war belustigt, dass man mich in Drvar angetroffen hatte, doch dann gab er mir zu verstehen, dass ich verhaftet sei und man mich nach Bari zurückschicken werde. Im Flugzeug saß ich dann mit ihm zusammen und ich kann mich noch gut daran erinnern, dass er sturzbetrunken war. Ich war enttäuscht und zum Teil auch verängstigt. Ich wusste nicht, was mit mir geschehen würde, und glaubte damals niemandem außer den Partisanen. Zugleich befürchtete ich, dass man das, was ich geschrieben hatte, nicht veröffentlichen würde. Ich wollte eigentlich länger bei den Partisanen bleiben und noch viele weitere Artikel schreiben. Gleichzeitig erfuhr ich, dass die Briten dabei waren, die erste offizielle Reise einiger Journalisten und Fotografen zu den Partisanen zu organisieren. Sie sollten diejenigen sein, die die offızielle Geschichte über die Partisanen erzählen. « ${ }^{62}$

Während Bernstein als militärischer Gefangener nach Bari zurückgebracht wurde, landete am 9. Mai 1944 in Drvar, in der Nähe von Bosanski Petrovac, tatsächlich ein Flugzeug mit der ersten offiziellen, von den Alliierten genehmigten Journalistengruppe. Sie bestand aus dem Berichterstatter des Time Magazine Stojan Pribićević, Sohn des Politikers Svetozar Pribićević, dem Fotografen der Agentur Reuters John Talbot, dem britischen Fotografen Gene Fowler und dem amerikanischen Fotografen Slade. Sechs Tage später wurde für sie ein Abendessen mit Tito organisiert. ${ }^{63}$ Bis heute gelten sie als die erste westliche Journalistendelegation, die den Hauptstab besucht hatte, weil ihre Berichte vor dem erst am 16. Juni 1944 im Yank Magazine veröffentlichten Interview von Bernstein erschienen sind. In seinem Artikel schrieb Bernstein unter anderem Folgendes:

\footnotetext{
61 Ebd.

62 Ebd.

63 Roberts, Walter E. Tito, Mihailović and the Allies, 1941-1945. Durham: Duke University Press 1987, S. 227.
} 
»Titos Kosmopolitismus wird noch offensichtlicher, je länger man sich in seiner Gesellschaft befindet. Er ist kein einfacher Bauernanführer, sondern ein Weltbürger. Tito ist in Wirklichkeit ein gebildeter Mensch im besten Sinne dieses Wortes. Es gibt Augenblicke, in denen er den Eindruck eines guten Schauspielers hinterlässt - die Uniform trägt er mit Talent. « ${ }^{64}$

Ein paar Monate später schickte Bernstein Gattin ein Paket mit dessen Filmen und veröffentlichte noch einige weitere Artikel, in denen er ihre gemeinsame Reise erwähnte. ${ }^{65}$ Bernstein war vor dem Krieg kein Mitglied der Kommunistischen Partei, doch die Reise nach Jugoslawien stellte für ihn die Verwirklichung seiner jugendlichen Ideale dar und ermöglichte seinen eigenen Beitrag zum Durchbruch der Informationsblockade. Vor Bernstein führte lediglich Associated Press, vermittelt über einen Mittelsmann der Partisanen in Bari, ein schriftliches Gespräch mit Tito. Das Militärkommando der Alliierten zensierte das Interview dennoch. Es wurde erst nach einigen Interventionen, auch seitens des amerikanischen Präsidenten Roosevelt, am 21. Mai 1944 veröffentlicht, was für die Anerkennung der Volksbefreiungsarmee und die künftige Unterstützung durch die Alliierten von entscheidender Bedeutung war. ${ }^{66}$ Die ersten Fotografien, die die Militärzensur der Alliierten durchbrachen, wurden vom britischen Leutnant Lambton Burn aufgenommen und am 6. Dezember 1943 im Life Magazine veröffentlicht. ${ }^{67}$

Nur ein paar Tage nach Titos Gespräch mit Pribićević begann am 25. Mai 1944 mit der sogenannten Siebten feindlichen Offensive der Angriff auf Drvar. Im Verlauf des »Unternehmens Rösselsprung«, bei dem Tito und das Hauptquartier der Partisanen außer Gefecht gesetzt werden sollten, gelang dem Hauptstab nur mit Mühe der Rückzug. Beim Angriff kamen zahlreiche ausländische Verbindungsoffiziere und Partisanen ums Leben, während Tito flüchten konnte und mit einem russischen Flugzeug vom jugoslawischen Territorium nach Bari ausgeflogen wurde. In Drvar gerieten Pribićević, Talbot und die beiden ausländischen Fotografen in Gefangenschaft, doch schafften die Partisanen, Pribićević bei einem rasch erfolgten Gegenangriff zu befreien. Auch die anderen konnten letztendlich ihre Freiheit zurückgewinnen. Vili Šimunov-Barba, Partisanenfotograf und erster Fotograf der Presseagentur TANJUG, wurde indes bei dem Versuch, seine Filmnegative auf der Straße von Drvar nach Oštrelj aus dem Feuer zu retten, getötet. Geboren in Ogulin als Vilim Schwarz, änderte er nach der Ausrufung des Unabhängigen Staates Kroatien seinen Nachnamen in Šimunov und schloss sich der Partisanenbewegung an. Er arbeitete bereits vor dem Krieg mit der Kommunistischen Partei Jugoslawiens zusammen und begann in Drvar mit der Einrichtung eines Partisanenarchivs. Zudem war er auch der erste offizielle Fotograf des Hauptstabs der Volksbefreiungsarmee und der Widerstandsbewegung Jugoslawiens.

64 Bernstein, Walter. Interview with Tito of Yugoslavia. In: Yank Magazine, 16.06.1944, S. 8-9.

65 Bernstein, Walter. Walk Through Yugoslavia. In: Yank Magazine, 28.07.1944, S. 8-9.

66 Roberts, Walter E. Tito, Mihailović and the Allies, 1941-1945. Durham: Duke University Press 1987, S. 227-228.

67 Kurtović, Nikolina. Communist Stardom in the Cold War: Josip Broz Tito in Western and Yugoslav Photography, 1943-1980.

Toronto: University of Toronto (Diss.) 2010, S. 55. 


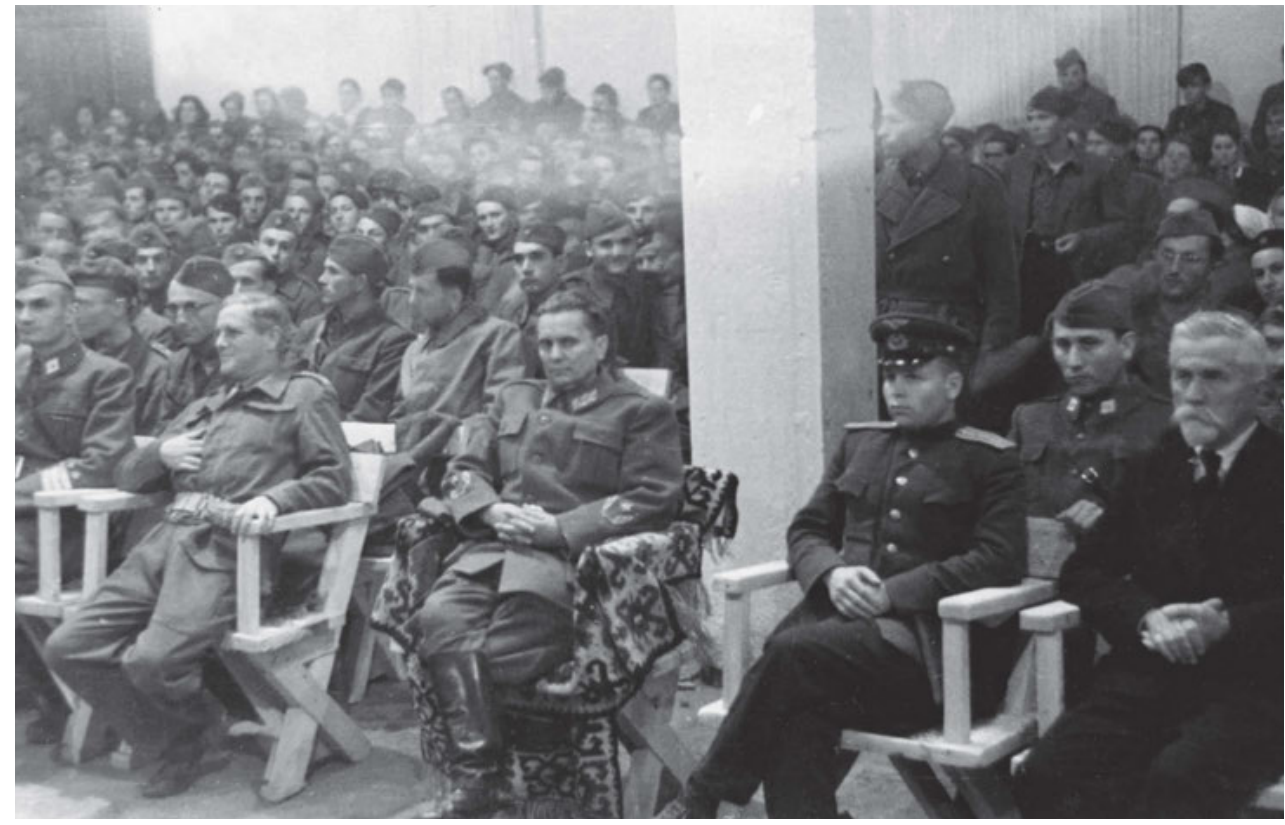

Zweiter Kongress der Vereinigten Antifaschistischen Jugendfront Jugoslawiens, Drvar, Bosnien-Herzegowina 1944. Randolph Churchill und Josip Broz Tito. Foto: Živko Gattin. Privatarchiv von Ingrid Gattin Pogutz.

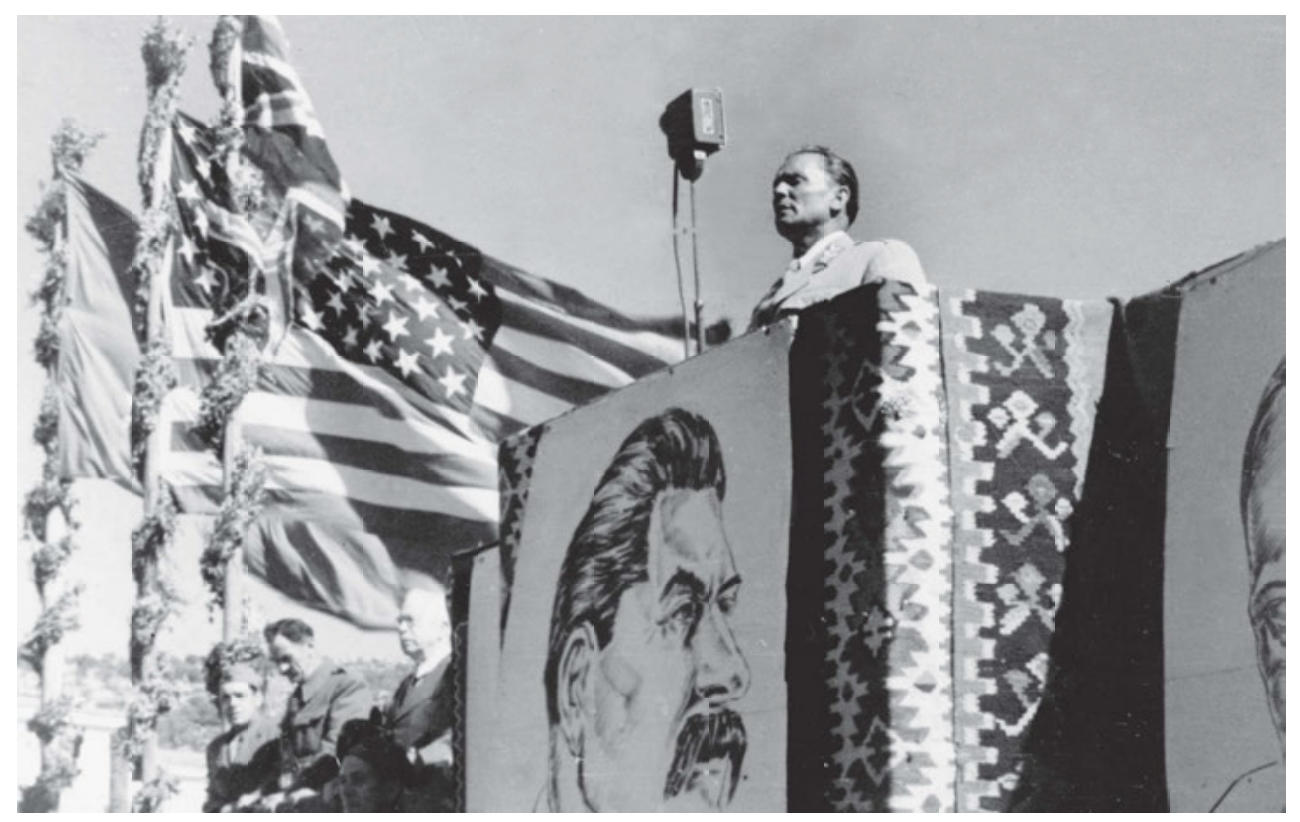

Titos Rede auf der Insel Vis, Kroatien, 1944. Foto: Živko Gattin. Privatarchiv von Ingrid Gattin Pogutz. 


\section{Dalmatien, Slawonien, Bosnien, Serbien, Slowenien ...}

Neben den bereits erwähnten dalmatinischen Fotografen sei noch Ante Roca erwähnt, der sich 1943 der Stabseinheit der 19. norddalmatinischen Division anschloss. ${ }^{68}$ Bei der Umsetzung der ihm anvertrauten Aufgabe, notwendiges Material zu beschaffen, nahmen ihn Soldaten der deutschen Wehrmacht fest und brachten ihn nach dem Verhör ins Lager nach Slavonski Brod. Ihm gelang die Flucht, woraufhin er als Fotograf der Zeitung Vjesnik zu arbeiten begann. ${ }^{69}$

Unbekannt ist bis heute, dass auch Stevan Benčić, Vorkriegsfotograf der Tageszeitung Politika und Abgeordneter in der Versammlung des Königreichs der Serben, Kroaten und Slowenen, Mitglied der Partisanenbewegung war. Seiner großen Liebe folgte er auf die Insel Hvar und weitete von dort mit der Zeit sein Geschäft von Budva bis Dubrovnik aus, indem er touristische Motive fotografierte und Ansichtskarten herstellte. Er war Vertreter des Unternehmens Agfa für diesen Teil Dalmatiens. Während der kurzen Regentschaft der Ustascha auf der Insel Hvar befand er sich in Gefangenschaft, doch seiner Familie gelang es, ihn durch Bestechung der lokalen Machthaber freizubekommen. Er unterstützte Boža Novak, den späteren namhaften kroatischen Journalisten. Benčić schloss sich 1943 den Partisanen an und begegnete dort in der Folgezeit Vladislav Ribnikar, der ihn mit der Nachrichtenagentur TANJUG bekannt machte. Zu jener Zeit nahm er ein Porträt von Tito auf, das später auf Briefmarken abgedruckt wurde. ${ }^{70}$

Eine besonders eindrucksvolle Fotosammlung, die heute im Kroatischen Historischen $\mathrm{Mu}$ seum in Zagreb verwahrt wird, schuf der Fotodienst des Regionalen Volksbefreiungsrates für Slawonien, in dem Pero Dragila, Vlado Potočnjak, Mate Tačković oder Milan Crnelić wirkten. ${ }^{71}$ Dieser Fotodienst erstellte Fotomontagen für besondere Anlässe, zum Beispiel eine Glückwunschkarte zum orthodoxen Weihnachtsfest. Der Dienst organisierte mit Erfolg Fotoausstellungen, darunter jene in Orahovica im Jahr 1944.

Neben den erwähnten Fotografen stechen in dieser Sammlung einige Bilder in quadratischem Format durch ihren Stil und ihre Qualität hervor. Der Urheber ist bis heute unbekannt geblieben, doch handelt es sich vermutlich um Miro Matašin, den Leiter der Fotosektion des Regionalen Volksbefreiungsrates für Slawonien. Der Name dieses Fotografen steht unter einer Aufnahme vom 31. Mai 1944, die in der Ortschaft Duboka Reka im Papuk-Gebirge entstand. Auf dem Bild sind der Chirurg Jože Koporc und die Instrumentierschwester Meri Barvinski zu sehen. ${ }^{72}$ Stil, Format und technische Qualität der Aufnahme sprechen dafür, dass sie aus derselben Hand wie die restlichen Fotos quadratischen Formats stammt, die sich heute in der Sammlung des Kroatischen Historischen Museums befinden. Matašins

68 Ivanuš, Rhea. Ratni ciklus Ante Roce Svjetlo na pepelu i Zadar 1944. In: Cukrov, Tončika (Hrsg.). Ante Roca fotograf stvarnosti. Zagreb: Hrvatski fotosavez 2013, S. 71.

69 Mutnjaković, Andrija. Ante Roce. In: Cukrov, Tončika (Hrsg.). Ante Roca fotograf stvarnosti. Zagreb: Hrvatski fotosavez 2013,

S. 15.

70 Mündliche Aussagen der Tochter von Stevan Benčić und der kroatischen Historikerin Zorica Stipetić am 01.12.2017.

71 Hlevnjak, Branka und Ivanuš, Rhea. Hrvatska antiratna fotografija: Prvi svjetski, Drugi svjetski i Domovinski rat. Zagreb: Udruga

za promicanje oblikovanja i umjetnosti, Design Art d. o. o., Centar za kulturu i obrazovanje 2008, S. 114.

72 Kocković, Braco. I tamo smo samo ljudi bili (tragovima partizanskih ranjenika). Zagreb: Spektar 1982, S. 57. 


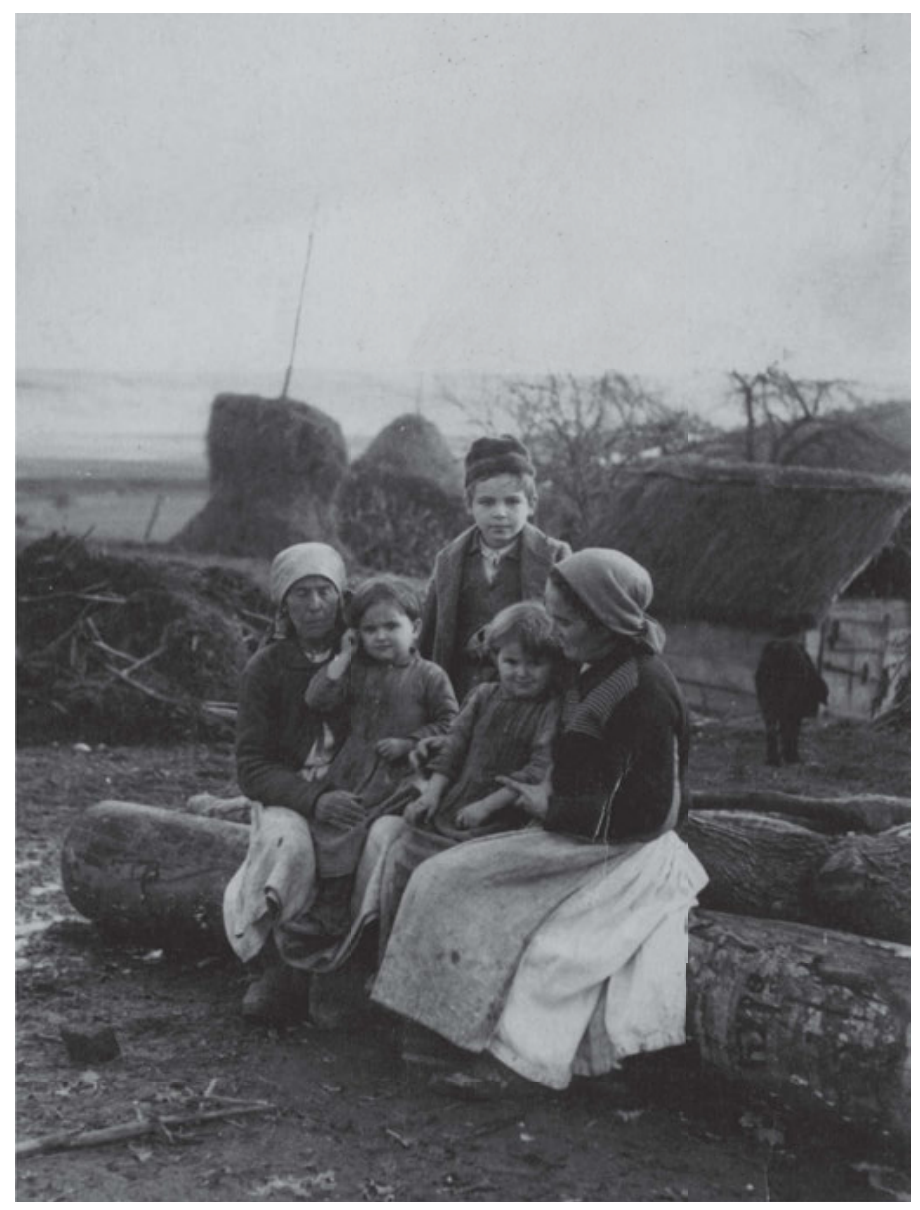

Mutter mit Kindern im Dorf Knezovljani in der Banija, Kroatien, April 1945.

Foto: Ante Roca. Zagreb, Kroatisches Historisches Museum | HPM-82093-2.

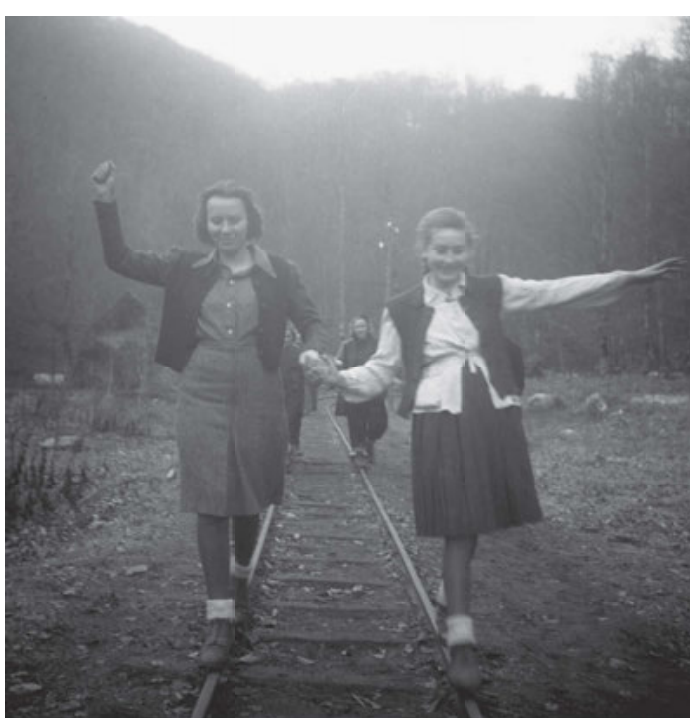

Partisaninnen in Slawonien, Kroatien, 1944.

Foto: Miro Matašin. Zagreb, Kroatisches Historisches Museum | HPM/MRNH-A-2203/1837.

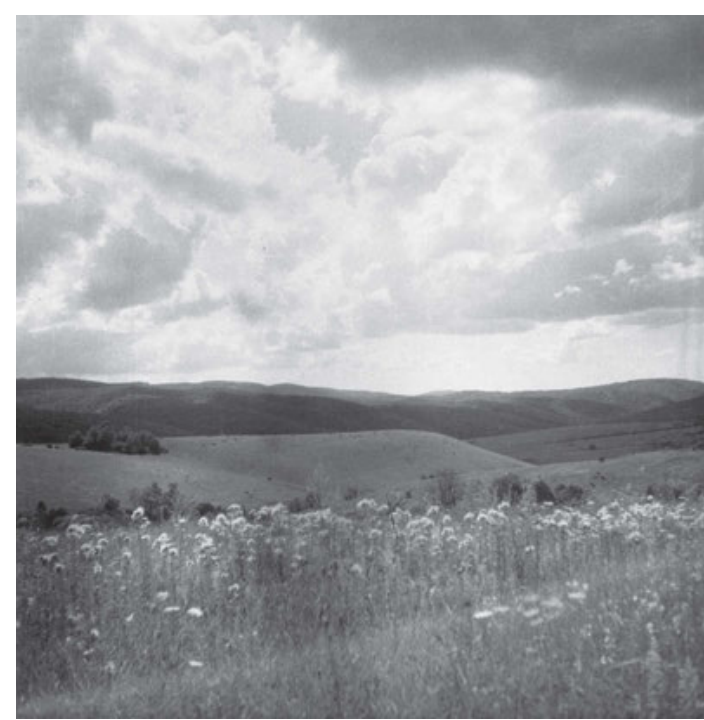

Slawonien. Foto: Miro Matašin. Zagreb, Kroatisches Historisches Museum | HPM/MRNH-A-2203/1695. 
Nachname ist unter der Fotografie fälschlicherweise mit »Marašin« angegeben, doch gab es keinen Partisanenfotografen mit diesem Nachnamen. Miro Matašin war durchaus aktiv, was auch der Katalog zur Ausstellung seiner Kriegsfotografien im Salon Becić in Slavonski Brod von 1981 dokumentiert. ${ }^{73}$ Matašin stellte in dieser Ausstellung die meisten seiner Fotografien zum ersten Mal vor, was dafür spricht, dass der talentierte Fotograf nach dem Zweiten Weltkrieg in Vergessenheit geraten war.

Doch wer war eigentlich Miro Matašin? Er wurde im Dorf Uljanik unweit des kroatischen Städtchens Garešnica geboren, wo sein Vater als Gemeindebeamter und Kaufmann arbeitete. Nach Abschluss der Handelsschule erwarb er kurz vor Kriegsbeginn seinen ersten Fotoapparat und baute sich ein Fotolabor auf, um sich als Amateurfotograf zu betätigen. Im Alter von 22 Jahren transportierte er auf einem Pferdewagen seine Fotoausrüstung, um in die Nähe von Zvečevo zu gelangen. Zu jener Zeit verwendete er Fotokameras vom Typ Leica und Rolleiflex, weshalb die meisten seiner Fotografien ein quadratisches Format $(6 \times 6 \mathrm{~cm})$ aufweisen. In der Umgebung von Zvečevo richtete er ein Fotolabor ein, wo er zusammen mit Nikola Popović und Drago Pavlić arbeitete. Viele Bilder entstanden bei seinen Landsleuten, in der tschechischen Brigade Jan Žiška. Man ernannte ihn zum Fotografen des Stabs der Vierzigsten Division, später begleitete Matašin Kosta Nadj und den Stab der Dritten Armee bei den Kämpfen zur Befreiung des Landes bis zur slowenisch-österreichischen Grenze. Nach der Demobilisation im Jahre 1946 arbeitete er als Verkäufer von Fotozubehör im Unternehmen Univerzal..$^{74}$ Dieser bescheidene und höchst talentierte Fotograf schuf einige der technisch und künstlerisch eindrucksvollsten Aufnahmen. Die Modelle auf seinen Bildern wirken gelöst, überdies fotografierte er aus großen Entfernungen in der Totale, die heute in der modernen Fotografie allgegenwärtig sind.

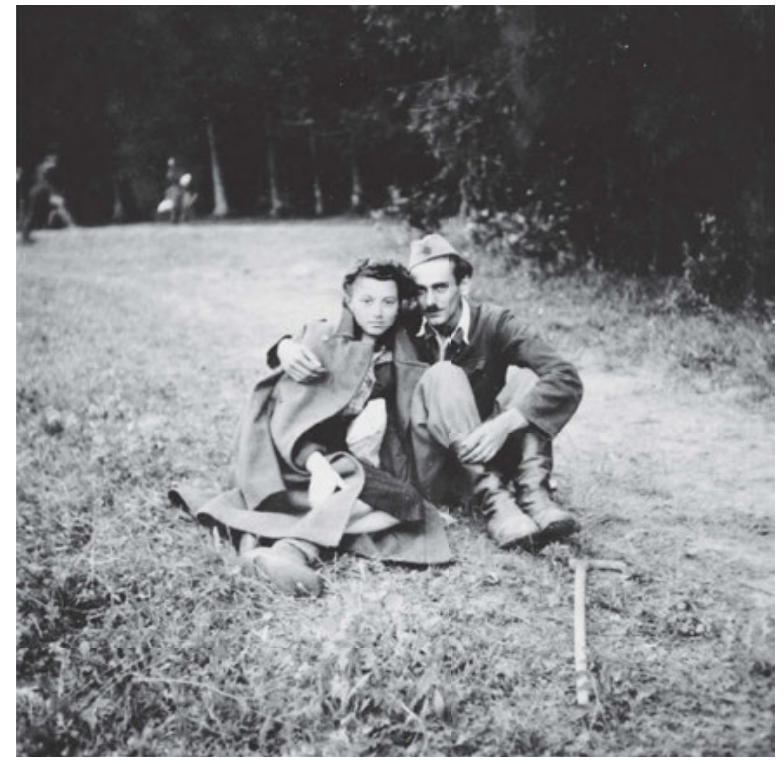

Am Ljutoč im Papuk-Gebirge, Slawonien, 1944. Invalidenheim des Siebenten Armeekorps. Foto: Miro Matašin. Zagreb, Kroatisches Historisches Museum I HPM/MRNHA-2203/1718.

73 Matašin, Miro. Ratne fotografije: Salon Becić. Ausst.-Kat. Slavonski Brod: Muzej radničkog i narodnooslobodilačkog pokreta 1981.

74 Ebd. 


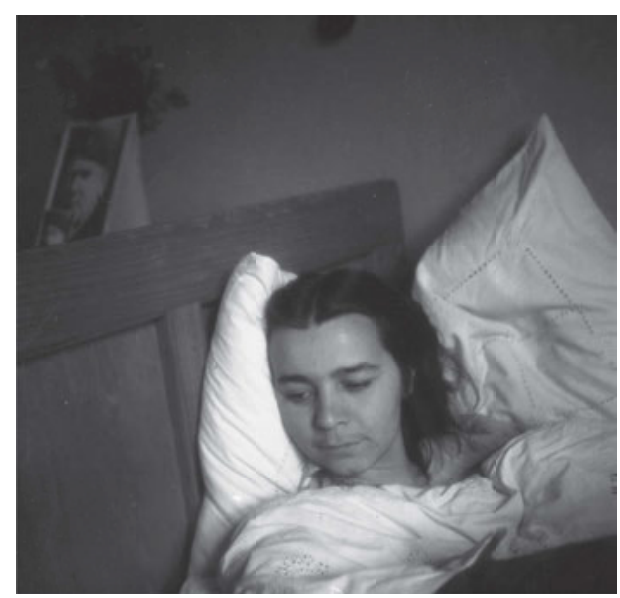

Junge Partisanin im Krankenhaus, Slawonien, 1944. Foto: Miro Matašin. Zagreb, Kroatisches Historisches Museum | HPM/MRNH-A-2203/1780.

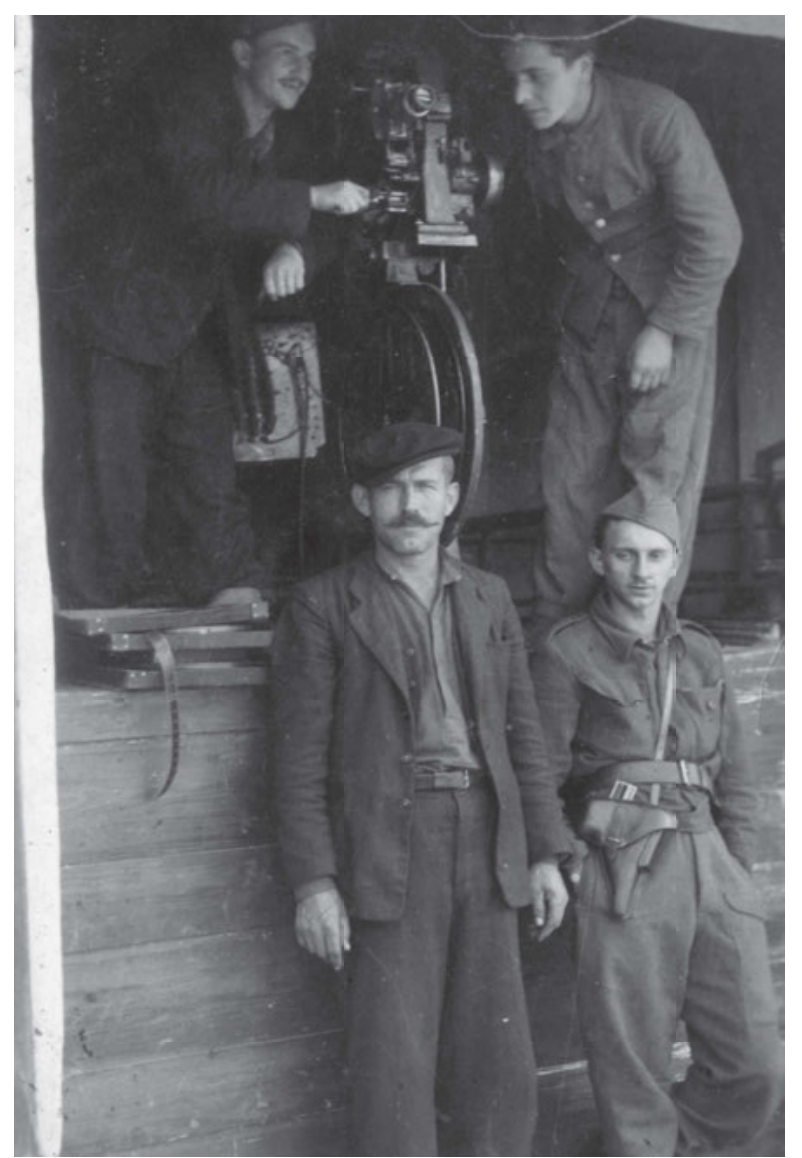

Erste Kinotruppe der Partisanen. Zvečevo, Slawonien, 1943. Foto: Fotodienst des Volksbefreiungsrates für Slawonien. Zagreb, Kroatisches Historisches Museum | HPM/MRNH-F-4312.

Zu den serbischen Fotografen, deren Entwicklung durch die Partisanenbewegung entscheidend geprägt wurde, zählen Jovan Ritopečki und Nikola Bibić. Ritopečki war während des Kriegs Radiotechniker, Kriegsberichterstatter und Fotograf in der Ersten VojvodinaBrigade. Nach dem Krieg arbeitete er eine Zeitlang als Fotograf für die Nachrichtenagentur TANJUG und die Tageszeitung Politika, um dann 1966 nach Wien zu ziehen, wo er als Fotograf in der Agentur Votava tätig war. Vier Jahre später machte er sich als Fotograf selbstständig, arbeitete mit dem österreichischen ORF und anderen staatlichen Institutionen zusammen und schuf zahlreiche Bilder über das Leben der Gastarbeiter in Österreich.

Nikola Bibić wiederum erlernte sein fotografisches Handwerk vom serbischen Fotografen Aleksandar Aca Simić aus Belgrad. Bibić hatte während seines Aufenthalts bei den Partisanen Kurse für Amateurfotografen organisiert. Nach dem Krieg setzte er seine erfolgreiche Laufbahn als Fotograf fort und gewann 1957 den World Press Photo Award. Er realisierte auch das Porträt des lächelnden Bergarbeiters Arif Heralić aus Zenica, dessen Konterfei Anfang der 1960er-Jahre auf dem 1.000-Dinar-Schein abgebildet war, worüber der Regisseur Vojdrag Berčić 1967 den Dokumentarfilm Devalvacija jednog osmijeha (Abwertung eines Lächelns) drehte. 


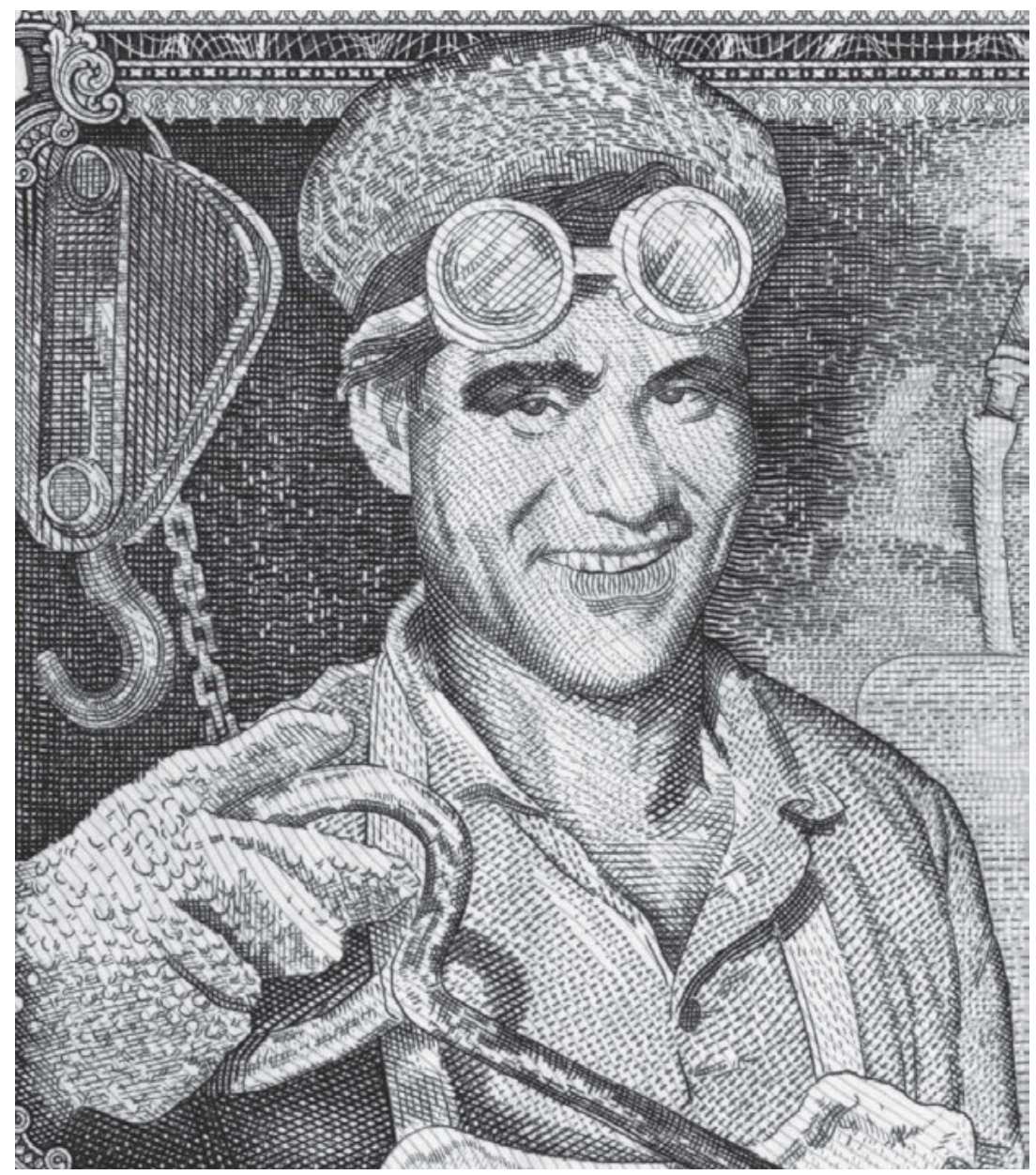

Foto des Bergarbeiters Arif Heralić aus Zenica, Bosnien und Herzegowina, aufgenommen 1954 von Nikola Bibić. Das Bild befand sich im sozialistischen Jugoslawien auf dem 1.000-Dinar-Schein.

Ein weiterer wichtiger Partisanenfotograf war der aus Bosnien-Herzegowina stammende Schriftsteller und Revolutionär Drago Mažar. Während des Krieges führte Mažar als Kommandant der Sechsten Lika-Einheit den Aufstand in Bosnien an und arbeitete zudem als militärischer Nachrichtenoffizier im Operativen Stab für die bosnische Krajina. Im Krieg verlor er zwei seiner Brüder - Josip Mažar-Šoša und Ivica Mažar. Alle drei wurden nach dem Krieg zu Volkshelden erklärt. Seine ersten Fotografien schuf Drago Mažar im Jahr 1942. Nach seinem Tod ist nur ein Teil seines fotografischen Werks erhalten geblieben, das sich, immer noch nicht abschließend bearbeitet und geordnet, im Archiv der Republika Srpska befindet. Einige seiner Fotografien wurden im Buch Partizanski album (Partisanenalbum) veröffentlicht, das keine nummerierten Seiten, aber klar strukturiertes und identifiziertes Fotomaterial sowie ein Vorwort aufweist, in dem Folgendes geschrieben steht:

"Fotografien zeichnen keine Worte auf, doch sie verleihen der Situation Macht. Diese Aufnahmen sind eine wichtige und inspirierende Geschichte des 'Fotografen<. Sie sind der Beleg unserer revolutionären Grundsätze und Formen, Beziehungen und Ereignisse, doch in diesem Zeugnis ist 
auch Lyrik enthalten, manchmal mit kaum vernehmbarem Ton des gerade erst erlebten Unglücks, häufiger jedoch gepaart mit dem Enthusiasmus einer gleichartigen Hoffnung. «7 $^{75}$

Hauptthemen seiner Fotografien sind Freiheit und Emanzipation. Mažar war ein gesellschaftlich engagierter Fotograf, der 1942 Schreckensszenen auf dem Kozara-Gebirge und die Folgen des »Unternehmens Westbosnien« dokumentierte. Bei dieser Militäraktion haben Truppen der Wehrmacht und der Ustascha, mit Unterstützung einzelner kleinerer Einheiten serbischer Tschetniks, 24.480 Menschen ermordet, darunter 8.893 Kinder unter vierzehn Jahren. Den Angaben des Gesundheitsministeriums und des Roten Kreuzes zufolge wurden weitere 7.460 Kinder aus insgesamt 138 Dörfern im Kozara-Gebirge verschleppt. ${ }^{76}$
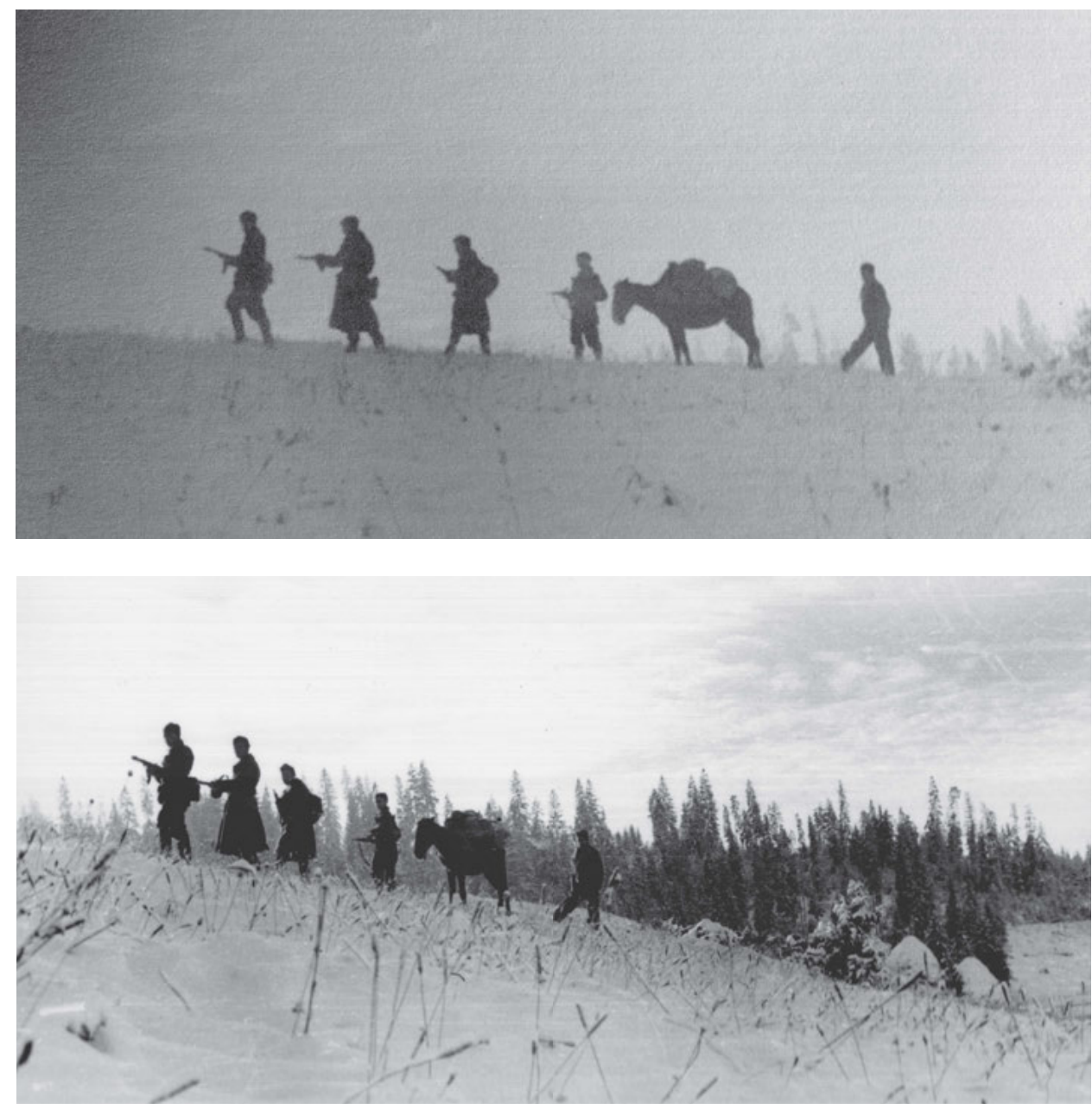

Von dem Fotografen Dragan Mažar aufgenommene Szenen. Archiv der Republik Srpska. Ohne Inv.-Nr.

75 Mažar, Drago. Partizanski album. Mit einem Vorwort von Jovo Popović. Banja Luka: Glas, Belgrad: 4. Jul. 1981.

76 Lukić, Dragoje. Zločini okupatora i njegovih saradnika nad decom kozarskog područja 1941.-1945. godine. In: Antonić, Zdravko und Marjanović, Joco. Kozara u Narodnooslobodilačkoj borbi i socijalističkoj revoluciji: radovi za naučnog skupa održanog na Kozari (Mrakovica) 27. i 28. oktobra 1977. godine. Prijedor: Nationalpark Kozara 1980, S. 283. 

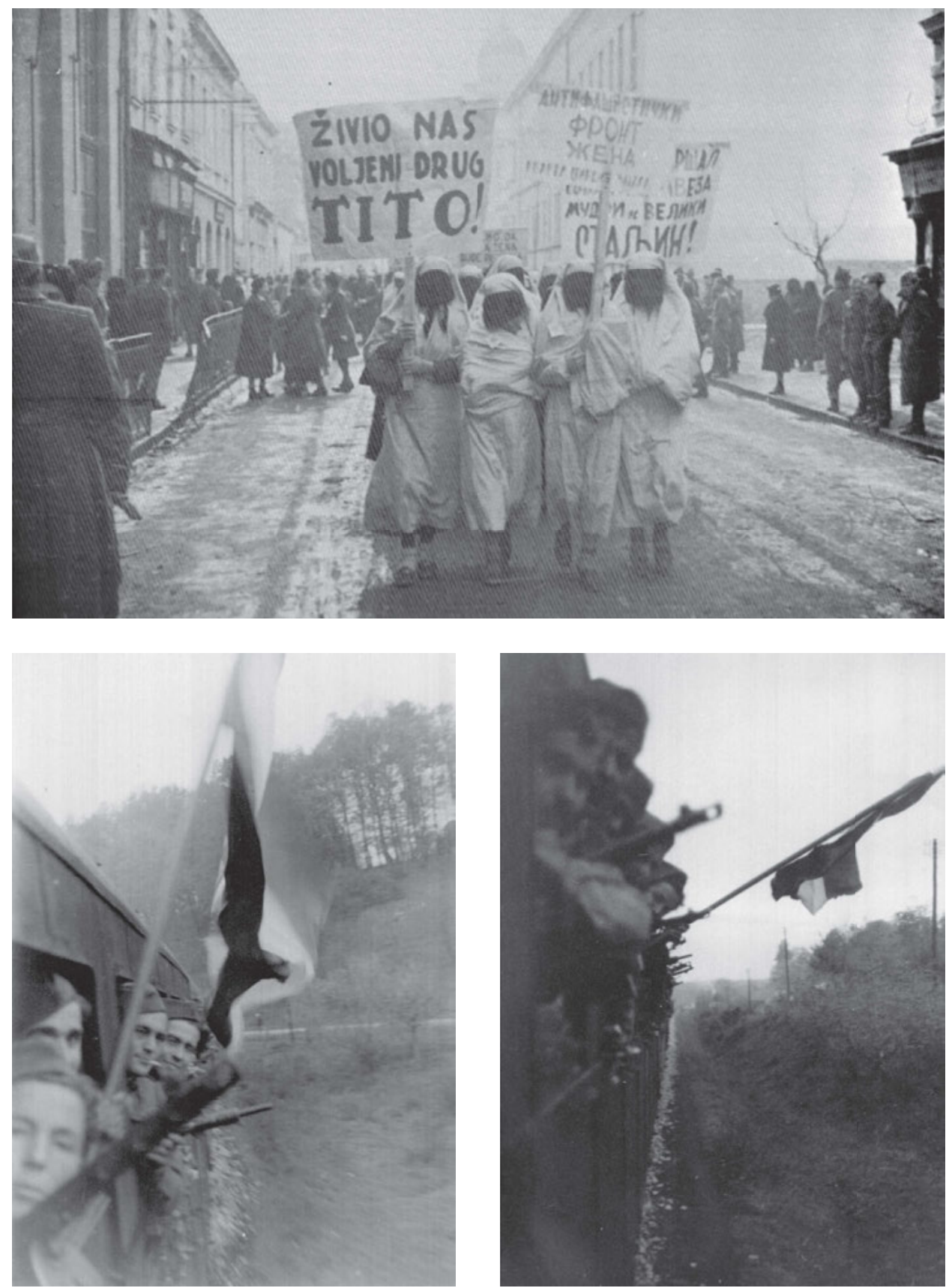

Von dem Fotografen Dragan Mažar aufgenommene Szenen. Archiv der Republik Srpska. Ohne Inv.-Nr. 

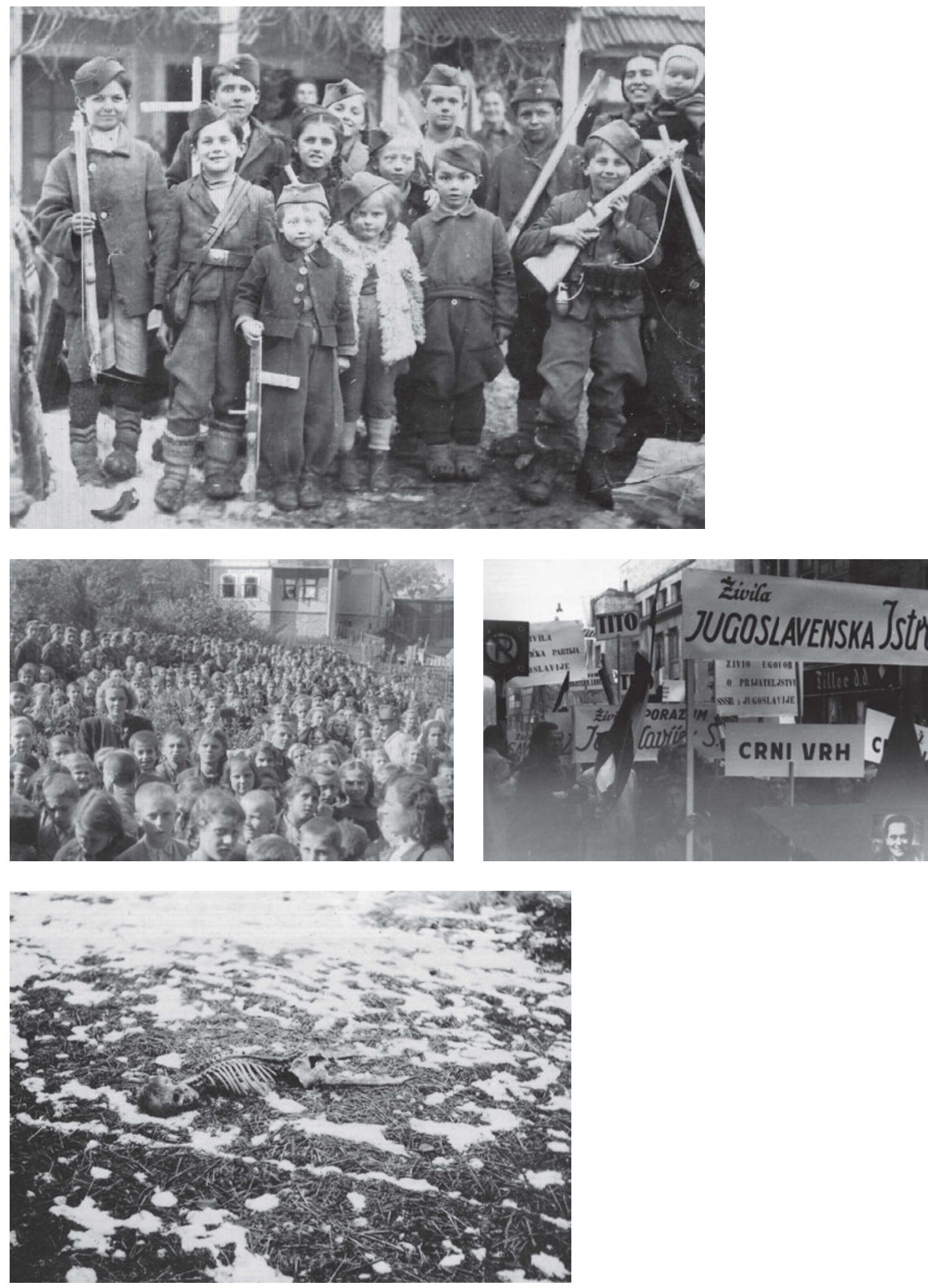

Von dem Fotografen Dragan Mažar aufgenommene Szenen.

Archiv der Republik Srpska. Ohne Inv.-Nr. 

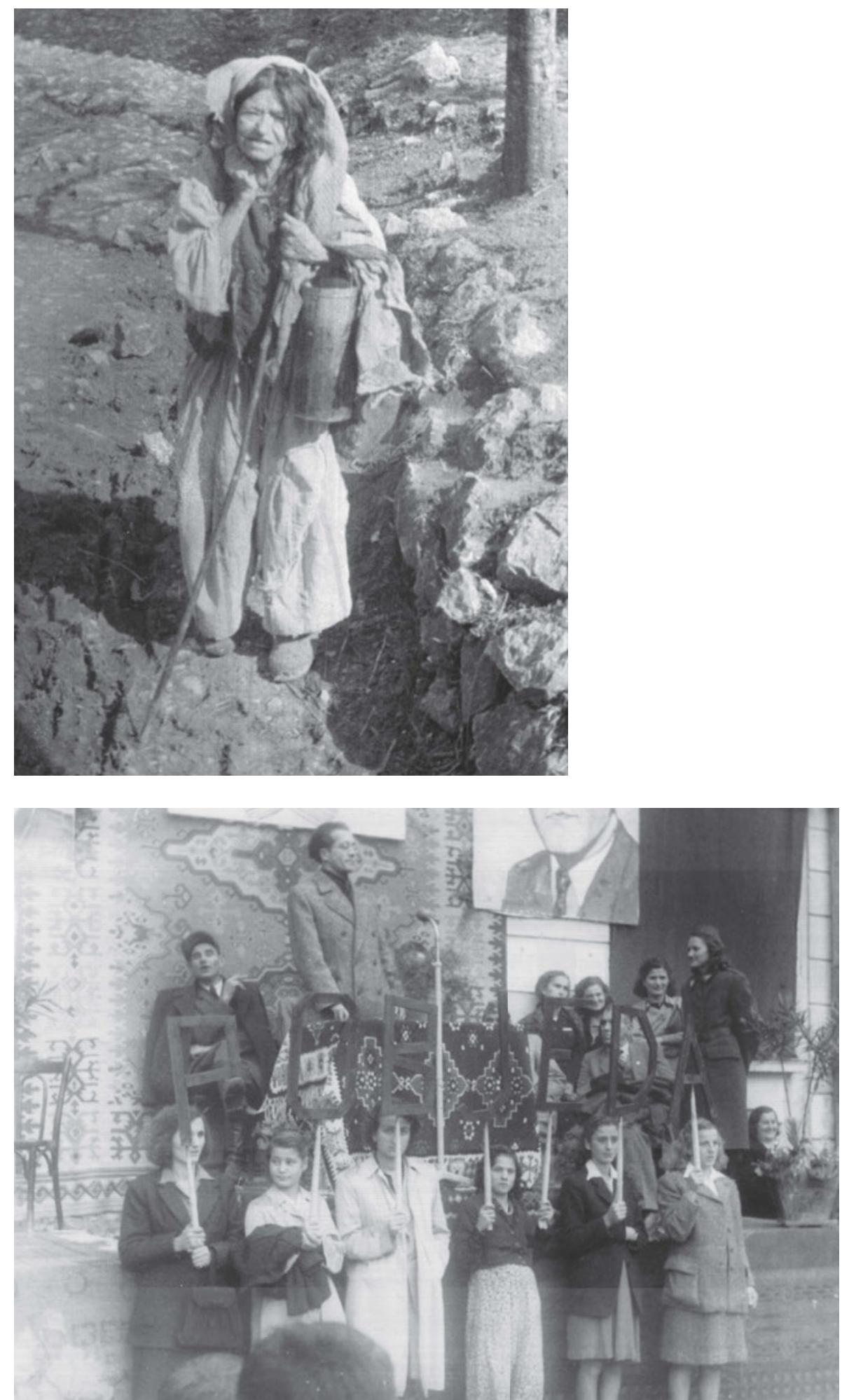

Von dem Fotografen Dragan Mažar aufgenommene Szenen. Archiv der Republik Srpska. Ohne Inv.-Nr. 
Savo Orovićc ${ }^{77}$ fotografierte während des gesamten Zweiten Weltkriegs die Ereignisse innerhalb der Partisanenbewegung, indem er Einheiten in Montenegro, Bosnien und Herzegowina, Dalmatien, Sandžak, Lika und Kordun begleitete. Vladimir Dedijer schrieb im Vorwort zu Orovićs 1951 veröffentlichtem Buch:

»In den ersten Monaten des Aufstands gab es keine organisierten Fotodienste, es arbeiteten lediglich einige Liebhaber der Fotografie mit überaus bescheidenen Mitteln. Leider ist ein Großteil dieser Fotografien in den Offensiven vernichtet worden. Wie viele Krieger und Amateurfotografen sind mit ihren Fotoapparaten und Filmen gefallen, wie viele wertvolle Aufnahmen wurden vernichtet, weil es keine technischen Möglichkeiten gab, die Filme zu entwickeln? «78

Zur gleichen Zeit, als Skrigin Josip Broz Tito im September 1942 in Mlinište fotografierte, machte auch Orović Aufnahmen von Tito. Später hielt er viele namhafte Persönlichkeiten wie Koča Popović, Ivan Milutinović, Sava Kovačević, Milovan Djilas, Fjodor Mahin und Kulturschaffende wie Ivan Goran Kovačić in Livno fest, wo dieser das Gedicht Grube offenbar vollendet hatte. Als Berufsoffizier fotografierte Orović stets militärisch präzise. Seine Bildeinstellungen waren immer schulisch exakt, die Vergrößerungen technisch sorgsam und ohne größere Experimente ausgeführt. Eine seiner bedeutendsten Fotografien, die den verwundeten Tito mit verbundenem Arm und Dr. Ribar zeigt, entstand am 9. Juni 1943 während der Schlacht an der Sutjeska, die Kovačić nicht überleben sollte.

Beleg für die Sparsamkeit beim Fotografieren und den Mangel an Fotomaterial ist ein Brief, den Orović im Dezember 1943 an den Hauptstab richtete. Er fügte dem Schreiben die seit Dezember 1941 geschaffenen ${ }^{79}$ Fotografien bei, wobei es sich lediglich um 124 Bilder handelte. $^{80}$

»Hier schicke ich Ihnen die angeforderten Fotografien der Partisanenaktionen bzw. eigentlich des Partisanenlebens zu, weil die Aktionen zumeist nachts ausgeführt werden, sodass die schönsten und wichtigsten Momente des Kampfes nicht aufgenommen werden können. Ich schicke nahezu alles, was ich fotografiert und verwahrt habe, ungeachtet ihrer Bedeutung, während ein Teil bei Fotografen in Bihać und in Livno verlorengegangen (verblieben) ist. ${ }^{81}$

Seine Aufzeichnungen dokumentieren überdies die strengen Regeln der Partisanen, denen zufolge ein Fotografieren der Partisanenkrankenhäuser verboten war. ${ }^{82}$ Probleme gab es allerdings auch beim Fotografieren der Alliierten, insbesondere auf der Insel Vis. ${ }^{83}$ Im Gegensatz zu Orović machte der Fotograf Pavle Bojčević eine Serie von Fotografien aus der

\footnotetext{
77 Savo Orović, montenegrinischer Komitadschi und Offizier der Armee des Königreichs Montenegro, Soldat im Ersten Weltkrieg und danach Oberst in der Armee des Königreichs Jugoslawien. Im Zweiten Weltkrieg nahm er von Anfang an Verbindung zu den Partisaneneinheiten auf, zog sich aber nach der Niederlage der Partisanenbewegung in Montenegro nach Bosnien und Herzegowina zurück. Im Mai 1943 wurde ihm der Offiziersrang eines Generalleutnants verliehen.

78 Orović, Savo. Fotografije iz Narodnooslobodilačkog rata 1941.-1945. Belgrad: Historisches Militärinstitut der Jugoslawischen Armee 1951, S. 6.

79 Ebd., S. 114.

80 Orović, Savo. Ratni dnevnik 1941.-1945. Belgrad: Hronometar 1972, S. 448.

81 Ebd.

82 Ebd., S. 332.

83 Ebd., S. 584.
} 
Vogelperspektive. Diese gehören zu den imposantesten Bildern der Partisanenkolonnen. Gerade wegen des Aufnahmewinkels verlieh er ihnen eine immense Monumentalität und eine nahezu filmische Szenografie.

In Mazedonien war die Situation im Bereich des Verlagswesens und der Kulturproduktion ausgesprochen schlecht, was auch die Spaltung des Staates in einen bulgarischen und einen albanischen Teil sowie die probulgarisch gestimmte Führung der provinziellen Kommunistischen Partei Jugoslawiens bedingte, die mit der Organisierung des bewaffneten Widerstands in Verzug war. Obwohl die Partisanenbewegung 1942 immer mehr Kämpfer zählte und das Zentralkomitee den erfahrenen Organisator und Parteiaktivisten Svetozar Vukmanović-Tempo nach Mazedonien schickte, um dort die Aktivitäten der Kommunistischen Partei Jugoslawiens zu struktuieren und zu festigen, stand in seinem Bericht an das Zentralkomitee der KPJ am 22. April 1944, dass in Mazedonien nur vier Zeitungen erscheinen würden und es nur ein paar Journalisten und einen Opernsänger aus Sofia, aber keine Fotografen gäbe. ${ }^{84}$ Dieselben Angaben sind auch in allen späteren Berichten zu finden.

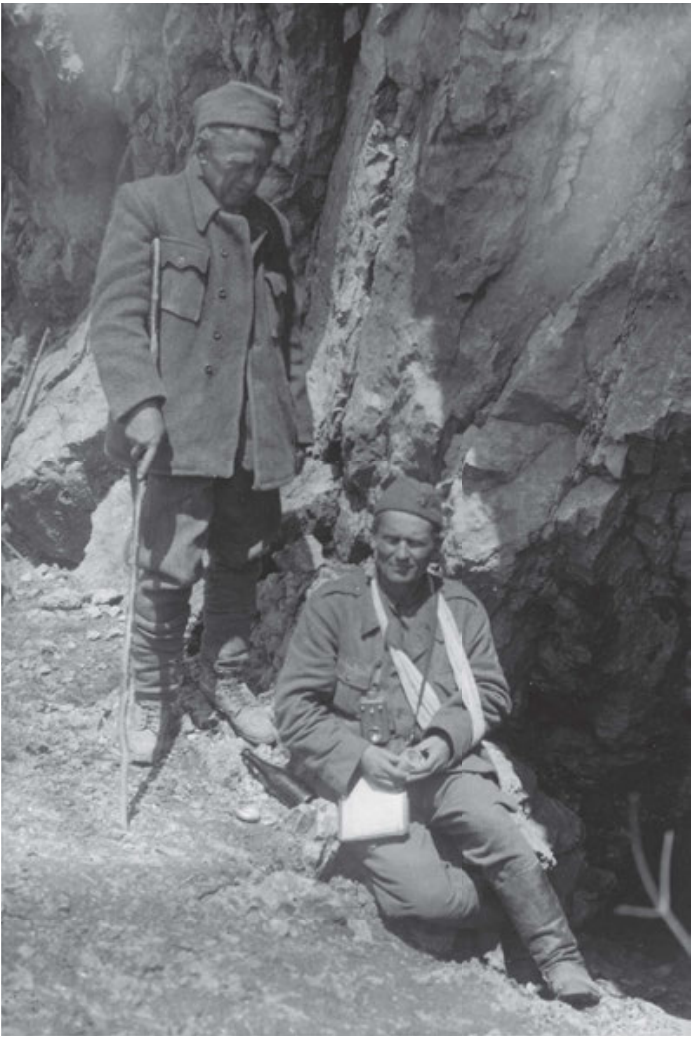

Der verwundete Josip Broz Tito zusammen mit Ivan Ribar, Sutjeska, 1943. Foto: Savo Orović. znaci.net.

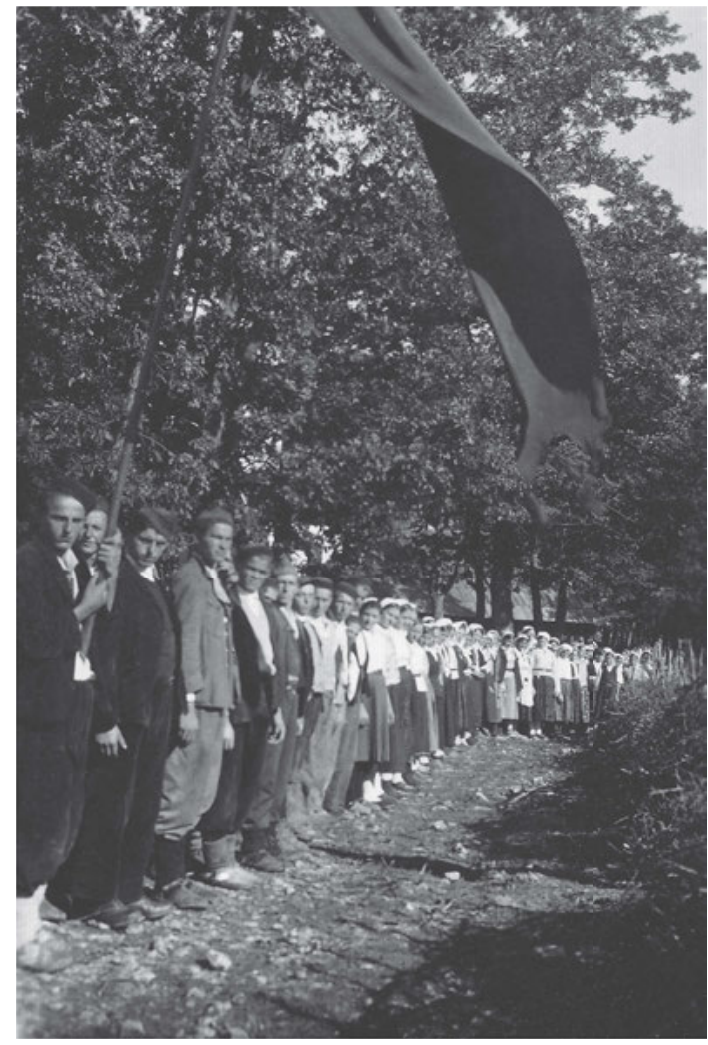

Jugendkompanie beim Treffen in Suvaj bei Bosanski Petrovac, 25. Oktober 1942, anlässlich der Wahlen der Volksbefreiungsräte. Foto: Savo Orović. Privatarchiv von Marko Strpić. 


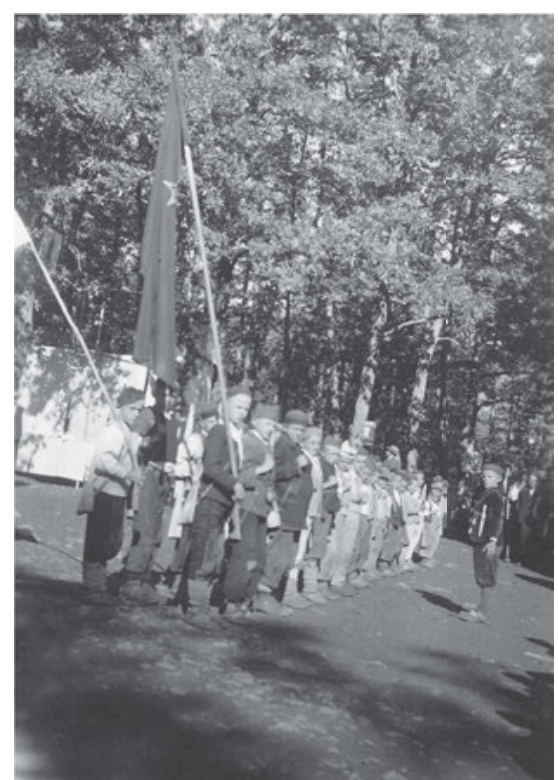

Jugendkompanie beim Treffen in Suvaj bei Bosanski Petrovac, 25. Oktober 1942, anlässlich der Wahlen der Volksbefreiungsräte. Foto: Savo Orović. Privatarchiv von Marko Strpić.

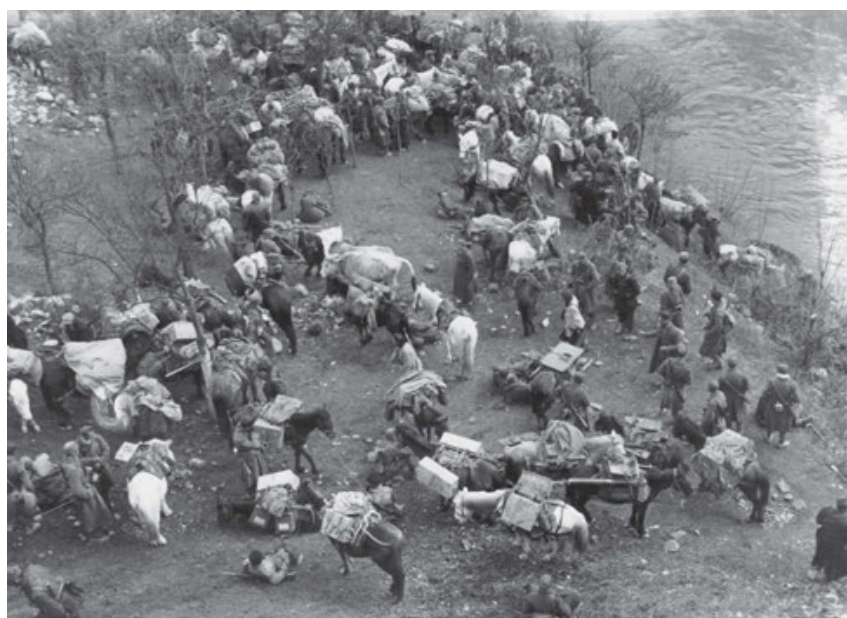

Schlacht am Fluss Neretva, Bosnien und Herzegowina, April 1943. Foto: Pavle Bojčević. Fotolabor des Historischen Archivs beim ZK BdKJ | MRNJ III-4557/znaci.net.

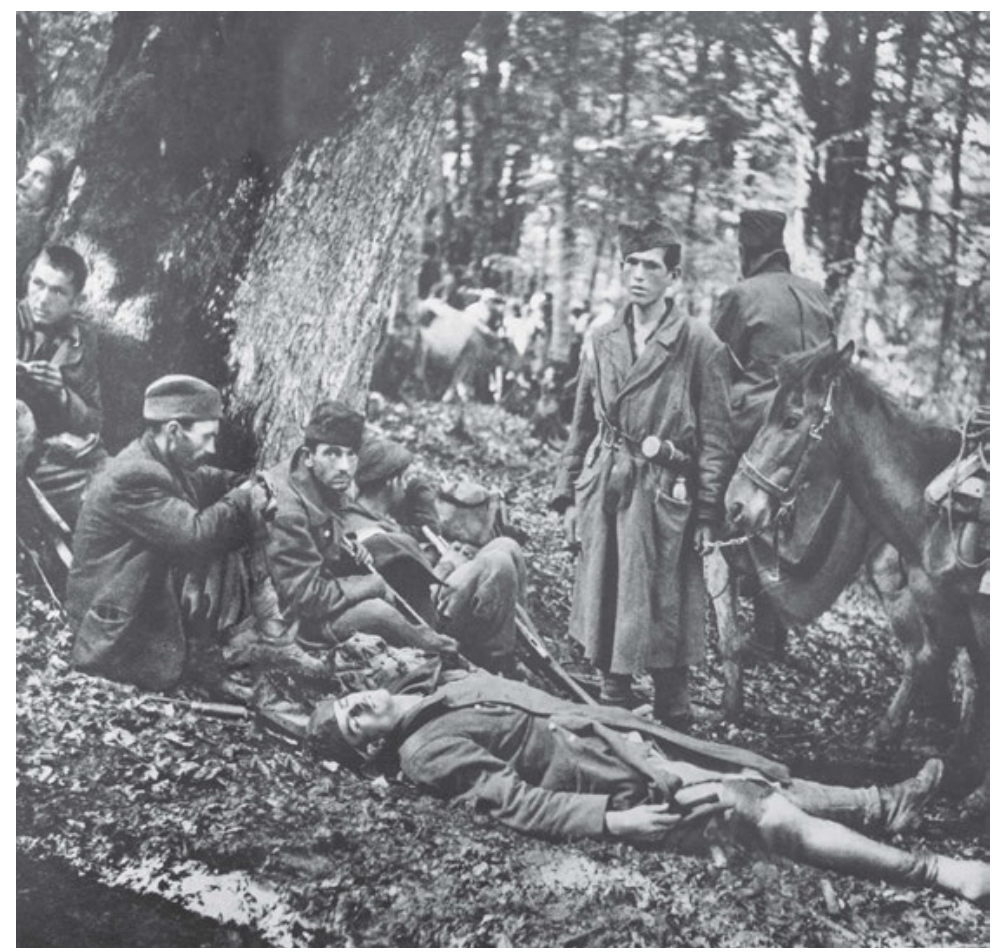

Milinklade, am Fluss Sutjeska gelegen (Schlacht an der Sutjeska),

9. Juni 1943. Foto: Žorž Skrigin. Aus: Skrigin, Žorž. Rat i pozornica.

[Krieg und Bühne] Belgrad: Turistička štampa 1968. 


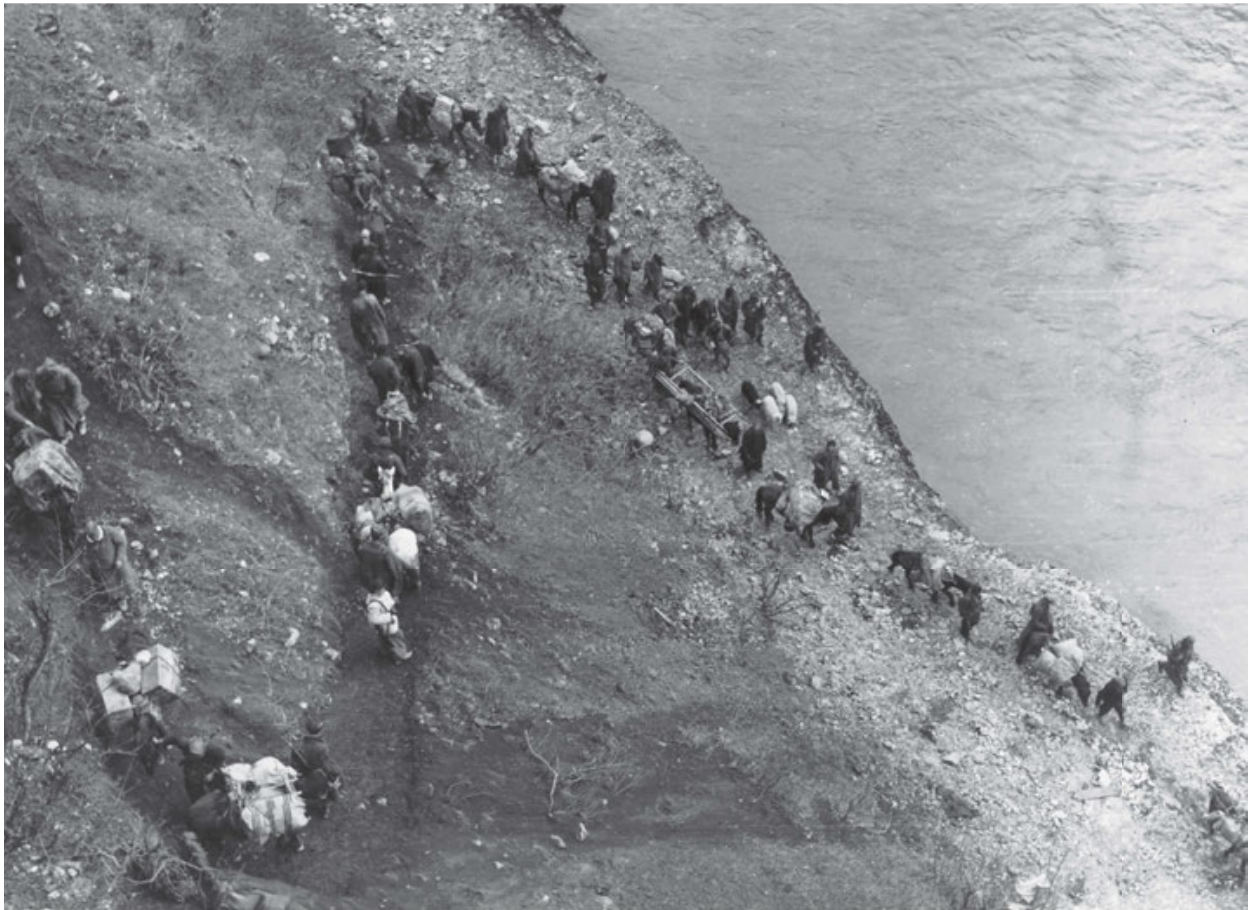

Vierte feindliche Offensive, Schlacht am Fluss Neretva, April 1943. Foto: Pavle Bojčević.

Fotolabor des Historischen Archivs beim ZK BdKJ | MRNJ III-4557/znaci.net.

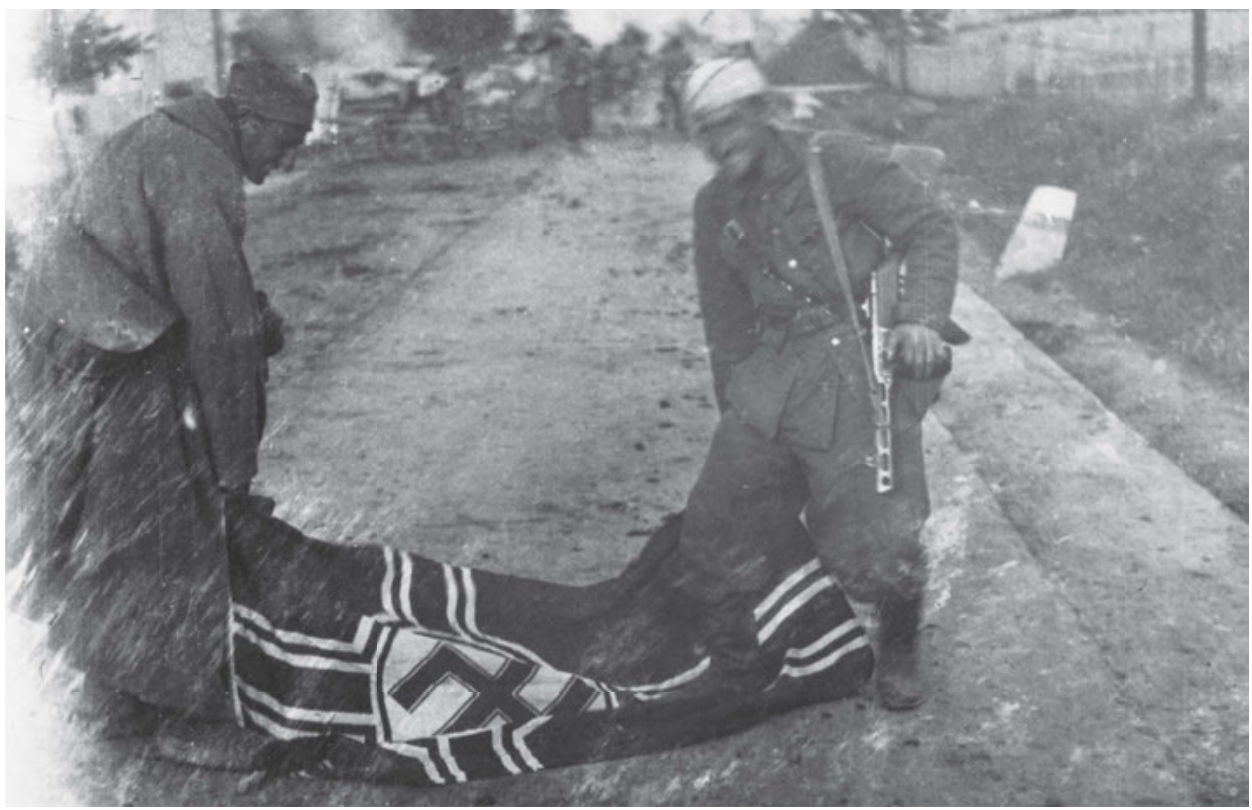

Mazedonien, 1945. Fotograf unbekannt. Belgrad, Militärmuseum | 13290. 


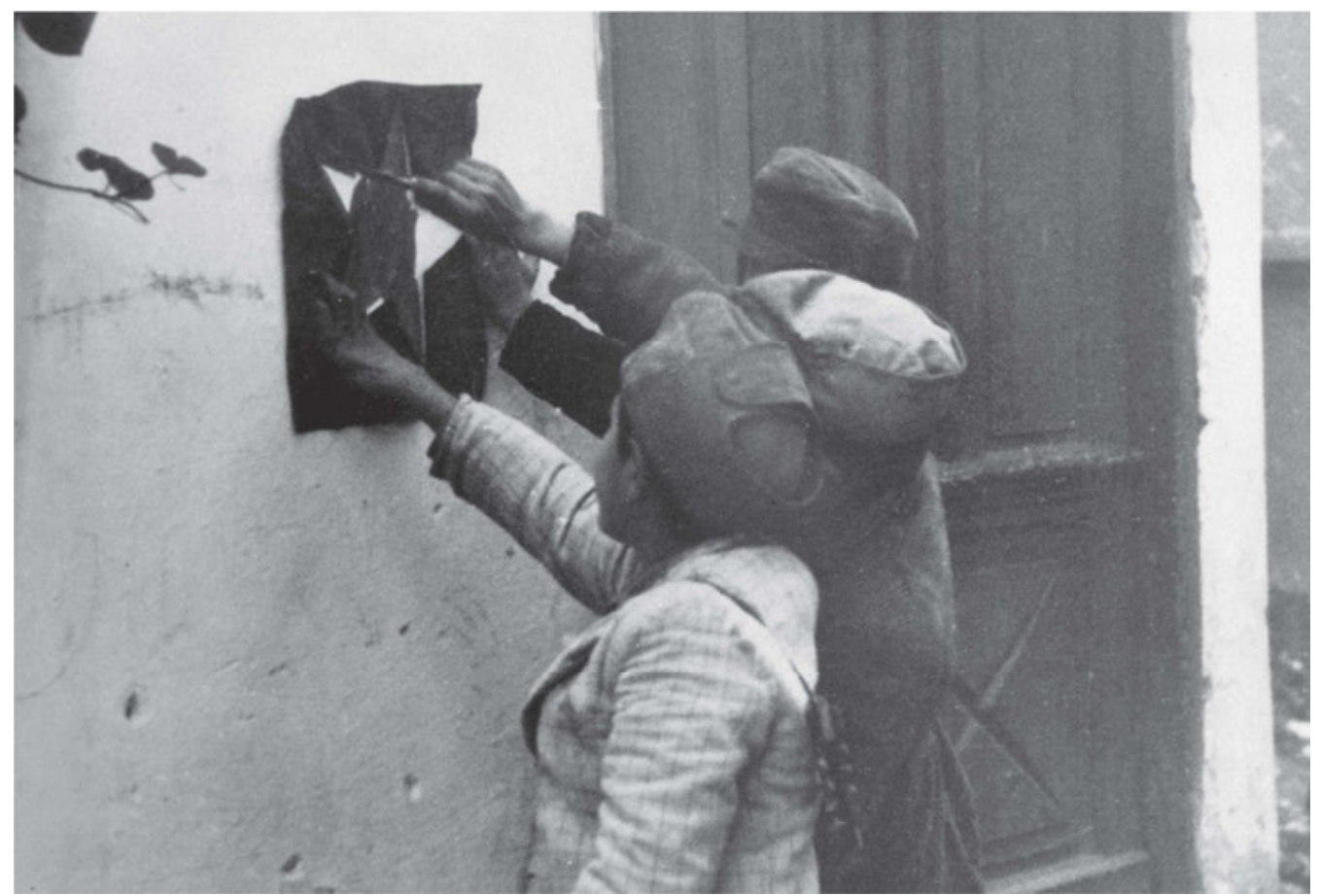

Jungpioniere zeichnen einen Roten Stern in Skoplje, Mazedonien. Foto unbekannt. Belgrad, Militärmuseum | 13288.

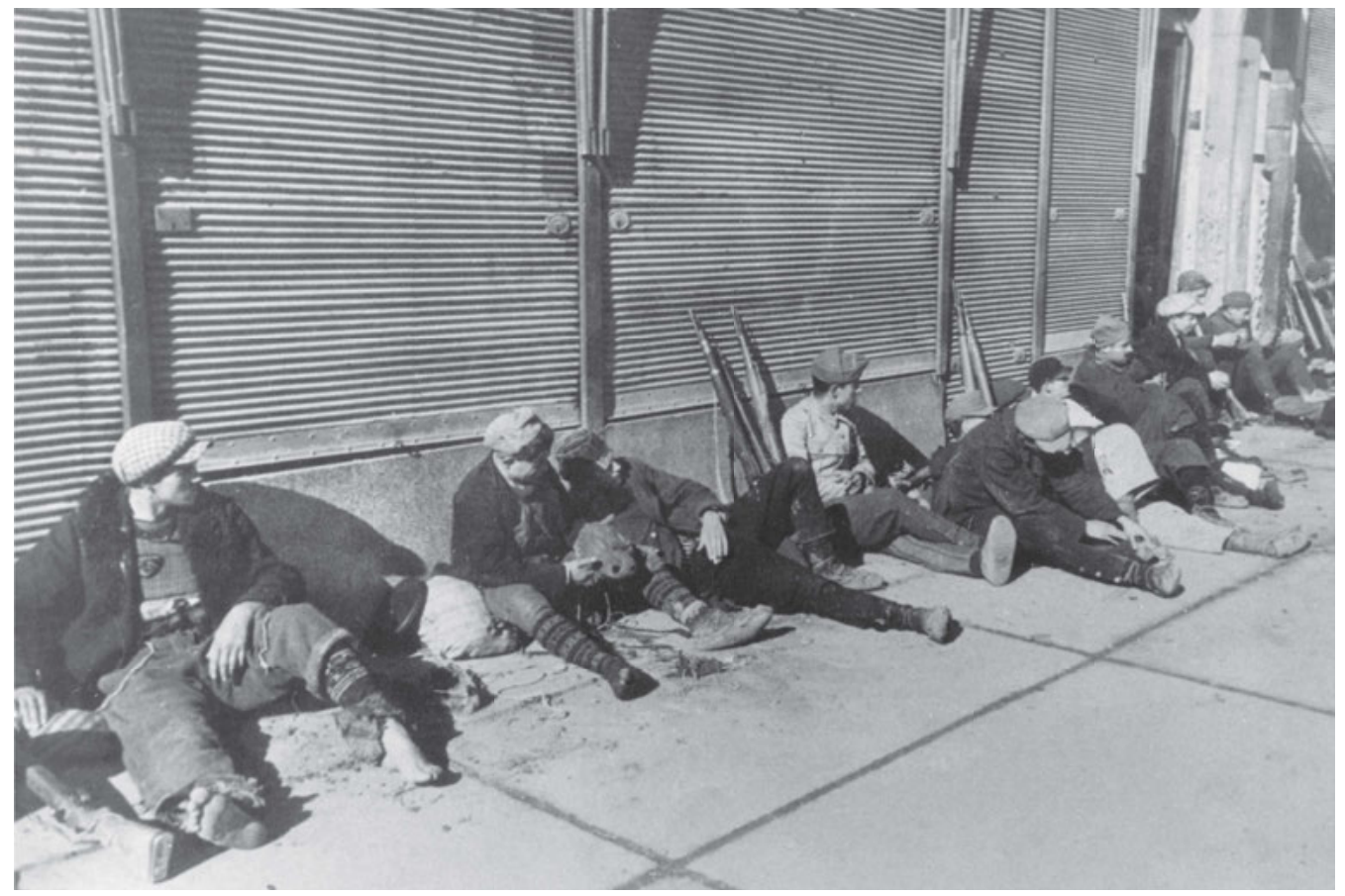

Mazedonische Einheiten, Skoplje, November 1944. Fotograf unbekannt. Belgrad, Militärmuseum | 413050. 
Nach der Kapitulation Italiens am 8. September 1943 und der Fünften feindlichen Offensive - der Schlacht an der Sutjeska - kam es zu einer verstärkten Zusammenarbeit mit den Allierten, vor allem mit dem Vereinigten Königreich unter Winston Churchill, die nach mehreren Jahren des Zögerns die Realität akzeptierten und die von Tito angeführte Partisanenbewegung als einzig relevante verbündete und antifaschistische Bewegung auf dem Gebiet Jugoslawiens anerkannten. Dies schlug sich auch in einer größeren Unterstützung in Form von Fotomaterial nieder. In Slowenien kam es in der nachfolgenden Zeit zur wahrscheinlich bedeutendsten Intensivierung der fotografischen Tätigkeit, was Tomaž Kladnik, Katarina Jurjavčić und Jože Dežman in ihrer Studie belegen: ${ }^{85}$ Im Winter 1943 und 1944 dokumentierten Edi Šelhaus, Mirko Trobec, Miloš Brelih, Vinko Bavec und Gojko Pipenbacher in der Unterkrain, Marjan Masterl in der Oberkrain, Ivan Lipar-Iztok, Stane Lepardič-Žan und Miroslav Lilik in der Steiermark sowie Čoro Škodlar im Neunten Korps in der Region Primorska die Ereignisse, während Jože Petek den Feldzug der Vierzehnten Division fotografierte. Mitglieder der Fotosektion der Slowenischen Volksbefreiungsfront (SNOS) waren zu dieser Zeit Alfred Kos, Stane Viršek und Frane Cerar. Bei den Partisanen fotografierte zudem der akademische Maler Božidar Jakac, und der Geschichtsprofessor Franjo Veselko hielt die Cankar-Brigade fest. ${ }^{86}$
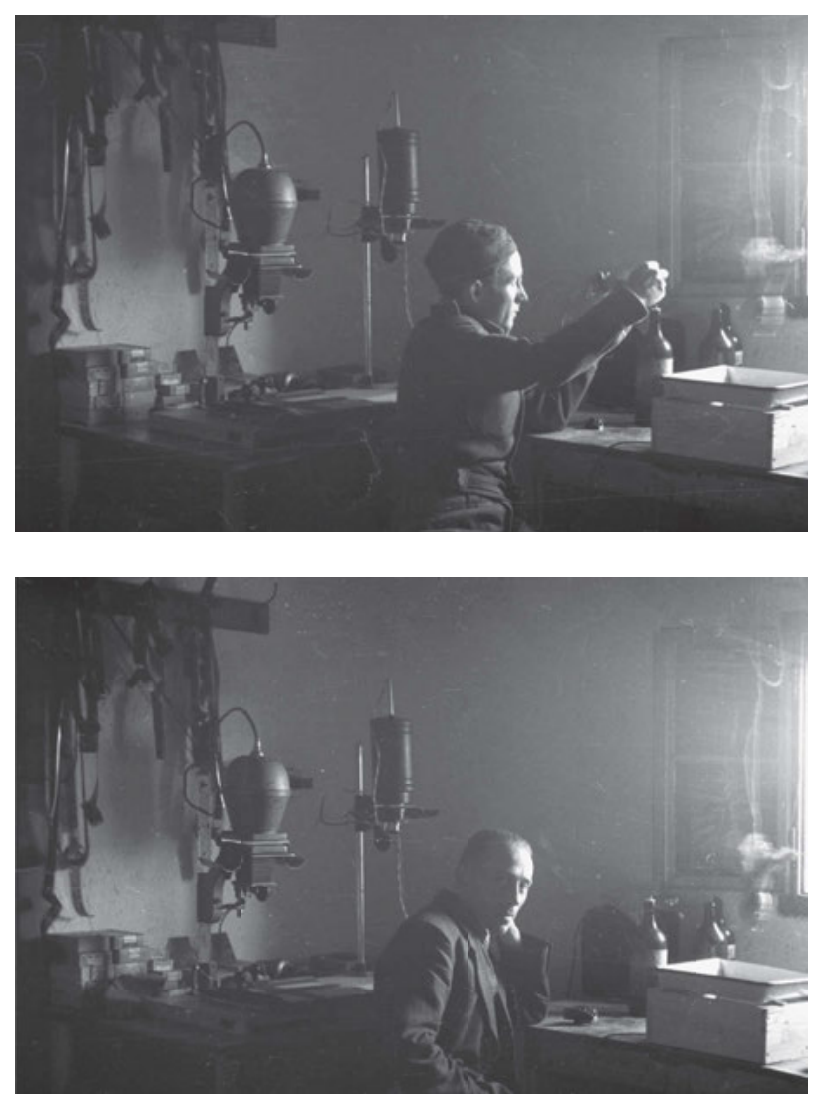

Franjo Veselko, Leiter der Fotosektion, überprüft Filme in einer Dunkelkammer, 23. Oktober 1944. Foto: Maksimilijan Zupančić. Ljubljana, Museum für Neuere Geschichte Sloweniens | TN389/38.

85 Kladnik, Tomaž, Jurjavčić, Katarina und Dežman, Jože. Vojne fotografije 1941.-1945. Partizanske jedinice. Ljubljana: Defensor 2010.

86 Ebd., S. 22. 


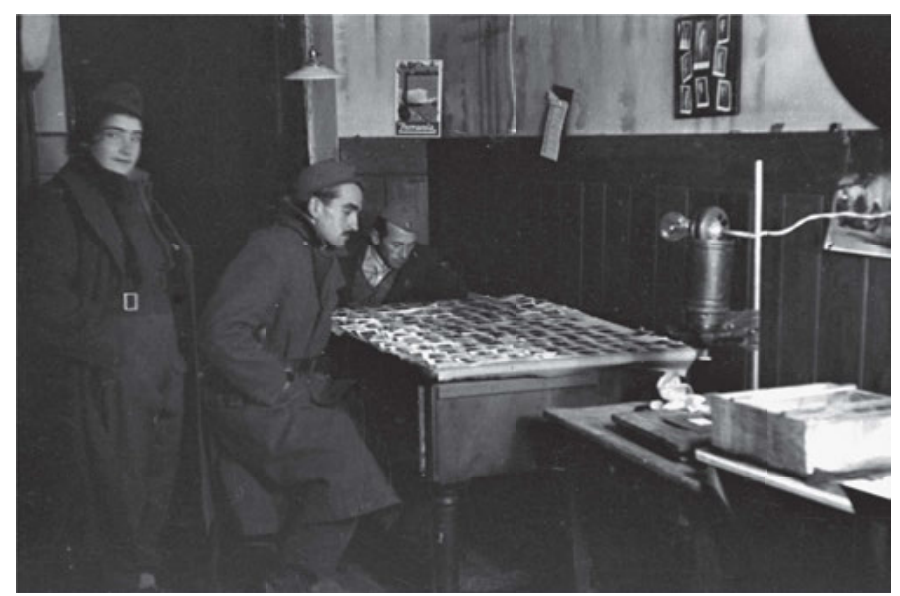

Fotografisches Atelier, Črnomelj, Slowenien. Foto: Alfred Kos. Ljubljana, Museum für Neuere Geschichte Sloweniens | TN529/4.
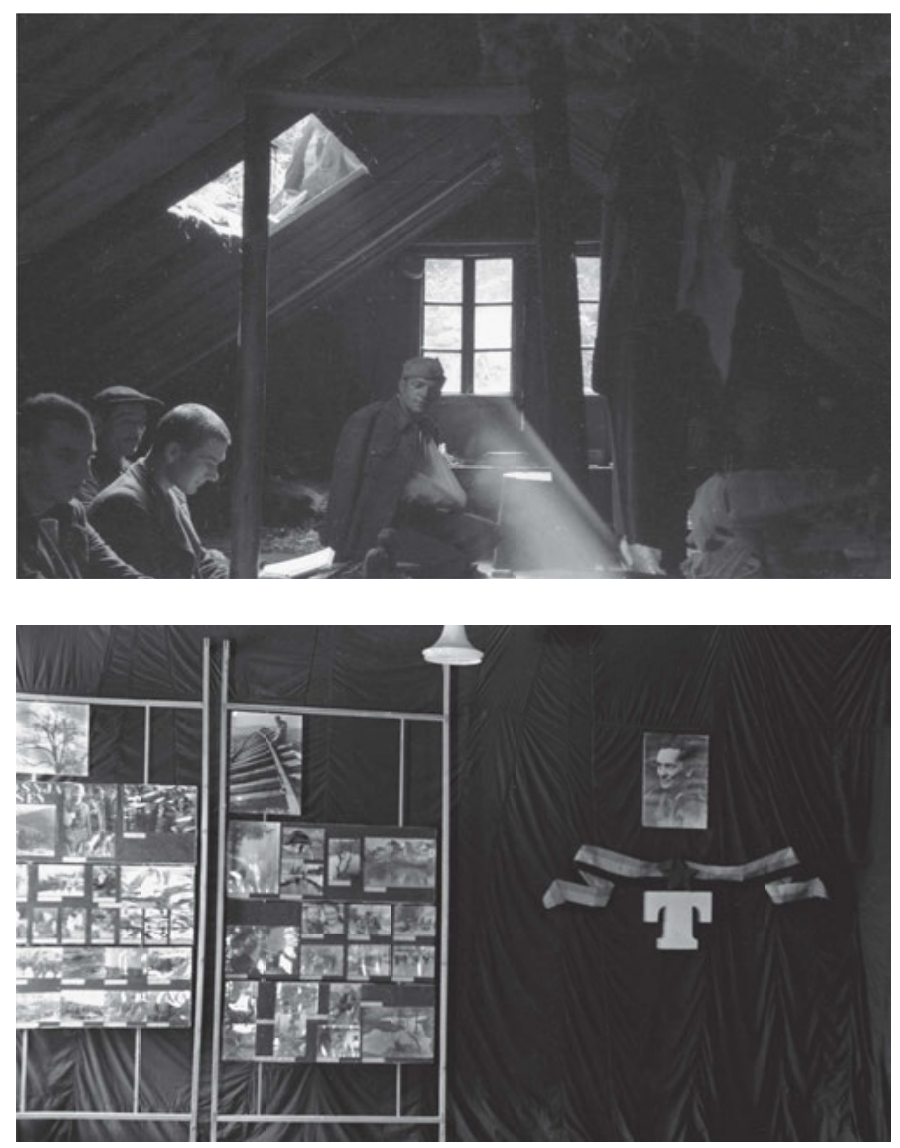

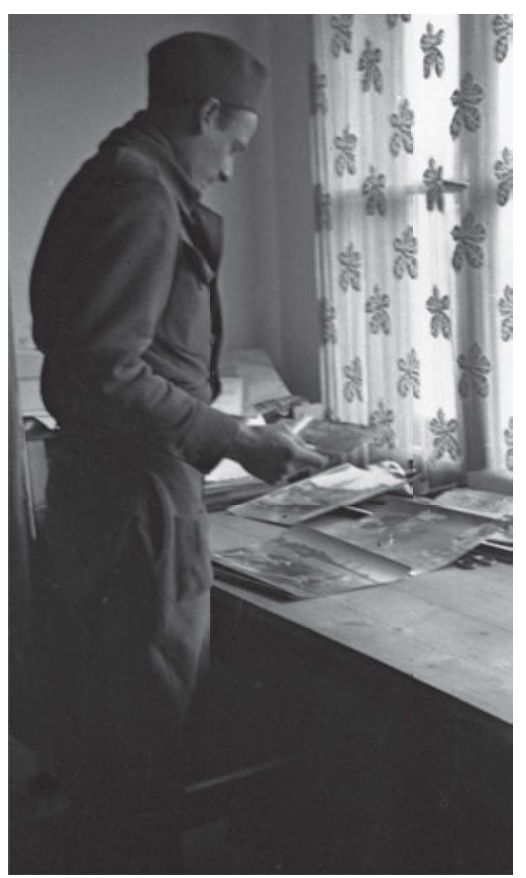

Fotografisches Atelier, Črnomelj, Slowenien. Foto: Alfred Kos. Ljubljana, Museum für Neuere Geschichte Sloweniens | TN529/22.

Partisanenkrankenhaus in Zgornji Hrastnik, Slowenien, Frühling 1944. Foto: Dr. Janez Milčinski. Ljubljana, Museum für Neuere Geschichte Sloweniens | 1227/15.

Fotoausstellung in Črnomelj, Slowenien, 25.-31. Dezember 1944. Foto: Jože Bitenc. Ljubljana, Museum für Neuere Geschichte Sloweniens | TN526/1 


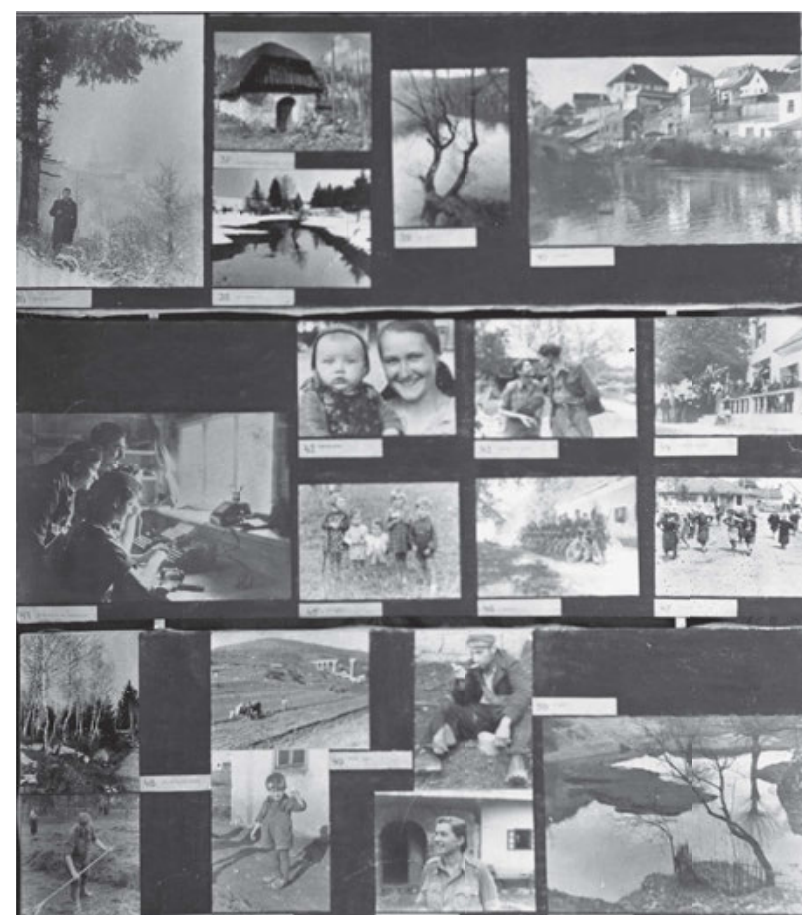

Fotoausstellung in Črnomelj, Slowenien, 25.-31. Dezember 1944. Foto: Jože Bitenc. Ljubljana, Museum für Neuere Geschichte Sloweniens | TN526/4.

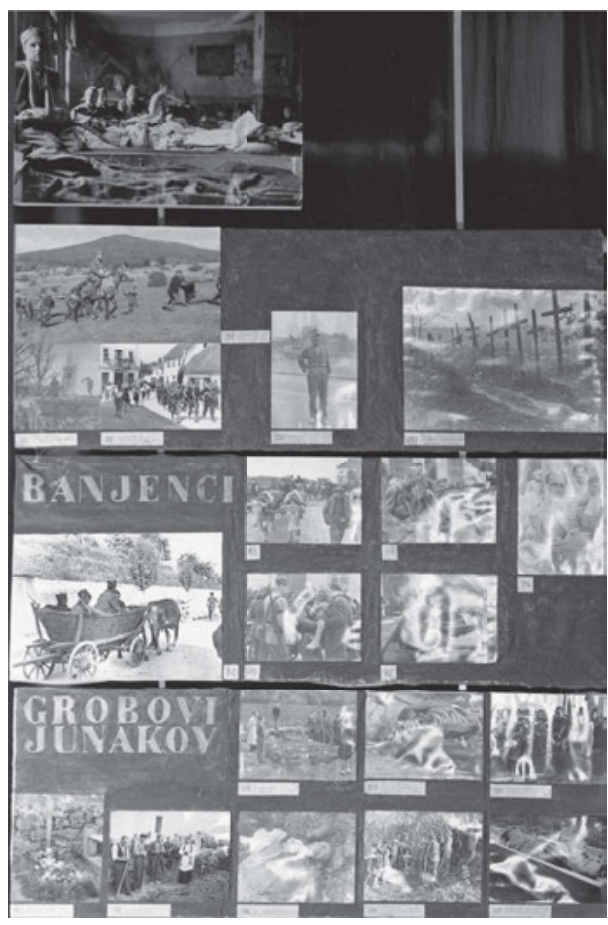

Fotoausstellung in Črnomelj, Slowenien, 25.-31. Dezember 1944. Foto: Jože Bitenc. Ljubljana, Museum für Neuere Geschichte Sloweniens | TN 526/2.

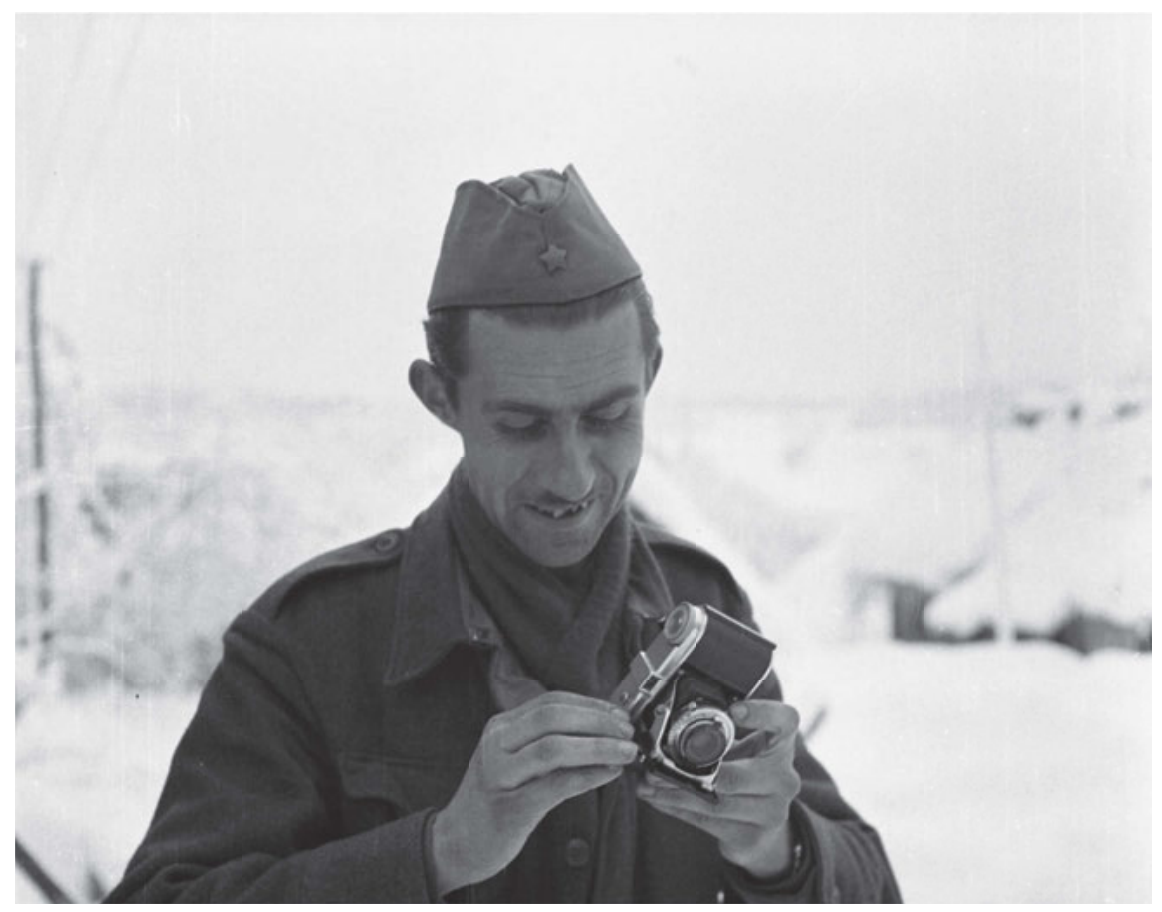

Durchbruch einer Propagandaeinheit bei Črnomelj, Slowenien. Viršek Stane mit einer neuen Kamera, 28. Februar 1945. Fotograf unbekannt. Ljubljana, Museum für Neuere Geschichte Sloweniens | TN1628/4. 
Der slowenische Fotodienst bildete einen der am besten organisierten innerhalb der Partisanenbewegung. Nach 1943 war die Zahl der Fotografen weitaus größer als in anderen jugoslawischen Republiken, gleichzeitig wurde auch die Ausstellungstätigkeit intensiviert. In Cerkno fand am 23. Februar 1945 eine wichtige Fotoausstellung aus Anlass des 27. Jahrestags der Gründung der Roten Armee statt, ausgerichtet von der Propagandaabteilung des Stabs des Neunten Korps ${ }^{87}$ Bei den slowenischen Fotografen ist insbesondere das Werk von Jože Petek zu erwähnen, der mit seinem dokumentarischen Ansatz, seinem Mut und kompromisslosen Dokumentarismus mit den Arbeiten des angesehenen Robert Capa konkurrieren kann. Hervorzuheben sind weiterhin Dr. Janez Milčinskis Bilder, die eine einzigartige anthropologische Analyse des Lebens in den Krankenhäusern der Partisanen darstellen.

Die Propagandaabteilung des Hauptstabs der Volksbefreiungsarmee und der Widerstandsbewegung Sloweniens organisierte eine Ausstellung mit 118 Fotografien am 5. Juni 1944 im Lakner-Salon in Črnomelj, am 9. Juni in Metlika und am 13. Juni in Semič. ${ }^{88}$ Die Präsentation war in vier thematische Blöcke unterteilt: Verbrechen der Besatzungsmächte, Leben und Kampf der Partisanenarmee, Versorgung der Verwundeten und Kulturveranstaltungen; in jedem der genannten Orte zog die Ausstellung 2.000 Besucher an. ${ }^{89}$ In Dvor kamen etwa 400 Menschen, von denen die Hälfte Soldaten waren. Die Besucher beanstandeten, dass Fotografien aus dem unmittelbaren Kriegsgeschehen fehlen würden und man das Leben der Partisanen nicht detailliert genug dargestellt habe. ${ }^{90}$ Dank der Bemühungen von Slavko Smolej, der die letzten Kämpfe in der Krain fotografierte, konnte die JeseniceBohinj-Einheit in Slowenien bereits während des Krieges ein beachtliches Fotomaterial sammeln. ${ }^{91}$

Das Allumfassende der Kulturproduktion der Partisanen und ihre Horizontalität führten dazu, dass sich die Kunst für alle Menschen öffnete - Akademiker und Arbeiter, Bauern und Künstler. Zu Dichtern und Schriftstellern wurden jene, die niemals zuvor Gedichte geschrieben und niemals zuvor Geschichten erzählt haben. Viele Fotografen haben sich gerade während des Krieges beruflich entwickelt, viele unbekannte Amateure haben zum ersten Mal fotografiert. Ebenso wie die Dichter, Schriftsteller, Schauspieler, Tänzer, Zeichner, Musiker, Bildhauer und Maler haben auch die Fotografen die Welt kommentiert und gezeigt - und zwar nicht nur als fotografisches Dokument oder als sfalscher fotografische Wahrheit, sondern häufig als ihre eigene künstlerische und politische Vision eines revolutionären Kampfes, der dauerhaften Frieden bringen sollte. Das vorliegende Kapitel beab-

87 Ljubič-Bogo, Mirko. Oris dejavnosti in služb. In: Lah-Boris, Borivoj (Hrsg.). Artilerija 9. korpusa. Ljubljana: Partizanska knjiga 1985, S. 260

88 Zbornik dokumenata i podataka o narodno-oslobodilačkom ratu jugoslovenskih naroda. Bd. IX/6: Partijsko-politička dokumenta 1943. godine. Belgrad 1967.

89 Ebd.

90 Ebd.

91 Pavlin, Mile. Jeseniško-bohinjski odred. Ljubljana: Knjižnica NOV in POS 1970, S. 317.24 Zbornik dokumenata i podataka o narodno-oslobodilačkom ratu jugoslovenskih naroda. Bd. II/6: Dokumenti vrhovnog štaba Narodnooslobodilačke vojske Jugoslavije 1942. Belgrad 1957.na zurück. Im Mai 1943 wurde ihm der Offiziersrang eines Generalleutnants verliehen. 
sichtigte aufzuzeigen, wie sich unter freiem Himmel und unter unmöglichen Bedingungen eine rege Produktion vollziehen konnte, die vor allem eine besondere Rolle in der Entfaltung des revolutionären Bewusstseins spielte, aber auch durch die Besonderheit der technischen Voraussetzungen geprägt wurde. 